UNIVERSIDADE DE BRASÍLIA

FACULDADE DE TECNOLOGIA

DEPARTAMENTO DE ENGENHARIA FLORESTAL

PROGRAMA DE PÓS-GRADUAÇÃO EM CIÊNCIAS FLORESTAIS

\title{
ÍNDICE DE QUALIDADE DO SOLO PARA A AVALIAÇÃO DO IMPACTO DE DIFERENTES USOS E MANEJOS E SUA APLICAÇÃO EM UMA ÁREA RURAL DE PLANALTINA (DF)
}

\author{
CLARA MILENA CONCHA LOZADA
}

ORIENTADOR: HENRIQUE MARINHO LEITE CHAVES

DISSERTAÇÃO DE MESTRADO EM CIÊNCIAS FLORESTAIS

PUBLICAÇÃO: PPGEFL.DM - 258/2015

BRASÍLIA/DF: MAIO / 2015 
UNIVERSIDADE DE BRASILIA

FACULDADE DE TECNOLOGIA

DEPARTAMENTO DE ENGENHARIA FLORESTAL

PROGRAMA DE PÓS-GRADUAÇ̃̃O EM CIÊNCIAS FLORESTAIS

"ÍNDICE DE QUALIDADE DO SOLO PARA A AVALIAÇ̃̃o DO IMPACTO DE DIFERENTES USOS E MANEJOS E SUA APLICAÇÃ̃O EM UMA ÁREA RURAL DE PLANALTINA (DF)"

\author{
CLARA MILENA CONCHA LOZADA
}

DISSERTAÇÃO DE MESTRADO ACADÊMICO SUBMETIDA AO PROGRAMA DE PÓS-GRADUAÇÃo EM CIÊNCIAS FLORESTAIS, DO DEPARTAMENTO DE ENGENHARIA FLORESTAL, DA FACULDADE DE TECNOLOGIA DA UNIVERSIDADE DE BRASILIA, COMO PARTE DOS REQUISITOS NECESSÁRIOS PARA A OBTENÇÃO DO GRAU DE MESTRE.

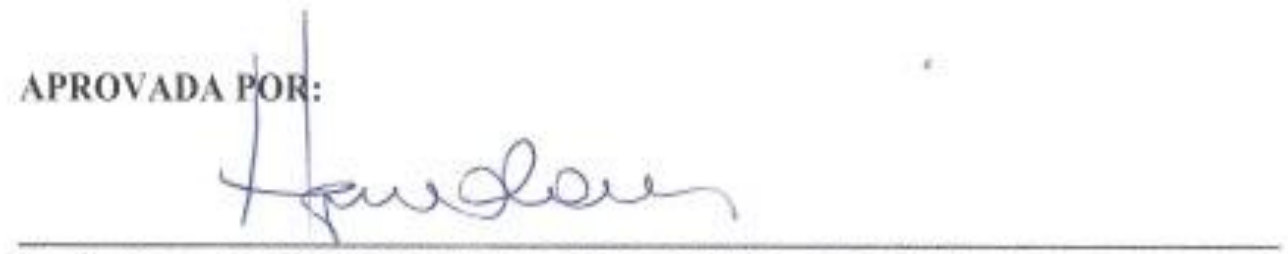

Prof Dr. HENRIQUE MARINHO LEITE CHAVES (Departamento de Engenharia Florestal-EF $(\mathrm{UnB})$;

(Orientador)

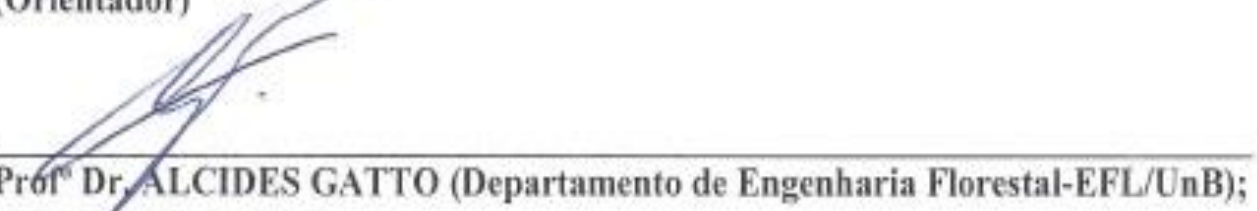
(Exanginador Interno)

\title{
Ricaudo de Oliveina Gaspan
}

Prof' Dr. RICARDO DE OLIVEIRA GASPAR (Departamento de Engenharia Florestal-EFL/UnB);

(Examinador Interno/Externo)

Prof' Dr. MAURO ELOI NAPPO (Departamento de Engenharia FlorestalEFL/UnB).

(Examinador Suplente)

Brasilia-DF, 29 de maio de 2015. 
Ficha catalográfica elaborada automaticamente, com os dados fornecidos pelo(a) autor(a)

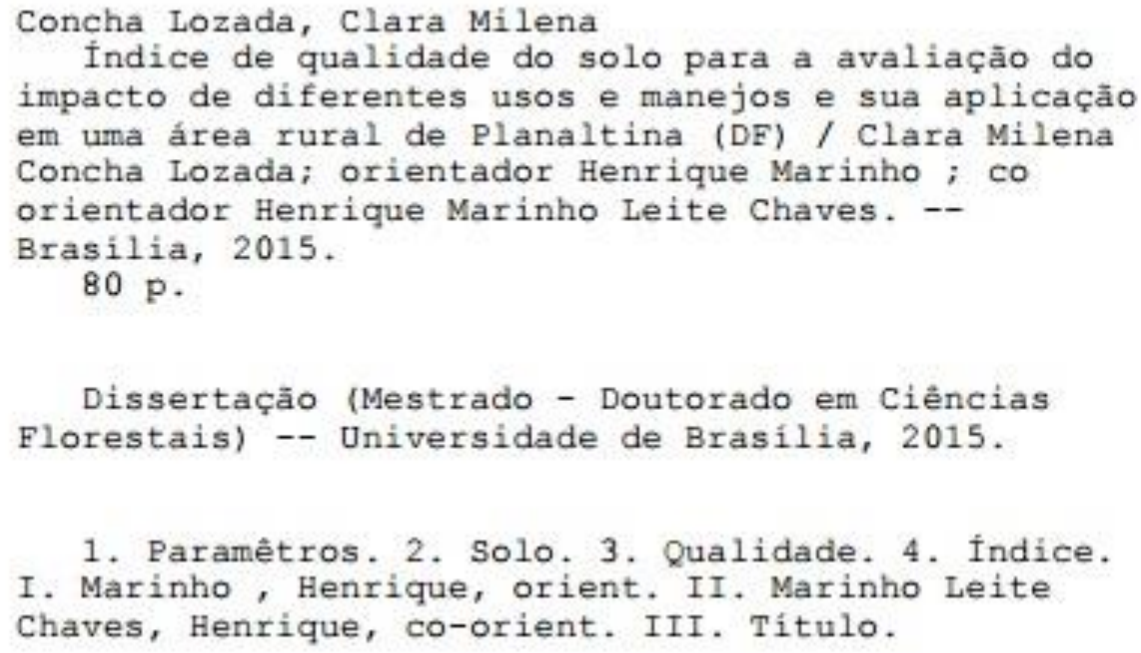

\section{REFERÊNCIA BIBLIOGRÁFICA}

CONCHA-LOZADA, C. M. 2015. Índice de qualidade do solo para a avaliação do impacto de diferentes usos e manejos e sua aplicação em uma área rural de Planaltina (DF). Dissertação de Mestrado. Publicação PPGEFL.DM - 258/2015. Programa de PósGraduação em Ciências Florestais, Departamento de Engenharia Florestal, Universidade de Brasília - UnB, Brasília-DF, 80f.

\section{CESSÃO DE DIREITOS}

AUTORA: Clara Milena Concha Lozada

TÍTULO: Índice de qualidade do solo para a avaliação do impacto de diferentes usos e manejos e sua aplicação em uma área rural de Planaltina (DF).

GRAU: Mestre

ANO: 2015

É concedido à Universidade de Brasília permissão para reproduzir cópias desta dissertação de mestrado e para emprestar ou vender tais cópias somente para propósitos acadêmicos. $\mathrm{O}$ autor reserva outros direitos de publicação e nenhuma parte desta dissertação de mestrado pode ser reproduzida sem autorização por escrito do autor. 
Onde estão agora os pequots? Onde estão os narragansetts, os moicanos, os pokanokets e muitas outras tribos outrora poderosas de nosso povo? Desapareceram diante da avareza e da opressão do Homem Branco, como a neve diante de um sol de verão, vamos nos deixar destruir, por nossa vez, sem luta, renunciar a nossas casas, a nossa terra dada pelo Grande Espírito, aos túmulos de nossos mortos e a tudo que nos é caro e sagrado? Seis que vão gritar comigo: "Nunca! Nunca!".

TECUMSEH, dos shawnees

Dedico este trabalho aos meus pais, vocês são os merecedores do meu título, vocês lutaram com força para me sustentar, para me fazer uma pessoa melhor. Minhas irmãs, vocês me acompanham sempre sem interessar a distância. Meus sobrinhos, especialmente para Ana Victoria Cardona Concha, gostaria que você estivesse aqui. Meu esposo John Robert Muñoz Chávez, nós podemos tudo juntos, nossa força não tem fim. Obrigada e totalmente grata.

Clara Milena Concha Lozada 


\section{AGRADECIMENTOS}

Agradeço à Universidade de Brasília - UnB, pela oportunidade de cursar o mestrado em Ciências Florestais, aos funcionários e professores do Departamento pelo contínuo aprendizado que me foi oferecido, à CAPES pela bolsa de estudo; as empresas "La Bromelia de Brasília" e a Fazenda "As Araras" e seus funcionários pela sua amabilidade e por me deixar desenvolver meu trabalho de campo na sua área campestre; ao professor Henrique Marinho Leite Chaves pela orientação; ao professor Fernando Vaz de Mello da Universidade Federal de Mato Grosso, por identificar o material entomológico e me deixar compreender com sorrisos irônicos que estou errada; ao professor Ricardo de Oliveira Gaspar por me assessorar e me ensinar a praticidade da estatística.

Fico profundamente grata com: os meus pais, Carlos Concha e Ana Ligia Losada, as minhas irmãs Carmen E. Concha Lozada e Natalia Concha Lozada; os meus sobrinhos Caterine Cardona Concha, Ana Victoria Cardona Concha e Santiago Paz Concha, por seu amor e apoio, porque vocês me fazem muito feliz. Família, vocês sempre estão me dando conforto na distância, sempre dando força para nós. Meu esposo John Robert Muñoz Chavez, por ser meu parceiro de batalhas, meu parceiro de sonhos, pela sua paciência e amor, meu amor por ser parte de todas as minhas loucuras muito obrigada.

Obrigada para nossos amigos e família em Brasília, Bruna Orellana e Jorge Breno, pelas palavras e risos, vocês sempre estão presentes nas nossas vidas e de aí não vão sair mais; aos meus colegas da pós-graduação que me apoiaram na minha amostragem de dados, foram de grande ajuda; aos meus compatriotas colombianos que me ajudaram nas minhas coletas e testes em campo. Aos amigos feitos no decorrer do mestrado, a vida aqui é mais simples por vocês, é mais feliz. 
RESUMO

ÍNDICE DE QUALIDADE DO SOLO PARA A AVALIAÇÃo DO IMPACTO DE DIFERENTES USOS E MANEJOS E SUA APLICAÇÃO EM UMA ÁREA RURAL DE PLANALTINA (DF).

\author{
Autor: Clara Milena Concha Lozada \\ Orientador: Henrique Marinho Leite Chaves \\ Programa de Pós-graduação em Ciências Florestais \\ Brasília, 29 de maio de 2015
}

Com o objetivo de desenvolver e aplicar um índice de qualidade do solo para a avaliação do impacto de diferentes usos e manejos em áreas de Cerrado, foram analisadas propriedades físicas (textura, taxa de infiltração de água no solo - TI e resistência mecânica do solo à penetração-RP), químicas (matéria orgânica do solo-MOS, saturação por bases-V, fosforo-P, acidez-pH, capacidade de troca de cátions-CTC) e biológicas (cobertura do solo e besouros coprófagos-C+R) de seis áreas experimentais, situadas sobre um Latossolo Vermelho franco-argilo-arenoso, na zona rural de Planaltina (DF). As seis áreas experimentais foram: Cerrado (stricto sensu)-CSS, Cerradão-CE, Reflorestamento de 10 anos (Enterolobium gummiferum)-R10, Reflorestamento de 1 ano (Handroanthus impetiginosus, Piptadenia gonoacantha, Triplaris gardneriana, Myracrodruon urundeuva, Sterculia striata)-R1, Lavoura de milho (Zea mays)-LM e uma Pastagem degradada (Brachiaria decumbens)-PD. Depois de obtidas as médias dos parâmetros F/Q/B em cada uma das áreas experimentais, foram atribuídos os escores 1, 2 e 3, para o terceiro, segundo e primeiro lugar do ranking das seis áreas, respectivamente, sendo a qualidade do solo estimada pela soma ponderada dos escores entre o número de variáveis de propriedade. $\mathrm{O}$ índice de qualidade do solo, calculado para as áreas experimentais acima, variou de 5,0 para o Cerradão até 2,2 para o Reflorestamento de 1 ano, sendo o primeiro classificado como Alto, e os outros cinco como médios.

Palavras-chave: parâmetros, solo, qualidade, índice. 


\title{
ABSTRACT \\ SOIL QUALITY INDEX TO ASSESSMENT THE IMPACT OF DIFFERENT USES AND PRACTICES AND IT IS APPLICATION IN A RURAL AREA OF PLANALTINA (DF).
}

\author{
Author: Clara Milena Concha Lozada \\ Supervisor: Henrique Marinho Leite Chaves \\ Programa de Pós-graduação em Ciências Florestais \\ Brasilia, May 29, 2015
}

In order to develop and implement a soil quality index to evaluate the impact of different uses and management in Cerrado areas, physical properties were analyzed (texture, infiltration-TI and penetration resistance-RP), chemical properties (organic matter-MOS, base saturation-SB, phosphorus-P, acidity- $\mathrm{pH}$, cation exchange capacity-CEC) and biological properties (soil covert-S and dung beetles-C+R) in six experimental areas located on a red oxisol, with a loamy texture, in a rural area of Planaltina (DF). The six experimental areas were: Cerrado stricto sensu-CSS, Cerradão-CE, Reforestation 10 years (Enterolobium gummiferum)-R10, Reforestation 1 year (Handroanthus impetiginosus, Piptadenia gonoacantha, Triplaris gardneriana, Myracrodruon urundeuva, Sterculia striata)-R 1, Corn (Zea mays)-CC and a Degraded pasture (Brachiaria decumbens)-DP. After obtaining the means of the F / Q / B parameters in each of the areas, scores were assigned for the three highest means, and the soil quality index estimated by the weighted sum of the scores. The soil quality index for the six experimental areas ranged from 5.0 to 2.2 , with the Cerradao presenting the highest value and the Reforestation $1 \mathrm{yr}$ the lowest.

Keywords: parameters, soil quality, index. 


\section{LISTA DE FIGURAS}

Figura 1. Layout das áreas de estudo e pontos de amostragem

Figura 2. Aspecto geral da área de Cerrado stricto sensu___ 22

Figura 3. Aspecto geral da área de Cerradão alterado __ 23

Figura 4. Aspecto geral da área de Reflorestamento de 10 anos __ 24

Figura 5. Aspecto geral da área de Reflorestamento de 1 ano __ 25

Figura 6. Aspecto geral da área de Lavoura de milho ___ 26

Figura 7. Aspecto geral da área de Pastagem degradada ___ 27

Figura 8. Triangulo de classificação textural ___ 28 


\section{LISTA DE TABELAS}

Tabela 1. Serviços ambientais fornecidos pelo solo 6

Tabela 2. Propriedades ou indicadores físicos que contribuem na avaliação da qualidade do solo

Tabela 3. Propriedades ou indicadores químicos que contribuem na avaliação da qualidade do solo 11

Tabela 4. Propriedades ou indicadores biológicos que contribuem na avaliação da qualidade do solo. 12

Tabela 5. Índices e indicadores de qualidade do solo 14

Tabela 7. Parâmetros utilizados no presente estudo e no desenvolvimento do $\operatorname{IQS}_{(\mathrm{f}, \mathrm{q}, \mathrm{b})} \ldots 37$

Tabela 8. Granulométrica das áreas experimentais 42

Tabela 9. ANOVA para os parâmetros físicos, químicos e biológicos 43

Tabela 10. Médias de velocidade de infiltração básica - VIB média 43

Tabela 11. Médias de resistência mecânica do solo à penetração - RP 44

Tabela 12. Médias do teor de fósforo no solo - P 45

Tabela 13. Médias de Matéria Orgânica do Solo - MOS 46

Tabela 14. Médias de Capacidade de Troca Catiônica - CTC 46

Tabela 15. Médias de $\mathrm{pH}_{\mathrm{H} 2 \mathrm{O}}$ das áreas experimentais. 47

Tabela 16. Médias de Saturação de Bases - V 48

Tabela 17. Médias do percentual de cobertura do solo - CS 49

Tabela 18. Médias de besouros coprófagos cavadores e roladores - $\mathrm{C}+\mathrm{R}$ 49

Tabela 20. Frequência das médias dos parâmetros físicos, químicos e biológicos em relação dos três primeiros lugares 56 


\section{SUMÁRIO}

\section{INTRODUÇÃO}

1.1. HIPÓTESE 3

1.2. OBJETIVOS 4

1.2.1. Objetivo Geral 4

1.2.2. Objetivos Específicos 4

2. REVISÃO BIBLIOGRÁFICA 5

2.1. RECURSO SOLO: FUNÇÕES E SERVIÇOS 5

2.2. DEFINIÇÃO DE QUALIDADE DO SOLO 7

2.3. PARÂMETROS E INDICADORES FÍSICOS, QUÍMICOS E BIOLÓGICOS QUE CONTRIBUEM PARA A QUALIDADE DO SOLO 8

2.4. ÍNDICES DE QUALIDADE DO SOLO E SUA APLICAÇÃO NA AVALIAÇÃO DOS IMPACTOS DO USO E MANEJO DO SOLO 13

2.5. CARACTERÍSTICAS EDAFOLÓGICAS DOS SOLOS DO CERRADO 19

3. MATERIAIS E MÉTODOS 20

3.1. CARACTERIZAÇÃO DAS ÁREAS DE ESTUDO E SEUS SOLOS 20

3.2. CARACTERIZAÇÃO TEXTURAL DOS SOLOS DAS SEIS ÁREAS EXPERIMENTAIS 28

3.3. SELEÇÃO DE PARÂMETROS PARA A ELABORAÇÃO DO ÍNDICE DE QUALIDADE DO SOLO - $\operatorname{IQS}_{(\mathrm{F}, \mathrm{Q}, \mathrm{B})}$ 29

3.3.1. Seleção dos Parâmetros Químicos 29

3.3.2. Seleção dos parâmetros físicos e biológicos__ 29

3.3.2.1. Taxa de infiltração de água no solo 30

3.3.2.2. Resistencia mecânica do solo à penetração 31

3.3.2.3. Cobertura do solo 32

3.3.2.4. Coleta de besouros coprófagos (Scarabaeidae: Scarabaeinae) 33

3.4. DELINEAMENTO EXPERIMENTAL 35

3.5. MODELO ESTATÍSTICO DO EXPERIMENTO 36

3.6. RELAÇÃO ENTRE OS PARÂMETROS DO SOLO E O IQS $(\mathrm{F,Q}, \mathrm{B})$ 36

3.7. TESTES ESTATÍSTICOS APLICADOS AOS PARÂMETROS FÍSICOS, QUÍMICOS E BIOLÓGICOS 38

3.8. FORMULAÇÃO DO ÍNDICE DE QUALIDADE DO SOLO - IQS IF,Q,B) 39 
4.1. Textura dos solos das áreas experimentais 42

4.2. Valores dos parâmetros físicos, químicos e biológicos 42

4.2.1. Médias de infiltrabilidade do solo - TI 43

4.2.2. Médias da resistência mecânica do solo à penetração - RP 44

4.2.3. Médias do teor de fósforo - $\mathrm{P}$ 44

4.2.4. Médias do teor de matéria orgânica do solo-MOS 45

4.2.5. Médias da capacidade de troca catiônica- CTC 46

4.2.6. Médias de $\mathrm{pH}$ 47

4.2.7. Médias da saturação por bases $-\mathrm{V}$ 48

4.2.8. Médias do parâmetro de cobertura do solo - CS 48

4.2.9. Médias de besouros cavadores e roladores (número de espécies) - $\mathrm{C}+\mathrm{R}$ 49

4.3. Análise de Clusters das propriedades físicas, químicas e biológicas do solo 52

4.3.1. Analise de clusters para as propriedades físicas do solo 52

4.3.2. Analise de clusters para as propriedades químicas do solo 53

4.3.3. Analise de cluster para as propriedades biológicas do solo 54

4.3.4. Analise de clusters com propriedades físicas, químicas e biológicas do solo 55

5. ÍNDICE DE QUALIDE DO SOLO - IQS $(\mathbf{f , q , b )}$ 56

6. CONCLUSÕES 58

ANEXO 1. BESOUROS COPRÓFAGOS (COLEÓPTERA: SCARABAEINAE) COLETADOS NAS SEIS ÁREAS DE PESQUISA 59

ANEXO 2. ÍNDICE DE QUALIDADE DO SOLO - IQS $\mathbf{S}_{(\mathbf{f}, \mathbf{q}, \mathbf{b})}$ DESENVOLVIDO COM PARAMETROS FÍSICOS, QUIMICOS E BIOLOGICOS DO SOLO 64 


\section{INTRODUÇÃO}

Diferentes autores têm usado distintas definições do solo, devido à multifuncionalidade deste recurso natural. No passado, o solo foi definido como o produto natural da intemperização e fragmentação da camada externa da superfície terrestre (JENNY, 1980). Posteriormente, o solo foi definido como a unidade fundamental para a dinâmica dos ecossistemas, onde ocorrem inter-relações entre fatores bióticos e abióticos (SEPÚLVEDA; TREJO; DAVID, 2005).

Entretanto, uma definição atual do solo é a de um corpo natural composto por sólidos, líquidos e gases na superfície da terra, caracterizado por horizontes e resultante de agregações, perdas, transferências e transformações de matéria e energia, e pela sua capacidade de suportar as plantas (USDA, 2010). O tipo de uso e manejo de uma área tem grande influência sobre os atributos físicos de qualidade do solo, especialmente nas camadas mais superficiais, onde a compressão mecânica parece ser mais atuante (ARAÚJO; GOEDERT; LACERDA, 2007).

O solo tem cinco funções essenciais: i) fornecer um ambiente para os organismos vivos; ii) regular o fluxo de água, armazenar e ciclar nutrientes e outros elementos; iii) servir de suporte para o crescimento das plantas e animais; iv) desintoxicar, ser tampão, filtrador e imobilizador de substâncias; v) fornecer suporte mecânico para os organismos vivos e as suas estruturas (DE LA ROSA; SOBRAL, 2008).

O solo também é o lócus de importantes atividades econômicas, tais como a agropecuária e o reflorestamento, sendo fonte de matérias primas, minerais e combustíveis fósseis. Se o solo se encontra em equilíbrio no tocante às suas propriedades físico-químicas e biológicas, o mesmo proporciona serviços ambientais adequados, culturas e pastagens produtivas, uma fauna diversa, e paisagens visivelmente aceitáveis (DORAN; ZEISS, 2000; MELLONI et al., 2008).

As propriedades físicas ou mecânicas do solo são resultantes das diferentes partículas que integram o solo, frutos da intemperização e fragmentação da camada superficial da terra, que determinam a capacidade de uso, trabalhabilidade, facilidade à penetração das raízes, aeração, a capacidade de drenagem e armazenamento de água, plasticidade e a retenção de nutrientes no interior do solo. Exemplos das propriedades físicas do solo é a profundidade, a textura, a estrutura, a porosidade, a umidade, a permeabilidade, a infiltração e a penetrabilidade (COSTA et al., 2003; BRADY; WEIL, 2002; BRADY; WEIL, 2008). 
As propriedades químicas do solo, resultantes da decomposição do seu material parental e da matéria orgânica, são responsáveis pela sua fertilidade e pelo fornecimento e disponibilidade de nutrientes às plantas (SCHOENHOLTZ; VAN MIEGROET; BURGER, 2000). Fazem parte dessas propriedades, por exemplo, o teor de fósforo, a acidez, a matéria orgânica, a capacidade de troca catiônica, e a saturação de bases (BRADY; WEIL, 2002).

As propriedades biológicas do solo são representadas pela biota que contribui para a transformação e decomposição da matéria orgânica presente no solo, afetando o seu uso e manejo, e contribuindo para sua erodabilidade. As bactérias, protozoários, nematódeos, micorrizos, ácaros, vermes, colêmbolos, isópteros, artrópodes, e dípteros são alguns exemplos de vida do solo (RUCKS et al., 2004).

Muitas propriedades químicas do solo influenciam diretamente os processos biológicos, e esses processos, em conjunto com os processos físicos do solo, determinam tanto a capacidade dos solos para reter, fornecer nutrientes, quanto à mobilidade e disponibilidade de água. Da mesma forma que o solo pode apresentar boas condições físicas, químicas e biológicas, ele também pode ser degradado ou perdido como resultado das ações antrópicas (SCHOENHOLTZ; VAN MIEGROET; BURGER, 2000; GARCÍA, 2005; VEZZANI; MIELNICZUK, 2009).

A degradação do solo decorre de processos que geram a redução na capacidade do solo para gerar bens e serviço, e para suportar a vida. Assim, uma das principais causas que leva à degradação do solo é a conversão do uso da terra, em especial a substituição da vegetação nativa por atividades agropecuárias extensivas e intensivas. Como consequência da degradação do solo, ocorre a redução da produtividade, a redução da capacidade de retenção de água, o aumento do escoamento superficial e da erosão (PACA, 2015).

Em função da importância da qualidade do solo e da sua manutenção, vários pesquisadores buscaram formas de avalia-la. (DORAN; PARKIN, 1994; CHAER; TÓTOLA, 2007). Entretanto, para que o conceito de qualidade do solo seja efetivo, é necessário ter índices constituídos por variáveis ou indicadores que ajudem na avaliação da condição do recurso, fornecendo informação sobre o seu estado atual e sobre suas tendências.

Nesse sentido, os indicadores de qualidade do solo devem permitir a avaliação da situação atual e identificar pontos críticos e os possíveis impactos antes de uma intervenção; devem permitir o monitoramento do impacto das atividades antrópicas e devem ajudar a determinar se o uso do solo é sustentável (WIENHOLD; ANDREWS; KARLEN, 2004; MELO FILHO; SOUZA; SOUZA, 2007). 
Para avaliar a qualidade do solo têm sido utilizados diferentes tipos de indicadores: i) físicos (textura, estrutura, porosidade, infiltração, penetrabilidade, condutividade, mecanismos de retenção de água e nutrientes); ii) químicos (capacidade de troca iônica, acidez ativa, teor de carbono); iii) biológicos (massa microbiana, respiração microbiana, associação de micorrizos, comunidades de nematódeos, enzimas, diversidade de invertebrados) (SCHOENHOLTZ; VAN MIEGROET; BURGER, 2000; DORAN; ZEISS, 2000).

De Araújo et al. (2012) concluiu que os mecanismos e procedimentos utilizados para a mensuração da qualidade do solo são úteis, desde que eles associem uma série de propriedades relacionadas às funções vitais do solo. Desse modo, se pode ter uma visão mais integrada dos ecossistemas, mesmo sabendo que dificilmente se conseguirá avaliar integralmente a qualidade do solo. Entretanto, apesar de existirem índices de qualidade do solo na literatura, a maioria considera apenas indicadores físico-químicos, de difícil obtenção, limitando sua robustez e aplicabilidade (BARRIOS et al., 2006).

Por isso, o presente estudo pretendeu desenvolver um índice de qualidade do solo com parâmetros físico-químico-biológicos de fácil obtenção no campo, e sensíveis às variações do uso e manejo do solo, que tenham relação com as funções do solo, e compreensíveis para os usuários (DORAN; ZEISS, 2000; SCHINDELBECK et al., 2008). Para ilustrar sua utilização, ele foi aplicado a diferentes situações de uso e manejo do solo típicas da região dos Cerrados.

\subsection{HIPÓTESE}

É possível desenvolver um índice de qualidade do solo baseado em propriedades físicas, químicas e biológicas, capaz de refletir as mudanças causadas pelo uso e manejo do solo, e de fácil e barata utilização. 


\subsection{OBJETIVOS}

\subsubsection{Objetivo Geral}

Desenvolver um índice de qualidade do solo e aplicá-lo a seis áreas experimentais da zona rural de Planaltina (DF).

\subsubsection{Objetivos Específicos}

- Levantar na literatura e selecionar propriedades físicas, químicas e biológicas responsáveis por importantes funções do solo, e selecionar aquelas mais adequadas para o desenvolvimento de um Índice de Qualidade do Solo.

- Desenvolver um Índice de Qualidade do Solo, baseado nas propriedades acima.

- Aplicar o Índice de Qualidade do Solo à áreas com diferentes tipos de usos e manejos. 


\section{REVISÃO BIBLIOGRÁFICA}

\subsection{RECURSO SOLO: FUNÇÕES E SERVIÇOS}

O solo se forma influenciado pelos fatores de clima, material parental, relevo, organismos vivos e tempo. Nesse processo, ocorre a degradação e transformação de diversos materiais orgânicos e inorgânicos para a geração das diferentes características do solo (LAL, 2005).

As diferentes características do solo permitem uma série de funções, como ser um meio para o crescimento das plantas; regular, estocar e proteger o fluxo de água no ambiente; promover a ciclagem de nutrientes e armazená-los; e servir como tampão ambiental na formação, atenuação e degradação de compostos prejudiciais ao ambiente. $\mathrm{O}$ solo é também um elemento importante da paisagem e do patrimônio cultural, além de ser fonte de matérias primas, fundamental nos processos produtivos (KARLEN et al., 1997; BLUM, 2005; SILVA; CORREA, 2009).

Dentre os serviços ambientais do solo estão a produção de alimentos e biomassa; o armazenamento de minerais, matéria orgânica, agua e outras sustâncias químicas; o habitat de organismos que vivem nele e sobre ele, a base das atividades humanas; e o caráter formador da paisagem (LARSON; PIERCE, 1991; BARRIOS, 2007).

Os processos que ocorrem no solo são dinâmicos, fazendo que ele seja considerado como um recurso vivo, cuja condição tem efeitos importantes na produção e o funcionamento integral dos ecossistemas. Assim, seu uso e manejo devem ser feitos com o maior cuidado e uma visão ampla, prevenindo a sua degradação e perda do potencial de produção e da previsão de outros serviços dos ecossistemas para as gerações futuras (BARRIOS; COUTINHO; MEDEIROS, 2011). Por isto diferentes autores, desde os mais antigos até os atuais, têm agrupado os serviços do solo de diferentes formas e características (Tabela 1). 
Tabela 1. Serviços ambientais fornecidos pelo solo.

\begin{tabular}{|c|c|}
\hline Serviços Ambientais do Solo & Fonte \\
\hline - Tamponamento e desintoxicação do solo e regulação do fluxo hídrico. & Daily (1997) \\
\hline - Decomposição e transformação de resíduos e matéria orgânica morta. & Daily (2000) \\
\hline - Retenção, armazenamento e ciclagem de nutrientes. & Blum (2005) \\
\hline - Regulação dos ciclos biogeoquímicos do solo e/ou a renovação da fertilidade do solo. & Makino et al. (2007) \\
\hline - Suporta e sustenta a produtividade vegetal e animal. & Doran; Parkin (1994) \\
\hline - Manter a qualidade do ar e da água. & Blum (2005) \\
\hline - Manter a saúde humana. & Lehmann; Stahr (2010) \\
\hline - Suportar a construção de edificações e a geração de áreas ou espaços de lazer. & Volchko et al. (2013) \\
\hline $\begin{array}{l}\text { - Suportar e sustentar a atividade biológica, a diversidade e a produtividade. } \\
\text { - Gera apoio às estruturas civis. } \\
\text { - Regulação do fluxo de água e de solutos. } \\
\text { - Filtragem e tamponamento de contaminantes. } \\
\text { - Regula a ciclagem de nutrientes. } \\
\text { - Protege tesouros arqueológicos associados à humanidade. }\end{array}$ & $\begin{array}{l}\text { Seybold et al. (1997) } \\
\text { Boumans et al. (2002) } \\
\text { Blum (2005) } \\
\text { Brown et al. (2005) } \\
\text { Lehmann; Stahr (2010) }\end{array}$ \\
\hline - Regulação do fluxo, armazenamento e oferta do recurso hídrico. & Karlen; Stott (1994) \\
\hline - Resistência ao stress e à perturbação. & Daily (2000) \\
\hline - Sustenta o crescimento das plantas. & Blum (2005) \\
\hline - Produção de biomassa nas áreas naturais, na agricultura e silvicultura. & Fisher; Turner; Morling (2009) \\
\hline $\begin{array}{l}\text { - Fornece relações solo-nutrientes (fluxo). } \\
\text { - Fornece relações solo-planta-água-sustâncias tóxicas (proteção). } \\
\text { - Fornece relações solo-planta-patógenos (controle). } \\
\text { - Fornece relações solo-paisagem (estética e estabilidade física). } \\
\text { - Fornece oportunidades de enraizamento e proliferação da vegetação (produção). }\end{array}$ & $\begin{array}{l}\text { Harris; Karlen; Mulla (1996) } \\
\text { Daily (2000) } \\
\text { Blum (2005) } \\
\text { Van Herwijnen et al. (2007) }\end{array}$ \\
\hline $\begin{array}{l}\text { - Proteção da fauna edáfica e da vegetação (proteção da diversidade). } \\
\text { - Armazenamento de nutrientes básicos (N, P, K). } \\
\text { - Valorização da conservação. } \\
\text { - Fornece habitats para as espécies e o a diversidade genética. } \\
\text { - Fornece matérias primas para a produção e sustento da humanidade }\end{array}$ & $\begin{array}{l}\text { Pimentel et al. (1997) } \\
\text { De Groot; Wilson; Boumans (2002) } \\
\text { Karlen et al. (2003) } \\
\text { European commission (2006) }\end{array}$ \\
\hline
\end{tabular}




\subsection{DEFINIÇÃO DE QUALIDADE DO SOLO}

Warkentin; Fletcher (1977) foram os pioneiros em considerar a qualidade do solo como instrumento de diagnóstico e gestão ambiental. Duas décadas depois, a discussão sobre qualidade do solo evoluiu para a questão da degradação dos recursos naturais, a sustentabilidade agrícola e as funções do solo. Nesta época, foi criado o Instituto de Qualidade do Solo do Ministério de Agricultura dos Estados Unidos, para reunir e difundir informação sobre o conceito de qualidade do solo (VEZZANI; MIELNICZUK, 2009).

Atualmente, o conceito atual de qualidade do solo é o proposto por Doran; Parkin (1994). Esses autores definiram qualidade do solo como "a capacidade de um solo para funcionar dentro dos limites de um ecossistema natural ou manejado, para sustentar a produtividade de plantas e animais, manter o aumentar a qualidade do ar e promover a saúde das plantas, dos animais e dos homens" (WIENHOLD; ANDREWS; KARLEN, 2004).

É importante reconhecer que a qualidade do solo é a base para o desenvolvimento da sustentabilidade agrícola e florestal, servindo como indicador para o manejo de terras, do solo e das culturas (HERRICK, 2000). Da mesma forma que o termo de qualidade do solo tem sido difundido e utilizado, outros termos, como "soil tilth" e "saúde do solo", são utilizados para fazer referencia a capacidade do solo para funcionar e suprir as necessidades do ecossistema e do homem (SCOTT; FORD, 2000).

Assim "soil tilth" é definido como a condição edafológica em relação à sua adequação para produção agrícola. O termo tem sido usado para descrever um determinado estado estrutural do solo e seus efeitos diretos e indiretos sobre os processos físicos, químicos e biológicos ocorridos no solo. O "soil tilth" é dinâmico, sujeito a mudanças das forças naturais ou artificiais, tais como o cultivo do solo (BOCKARI-GEVAO et al., 2006).

A "saúde do solo", considerada um sinônimo da qualidade do solo, é definida como uma característica integradora que reflete a capacidade do solo para responder aos diversos tipos de uso e manejo, mantendo a produtividade agrícola, e aprovisionando outros serviços do ecossistema. Também retrata o solo como um ser vivo, cujas funções são mediadas por organismos, requerendo um manejo apropriado (KIBBLEWHITE et al., 2008).

Para se monitorar a qualidade do solo e sua dinâmica, foram desenvolvidos índices de qualidade do solo baseados em propriedades ou indicadores físicos, químicos e 
biológicos. Assim, os eventuais impactos detectados podem ser mitigados, permitindo às gerações atuais e futuras manter o provimento dos bens e serviços no solo (RICKLEFS, 2003; ARAÚJO; GOEDERT; LACERDA, 2007).

As propriedades ou indicadores físico-químicos do solo como textura, estrutura, porosidade, capacidade de infiltração de água, resistência mecânica à penetração, acidez ativa, fertilidade (macronutrientes e micronutrientes), entre outros, regulam o fluxo de água e nutrientes. Também ajudam no desenvolvimento radicular e fornecem habitats para as espécies associadas ao solo (VEZZANI; MIELNICKZUK, 2009).

As propriedades ou indicadores biológicos do solo estão relacionados à abundância, à diversidade e atividade dos organismos que habitam em ele. São importantes porque são sensíveis às variações nas propriedades físico-químicas do solo. Assim, podem responder aos efeitos da antropização por meio de alterações fisiológicas, ou por alterações na capacidade de acumulação de elementos ou substâncias, ou na variação da sua diversidade. Os indicadores biológicos mais conhecidos são os fungos, bactérias, minhocas, besouros coprófagos e plantas (BAGLIANO, 2012).

\subsection{PARÂMETROS E INDICADORES FÍSICOS, QUÍMICOS E BIOLÓGICOS QUE CONTRIBUEM PARA A QUALIDADE DO SOLO}

Para avaliar a qualidade do solo é preciso utilizar parâmetros ou indicadores, pois sem eles a qualidade do recurso não pode ser medida de forma direta. Os indicadores de qualidade do solo são propriedades mensuráveis (quantitativas ou qualitativas) que refletem o efeito de um processo ou atividade, e que permitem caracterizar, avaliar e acompanhar as alterações ocorridas num dado ecossistema (DE ARAÚJO et al., 2012).

O efeito do tipo de uso e manejo do solo sobre a sua qualidade, por sua vez, pode ser avaliada por meio de parâmetros ou indicadores físicos, químicos e biológicos. Os parâmetros ou indicadores, avaliados de forma conjunta, contribuem para encontrar soluções para os impactos das atividades ao solo, levando-se em conta as inter-relações e as sinergias nele ocorrentes (CRUZ et al., 2004; GOEDERT; OLIVEIRA, 2007).

Os parâmetros físicos como textura, estrutura, porosidade, resistência mecânica à penetração, e capacidade de infiltração de água, são indicadores da capacidade de uso do solo, da resistência e da facilidade de enraizamento das plantas, da capacidade de armazenamento de água, da plasticidade e da capacidade de retenção de nutrientes, 
responsáveis pela produção e pela sustentação da vida (LAL, 2000; REYNOLDS et al., 2002; RUCKS et al., 2004; Tabela 2).

Os parâmetros químicos, por sua vez, são aqueles relativos à fertilidade (teores de nitrogênio, fosforo, potássio, cálcio, magnésio etc.), acidez, capacidade de troca de íons, matéria orgânica do solo, saturação de bases, entre outros. Nesse sentido, a análise química do solo é um poderoso instrumento par a sua caracterização e comportamento no longo prazo, uma vez que auxilia na formulação de estratégias corretivas do solo, uso e manejo (FUNACH; ASCAPAM; PRONATTA, 2002; BARRIOS; COUTINHO; MEDEIROS, 2011) (Tabela 3).

Finalmente, os parâmetros biológicos são constituídos por grupos de organismos que habitam no solo, incluindo pequenos vertebrados, insetos, minhocas, nematódeos, protozoários, botiferos e algas, fungos, bactérias, actinomicetes. Esses indivíduos são responsáveis pela decomposição de materiais orgânicos, pela mineralização de compostos orgânicos, pelo fornecimento de reservas alimentares, pela ciclagem de nutrientes, aeração e infiltração de água no solo (MAHILUM, 2004) (Tabela 4). 
Tabela 2. Propriedades ou indicadores físicos que contribuem na avaliação da qualidade do solo.

\begin{tabular}{|c|c|c|}
\hline Parâmetro & Descrição & Fonte \\
\hline \multirow{3}{*}{ Textura } & - Refere-se ao tamanho das partículas do solo. & Hillel (1982) \\
\hline & - Responsável pela fertilidade potencial, aeração, permeabilidade, profundidade efetiva e umidade. & Reichert; Reinert; Braida (2003) \\
\hline & - Relação direta com todos os parâmetros físicos, químicos e biológicos do solo. & Barrios; Coutinho; Medeiros (2012) \\
\hline \multirow{4}{*}{ Estrutura } & - Influenciada pelo clima e influencia a atividade biológica. & Hillel (1982) \\
\hline & - Vulnerável ao uso e manejo do solo, a forças destrutivas de natureza mecânica e físico-químicas. & Reichert; Reinert; Braida (2003) \\
\hline & - Afeta a retenção e transmissão de fluidos, infiltração e aeração no solo. & Kibblewhite et al. (2008) \\
\hline & - Influencia fenômenos de germinação, crescimento das raízes, tráfego terrestre e erosão. & Barrios; Coutinho; Medeiros (2012) \\
\hline \multirow{3}{*}{ Profundidade } & - Indica a capacidade de enraizamento das plantas. & IBGE (2007) \\
\hline & - Influencia a porosidade e aeração do solo. & Uberti (2011) \\
\hline & - Influenciada e influencia o nível freático (acumulação/armazenamento de água/umidade). & Barrios; Coutinho; Medeiros (2012) \\
\hline Porosidade & $\begin{array}{l}\text { - É a fração de volume de poros. } \\
\text { - Influenciada pelo tipo de solo e grau de compactação da estrutura. } \\
\text { - Influencia a ventilação do solo, a condução de água e nutrientes, o crescimento radicular. } \\
\text { - Influencia o abastecimento de oxigênio, liberação de Dióxido de Carbono. }\end{array}$ & $\begin{array}{l}\text { Hillel (1982) } \\
\text { Carvalho; Goedert; Armando (2004) } \\
\text { Barrios; Coutinho; Medeiros (2012) }\end{array}$ \\
\hline Umidade & $\begin{array}{l}\text { - Relação com os diferentes comportamentos do solo. } \\
\text { - Influenciada pela porosidade do solo. } \\
\text { - Influencia a consistência do solo (pegajosa, plástica, dura ou rígida). }\end{array}$ & $\begin{array}{l}\text { Rucks } \\
\text { et al. (2004) }\end{array}$ \\
\hline Permeabilidade & $\begin{array}{l}\text { - Influencia o enraizamento/Influencia a infiltração de água no perfil do solo. } \\
\text { - Permite conhecer o tipo de drenagem, recalques de água, rebaixamento do nível de água. } \\
\text { - Influencia a viabilidade de agrossistemas. }\end{array}$ & $\begin{array}{l}\text { Caputo (1996) } \\
\text { Braja (2007) }\end{array}$ \\
\hline $\begin{array}{l}\text { Capacidade à } \\
\text { infiltração de água }\end{array}$ & $\begin{array}{l}\text { - Influenciada o afetada pela textura e a umidade do solo. } \\
\text { - Inversamente relacionada ao tamanho das partículas do solo. } \\
\text { - Influenciada pelo conteúdo de argila e a taxa de infiltração. } \\
\text { - Influenciada e influencia a relação água-solo. } \\
\text { - Indica o risco de erosão, irrigação, sucesso das culturas e o desenvolvimento da planta. }\end{array}$ & $\begin{array}{l}\text { Hillel (1982) } \\
\text { Reichert; Reinert; Braida (2003) } \\
\text { Mahilum (2004) } \\
\text { Miller (2007) }\end{array}$ \\
\hline $\begin{array}{l}\text { Resistencia mecânica } \\
\text { à penetração }\end{array}$ & $\begin{array}{l}\text { - Indica a capacidade do solo para ser penetrado. } \\
\text { - Influenciada pelo tipo de uso e manejo do solo. } \\
\text { - Relação direta com a estrutura do solo. } \\
\text { - Influencia o crescimento radicular das plantas. }\end{array}$ & $\begin{array}{l}\text { Letey (1985) } \\
\text { Reichert; Reinert; Braida (2003) } \\
\text { Carvalho; Goedert; Armando (2004) } \\
\text { Tavares; Ribon (2008) }\end{array}$ \\
\hline
\end{tabular}


Tabela 3. Propriedades ou indicadores químicos que contribuem na avaliação da qualidade do solo.

\begin{tabular}{|c|c|c|}
\hline Parâmetro & Descrição & Fonte \\
\hline $\begin{array}{l}\text { Matéria Orgânica do } \\
\text { Solo (MOS) }\end{array}$ & $\begin{array}{l}\text { - Fator de controle da capacidade do solo para fornecer serviços agrícolas e ambientais. } \\
\text { - Influencia a presença de nutrientes no solo. } \\
\text { - Influencia a reserva transitória de MOS, ou material de fácil decomposição. } \\
\text { - Influencia a MO-humificada, ou material de decomposição em longo prazo. } \\
\text { - Influencia a biomassa ou biota e fauna do solo. } \\
\text { - Influencia a ciclagem de nutrientes, agregação do solo, e a dinâmica da água. } \\
\text { - Fonte energia para a atividade biológica. }\end{array}$ & $\begin{array}{l}\text { Reichert; Reinert; Braida (2003) } \\
\text { Santos et al. (2006) } \\
\text { Roscoe; Boddey; Salton (2006) } \\
\text { Manlay et al. (2007) } \\
\text { Cardoso et al. (2011) }\end{array}$ \\
\hline Saturação de Bases (V) & $\begin{array}{l}\text { - Influenciada pela a acidez do solo, variando de acordo com o tipo de solo. } \\
\text { - Influencia o calculo da quantidade de limo para neutralizar um solo ácido. } \\
\text { - Influenciada pela matéria orgânica do solo. }\end{array}$ & $\begin{array}{l}\text { Pratt (1966) } \\
\text { Garavito (1974) } \\
\text { Reichert; Reinert; Braida (2003) } \\
\text { Santos et al. (2006) } \\
\text { IBGE (2007) }\end{array}$ \\
\hline $\begin{array}{l}\text { Capacidade de Troca } \\
\text { Catiônica (CTC) }\end{array}$ & $\begin{array}{l}\text { - É a medida de cargas negativas do solo (numero total de posições trocáveis). } \\
\text { - Influenciada pelo conteúdo de matéria orgânica no solo. } \\
\text { - Indica a necessidade de adesão ou liberação de elementos no solo }\end{array}$ & $\begin{array}{l}\text { Garavito (1974) } \\
\text { Lopes; Guilherme (1992) } \\
\text { Reichert; Reinert; Braida (2003) } \\
\text { Bertella et al. (2008) }\end{array}$ \\
\hline Acidez ativa $(\mathrm{pH})$ & $\begin{array}{l}\text { - Influencia a fertilidade do solo. } \\
\text { - Influencia a concentração de íons e substâncias tóxicas no solo. } \\
\text { - Responsável da CTC do solo e raízes. } \\
\text { - Influencia a presença de enfermidades das plantas. } \\
\text { - Influência a disponibilidade de nutriente, absorção de nutrientes pelas plantas. }\end{array}$ & $\begin{array}{l}\text { Garavito (1974) } \\
\text { Smith; Smith (2001) } \\
\text { Reichert; Reinert; Braida (2003) }\end{array}$ \\
\hline Fósforo (P) & $\begin{array}{l}\text { - Influencia o desenvolvimento das plantas, junto com o nitrogênio e o potássio. } \\
\text { - Influenciada pela gênese do solo (rocha mãe). } \\
\text { - Influencia a vida das plantas, além que é constituinte importante de ácidos nucléicos, enzimas, } \\
\text { vitaminas, fosfolipídios, fitina e é indispensável nos processos de transformações de energia. }\end{array}$ & $\begin{array}{l}\text { Corey (1968) } \\
\text { Garavito (1974) } \\
\text { Reichert; Reinert; Braida (2003) }\end{array}$ \\
\hline
\end{tabular}


Tabela 4. Propriedades ou indicadores biológicos que contribuem na avaliação da qualidade do solo.

\begin{tabular}{|c|c|c|}
\hline Parâmetro & Descrição & Fonte \\
\hline $\begin{array}{l}\text { Microflora do solo } \\
\text { (Bactérias, Algas e Fungos) }\end{array}$ & $\begin{array}{l}\text { - Degradam contaminantes do solo, decompõem complexos de carbono. } \\
\text { - Auxiliam a decomposição e armazenamento de matéria orgânica do solo. } \\
\text { - Auxiliam na retenção e armazenamento de nutrientes no solo. } \\
\text { - Auxilia a formação de agregados utilizando as partículas do solo. } \\
\text { - Podem converter-se em patógenos. }\end{array}$ & $\begin{array}{l}\text { Lanza; Hernádez; Carvajal (2000) } \\
\text { García; Bello (2004) } \\
\text { Moravec et al. (2014) }\end{array}$ \\
\hline $\begin{array}{l}\text { Microfauna do solo } \\
\text { (protozoários, Nematóides, } \\
\text { Rotíferos, Colêmbolos, Acaro) }\end{array}$ & $\begin{array}{l}\text { - Seu tamanho varia entre } 4 \text { e } 100 \mu \mathrm{m} . \\
\text { - Influenciam a decomposição de resíduos vegetais e animais. } \\
\text { - Controla o crescimento de fungos e bactérias. } \\
\text { - Atuam indiretamente na ciclagem de nutrientes. } \\
\text { - Regulam populações de bactérias e fungos. }\end{array}$ & $\begin{array}{l}\text { Hanlon; Anderson (1979) } \\
\text { Stork; Eggleton (1992) } \\
\text { Moço et al. (2005) }\end{array}$ \\
\hline $\begin{array}{l}\text { Mesofauna do solo } \\
\text { (Aracnídea, Acari, Collembola, } \\
\text { Himenóptera, Díptera, Protura, } \\
\text { Diplura, Simphyla, Enchytraeidae, } \\
\text { Isóptera, Quilópode, Diplópode, } \\
\text { Molusca e pequenos Coleópteros) }\end{array}$ & $\begin{array}{l}\text { - Seu tamanho varia entre } 100 \mu \mathrm{m} \text { e } 2 \mathrm{~mm} \text {. } \\
\text { - Relação direta solo-planta (decomposição). } \\
\text { - Auxiliam a ciclagem de nutrientes e aeração do solo. } \\
\text { - Influencia a transformação, armazenamento e disponibilidade de nutrientes. } \\
\text { - Influenciam a porosidade do solo e a estrutura da vegetação. } \\
\text { - Relação direta com o tipo de uso e manejo do solo. } \\
\text { - Sensíveis às mudanças climáticas e ajudam no controle natural doenças no solo. }\end{array}$ & $\begin{array}{l}\text { Martin (1991) } \\
\text { Decaëns et al. (1998) } \\
\text { Da Silva et al. (2011) } \\
\text { Barrios; Coutinho; Medeiros (2012) } \\
\text { Quintero; Roslin (2005) } \\
\text { Moço et al. (2005) } \\
\text { Turbé et al. (2010) }\end{array}$ \\
\hline $\begin{array}{l}\text { Macrofauna do solo } \\
\text { (Aracnídea, Himenóptera, Díptera, } \\
\text { Simphyla, Enchytraeidae, Isóptera, } \\
\text { Quilópode, Diplópode, Molusca e } \\
\text { pequenos Coleópteros) }\end{array}$ & $\begin{array}{l}\text { - Seu tamanho varia entre } 2 \text { e } 20 \mathrm{~mm} \text {. } \\
\text { - Auxilia o transporte de materiais estruturais do solo. } \\
\text { - Auxilia a fragmentação do resíduo vegetal e sua redistribuição. } \\
\text { - Influencia a porosidade do solo. } \\
\text { - Predação de outros invertebrados. } \\
\text { - Contribuição direta na estruturação do solo }\end{array}$ & $\begin{array}{l}\text { Swift; Heal; Anderson (1979) } \\
\text { Da Silva et al. (2011) } \\
\text { Barrios; Coutinho; Medeiros (2012) } \\
\text { Moço et al. (2005) } \\
\text { Turbé et al. (2010) }\end{array}$ \\
\hline $\begin{array}{l}\text { Plantas } \\
\text { (Rubiáceas, Melastomatáceas) }\end{array}$ & $\begin{array}{l}\text { - Relação direta com a físico-química do solo. } \\
\text { - Relação direta com a associação de fauna edáfica (decomposição). } \\
\text { - Regulação do fluxo de minerais. } \\
\text { - Regulação de substancias contaminantes do solo. }\end{array}$ & $\begin{array}{l}\text { Primavessi (1981) } \\
\text { Villareal et al. (2004) } \\
\text { Villareal et al. (2006) } \\
\text { Bagliano (2012) }\end{array}$ \\
\hline
\end{tabular}




\section{4. ÍNDICES DE QUALIDADE DO SOLO E SUA APLICAÇÃO NA AVALIAÇÃO DOS IMPACTOS DO USO E MANEJO DO SOLO}

Um índice revela o estado de um sistema, podendo ser construído para analisar dados através da união de elementos com relações estabelecidas. Um indicador pode ser um dado individual ou um agregado de informações. Um bom índice ou indicador deve conter atributos como simplicidade, quantificação estatística, ser lógico e comunicar o estado do fenômeno observado (SHIELDS; SOLAR; MARTIN, 2002; SICHE et al., 2007).

Quando se trata da qualidade do solo, se destaca a necessidade de um conjunto de parâmetros ou indicadores físicos, químicos e biológicos, para a obtenção de um índice confiável. Este índice deve diagnosticar a condição atual dos solos, estimar sua degradação, e permitir a avaliação do impacto do uso e manejo do solo na qualidade do recurso (CONCEIÇÃO et al., 2005; BARRIOS et al., 2006).

Um índice de qualidade do solo deve integrar propriedades físicas, químicas e biológicas do solo e os respectivos processos; ser acessível a diferentes usuários e aplicável a distintas condições de campo; ser sensível a variações do uso e manejo do solo e do clima ao longo do tempo (DORAN; PARKIN, 1994; GLOVER; REGANOLD; ANDREWS, 2000). Entretanto, estudos relacionados à qualidade do solo em áreas sob diferentes sistemas de manejo são ainda escassos na literatura (VEZZANI; MIELNICZUK, 2009; DE FREITAS et al., 2012) (Tabela 5). 
Tabela 5. Índices e indicadores de qualidade do solo

\begin{tabular}{|c|c|c|c|}
\hline Índice & Características e aplicação & Parâmetros ou indicadores & Fonte \\
\hline $\mathrm{IQS}_{1}$ e IQS $\mathrm{I}_{2}$ & $\begin{array}{l}\text { - São dois índices, para diferentes sistemas } \\
\text { de uso e manejo florestal e cerrado nativo } \\
\text { adjacentes, através da avaliação integrada } \\
\text { de parâmetros físicos e químicos. } \\
\text { - Para o IQS } S_{1} \text { os sistemas naturais foram } \\
\text { considerados como referência. } \\
\text { - O IQS } S_{2} \text { foi gerado a partir de um modelo } \\
\text { aditivo que considera as principais funções } \\
\text { do solo e os indicadores de qualidade a elas } \\
\text { associados. } \\
\text { - Foram atribuídos pesos para as funções e } \\
\text { indicadores. } \\
\text { - O IQS } S_{1} \text { indicou deteriorações causadas no } \\
\text { solo quando se converte os sistemas nativos } \\
\text { em florestas plantadas. } \\
\text { - O IQS } \text { I }_{2} \text { foi eficiente em identificar as } \\
\text { funções do solo em melhores ou piores } \\
\text { condições respeito ao uso e manejo atuais } \\
\text { apontando para uma possível melhoria nas } \\
\text { situações mais criticas. }\end{array}$ & $\begin{array}{l}\text { 1. Parâmetros físicos: } \\
\text { - Porosidade do solo. } \\
\text { - Condutividade hidráulica saturada. } \\
\text { - Densidade do solo. } \\
\text { - Diâmetro médio geométrico dos } \\
\text { agregados. } \\
\text { 2. Parâmetros químicos: } \\
\text { - pH em água. } \\
\text { - Carbono orgânico total. } \\
\text { - Fósforo disponível. } \\
\text { - Cátions trocáveis. } \\
\text { - Alumínio extraível. } \\
\text { - Acidez extraível. }\end{array}$ & De Freitas et al. (2012) \\
\hline $\begin{array}{l}\text { Índice de qualidade do solo } \\
\qquad \text { (SQI) }\end{array}$ & $\begin{array}{l}\text { - Expressa a capacidade do solo para } \\
\text { desenvolver serviços ecossistêmicos e } \\
\text { sociais. } \\
\text { - Depende do grau de desempenho das } \\
\text { funções do solo, como: capacidade } \\
\text { funcional do solo (SFA) e Propriedades de } \\
\text { resposta do solo. } \\
\text {-A qualidade do solo pode apoiar avaliações } \\
\text { das sinergias entre o uso do solo local e as } \\
\text { propriedades de regulação. }\end{array}$ & $\begin{array}{l}\text { 1. Capacidade funcional do solo (SFA): } \\
\text { numero de diferentes funções que o solo } \\
\text { suporta para funcionar. } \\
\text { 2. Propriedades de resposta (SRP): } \\
\text { condicionadores das funções do solo. } \\
\text { 3. Fatores influenciadores: clima, } \\
\text { hidrologia, relevo, entre outros. }\end{array}$ & Tóth; Stolbovoy; Montanarella (2007) \\
\hline Índice de fauna do solo para & - Assume a diversidade da comunidade & 1. Presença / ausência / abundancia de & Yan et al. (2012) \\
\hline
\end{tabular}




\begin{tabular}{|c|c|c|c|}
\hline Índice & Características e aplicação & Parâmetros ou indicadores & Fonte \\
\hline $\begin{array}{l}\text { avaliar a qualidade do solo } \\
\text { (FAI) }\end{array}$ & $\begin{array}{l}\text { faunística do solo junto com suas } \\
\text { características funcionais e a abundância de } \\
\text { seus membros (índice de Fauna com } \\
\text { fundamento na abundancia, referido como } \\
\text { FAI). } \\
\text { - O índice FAI está constituído em dois } \\
\text { passos: } \\
\text { A. Qualidade do solo resultado do produto } \\
\text { de entre o número de espécies da } \\
\text { comunidade do solo (riqueza de espécies) e } \\
\text { o rendimento da fauna do solo em } \\
\text { funcionamento (rasgos funcionais para } \\
\text { estimar). } \\
\text { B. FAI resultado do produto entre a } \\
\text { qualidade do solo da área estudada e a } \\
\text { qualidade do solo com mais alta qualidade. } \\
\text { - O FAI proporciona informação importante } \\
\text { para a vinculação de rasgos funcionais da } \\
\text { fauna do solo e as condições ambientais } \\
\text { embaixo da terra. }\end{array}$ & $\begin{array}{l}\text { artrópodes do solo. } \\
\text { 2. Funções desempenhadas pelas } \\
\text { diferentes espécies de fauna do solo, como: } \\
\text { a capacidade de transporte e quantidade de } \\
\text { perfurações. }\end{array}$ & \\
\hline Índice de signos vitais do solo & $\begin{array}{l}\text { - Avalia a saúde do solo florestal. } \\
\text { - Pode ser usado como indicador do risco de } \\
\text { degradação da floresta, e como indicador de } \\
\text { variação da qualidade do solo em função de } \\
\text { fatores de estresse ambiental. } \\
\text { - É calculado em duas fases: } \\
\text { A. Índice total de qualidade do solo: } \\
\text { somatória dos valores individuais dos } \\
\text { índices das propriedades do solo. } \\
\text { B. Índice de qualidade do solo em } \\
\text { percentagem: divisão entre o índice total de } \\
\text { qualidade do solo e o índice de qualidade } \\
\text { do solo máximo das propriedades avaliadas }\end{array}$ & $\begin{array}{l}\text { - } 19 \text { Propriedades físicas e químicas do } \\
\text { solo: densidade aparente, fragmentos } \\
\text { grosseiros, pH, carbono total em solos } \\
\text { minerais, nitrogênio total em solos } \\
\text { minerais, percentagem de sódio trocável, } \\
\text { potássio, magnésio, cálcio, alumínio, } \\
\text { manganésio, ferro, níquel, cobre, zinco, } \\
\text { cadmio, enxofre e chumbo. }\end{array}$ & Amacher; O’Neill; Perry (2007) \\
\hline
\end{tabular}




\begin{tabular}{|c|c|c|c|}
\hline Índice & Características e aplicação & Parâmetros ou indicadores & Fonte \\
\hline & $\begin{array}{l}\text { e finalmente multiplicado por } 100 \text {. } \\
\text { - O banco de dados pode ser estratificado } \\
\text { por ecoregião, tipo de floresta, tipo de solo, } \\
\text { assim apropriadas estimativas populacionais } \\
\text { podem ser calculadas. }\end{array}$ & & \\
\hline Macro-fauna edáfica & $\begin{array}{l}\text { - Uso de macrofauna como indicador } \\
\text { biológico do estado de conservação do solo. } \\
\text { - Uso de macrofauna para predição do } \\
\text { estado de conservação/degradação do solo. } \\
\text { - Recomendados como bons indicadores } \\
\text { para a avaliação da qualidade do solo por } \\
\text { ser sensíveis às mudanças relacionadas ao } \\
\text { uso e manejo do solo. }\end{array}$ & $\begin{array}{l}\text { - Invertebrados maiores de } 2 \mathrm{~mm} \text { de } \\
\text { diâmetro. }\end{array}$ & Cabrera (2012) \\
\hline $\begin{array}{c}\text { Dinâmica da Matéria } \\
\text { Orgânica }\end{array}$ & $\begin{array}{l}\text { - Uso da matéria orgânica como indicador } \\
\text { da qualidade do solo pela sua influência em } \\
\text { outros atributos essenciais para que o solo } \\
\text { desempenhe suas funções. } \\
\text { - Avaliação de diferentes usos e manejos do } \\
\text { solo. } \\
\text { - Detecção de alterações da qualidade do } \\
\text { solo induzidas pelos diferentes usos e } \\
\text { manejos do recurso. }\end{array}$ & $\begin{array}{l}\text { 1. Matéria orgânica do solo: } \\
\text { - Carbono orgânico total. } \\
\text { - Nitrogênio total. } \\
\text { 2. Biomassa microbiana }\end{array}$ & Conceição et al. (2005) \\
\hline Índice de Qualidade & $\begin{array}{l}\text { - O uso dos parâmetros foi aplicado na } \\
\text { avaliação comparativa do uso e manejo do } \\
\text { solo e a sua qualidade. } \\
\text { - Avaliação da qualidade do solo sob um } \\
\text { Latossolo Vermelho-Amarelo. } \\
\text { - Mediante análise das propriedades físicas, } \\
\text { químicas e biológicas e da elaboração de } \\
\text { um modelo comparativo, avaliar o nível de } \\
\text { degradação do solo em função do uso de } \\
\text { cada área. } \\
\text { - O uso de parâmetros físicos, químicos e }\end{array}$ & $\begin{array}{l}\text { 1. Propriedades físicas: } \\
\text { - Densidade do solo. } \\
\text { - Porosidade total. } \\
\text { - Resistência mecânica à penetração } \\
\text { vertical. } \\
\text { - Taxa de infiltração de água. } \\
\text { 2. Propriedades químicas: } \\
\text { - Conteúdo de matéria orgânica do solo. } \\
\text { - Capacidade de troca de cátions. }\end{array}$ & Araújo; Goedert; Lacerda (2007) \\
\hline
\end{tabular}




\begin{tabular}{|c|c|c|c|}
\hline Índice & Características e aplicação & Parâmetros ou indicadores & Fonte \\
\hline & $\begin{array}{l}\text { biológicos evidenciou uma relação estreita e } \\
\text { inversa entre a qualidade do solo e a } \\
\text { intensidade de uso a que as áreas foram } \\
\text { submetidas. }\end{array}$ & $\begin{array}{l}\text { 3. Propriedades biológicas: } \\
\text { - Carbono na biomassa microbiana. - } \\
\text { Respiração basal. }\end{array}$ & \\
\hline $\begin{array}{l}\text { Índice de qualidade sub- } \\
\text { superficial }\end{array}$ & $\begin{array}{l}\text { - Índice de qualidade do solo (IQS) para } \\
\text { os horizontes subsuperficiais em um } \\
\text { Latossolo Amarelo coeso Argissólico } \\
\text { (LAx) dos Tabuleiros Costeiros, sob } \\
\text { floresta natural. } \\
\text { - Avaliação da capacidade agrícola do solo. } \\
\text { - Avaliação da necessidade do solo para ser } \\
\text { tratado previamente às atividades de } \\
\text { produção. } \\
\text { - Índice especifico para áreas de tabuleiros } \\
\text { costeiros. }\end{array}$ & $\begin{array}{l}11 \text { parâmetros: macroporosidade, densidade } \\
\text { do solo, condutividade hidráulica saturada, } \\
\text { retenção de água a }-33 \mathrm{kPa} \text {, relação de } \\
\text { disponibilidade de água no solo (AD/PT), } \\
\mathrm{pH} \text {, resistência à penetração, capacidade de } \\
\text { troca catiônica, percentagem de saturação } \\
\text { por bases, percentagem de saturação por } \\
\text { alumínio (m) e teor de matéria orgânica. }\end{array}$ & Melo Filho; Souza; Souza (2007) \\
\hline Besouros coprófagos & $\begin{array}{l}\text { - Utilizados como indicador de qualidade } \\
\text { do solo pela sua sensibilidade às mudanças } \\
\text { do solo de acordo ao seu uso e manejo. } \\
\text { - Ampla distribuição geográfica. } \\
\text { - Sua presença / ausência / riqueza / } \\
\text { abundancia está intimamente ligada ao nível } \\
\text { de antropização do ambiente. } \\
\text { - Relação direta com as funções e serviços } \\
\text { ofertados pelo solo. } \\
\text { - Possuem protocolos de amostragem } \\
\text { padronizados e taxonomia acessível. } \\
\text { - Apresentam variadas respostas aos } \\
\text { ambientes florestais e cultivados, motivo } \\
\text { pelo qual são usados como parâmetro de } \\
\text { avaliação às respostas biológicas. } \\
\text { - Proveem diferentes serviços ecológicos, } \\
\text { como a dispersão de sementes, polinização, } \\
\text { e ciclagem de nutrientes, de modo tal que as }\end{array}$ & $\begin{array}{l}\text { Besouros coprófagos (Scarabaeidae: } \\
\text { Scarabaeinae) }\end{array}$ & $\begin{array}{l}\text { Guillard (1967) } \\
\text { Kalisz; Stone (1984) } \\
\text { Bertrand; Lumaret (1984) } \\
\text { Louiseau et al. (1984) } \\
\text { Didham et al. (1996) } \\
\text { Vaz-de-Mello (2000) } \\
\text { Escobar (2000) } \\
\text { Celi; Dávalos (2001) } \\
\text { McGeoch; Van Rensburg; Botes (2002) } \\
\text { Kimberling; Karr; Fore (2001) } \\
\text { Davis et al. (2001) } \\
\text { Gallo et al. (2002) } \\
\text { Thomanzini; Thomanzini (2002) } \\
\text { Milhomem, Mello, Diniz (2003) } \\
\text { Wink et al. (2005) }\end{array}$ \\
\hline
\end{tabular}




\begin{tabular}{|c|c|c|c|}
\hline Índice & Características e aplicação & Parâmetros ou indicadores & Fonte \\
\hline & $\begin{array}{l}\text { mudanças nas suas comunidades põem em } \\
\text { risco o funcionamento do ecossistema. } \\
\text { - Proporcionam importantes mudanças } \\
\text { físico-químicas no solo, pela ciclagem e } \\
\text { incorporação de nutrientes no solo. } \\
\text { - Proporcionam o enriquecimento dos } \\
\text { horizontes edáficos adjacentes, atraindo } \\
\text { outros micro-artrópodos e ácaros e } \\
\text { colêmbolos. }\end{array}$ & & \\
\hline
\end{tabular}




\subsection{CARACTERÍSTICAS EDAFOLÓGICAS DOS SOLOS DO CERRADO}

O termo Cerrado é comumente utilizado para designar o conjunto de ecossistemas de savanas, matas, campos e matas de galeria que ocorrem no Brasil central. O cerrado abrange cerca de dois milhões de quilômetros quadrados, equivalente a quase um quarto do território nacional sendo, portanto, a segunda maior formação vegetal brasileira e também a savana tropical mais rica e ameaçada do planeta. O clima do cerrado se caracteriza por dois períodos, um chuvoso que dura de outubro a março, e outro seco que dura de abril a setembro (KLINK; MACHADO, 2005).

Os principais solos do cerrado são Latossolos (Vermelho, Vermelho-amarelo), cobrindo 45,7\% da área, Neossolos Quartzarênicos, com 15,2\%, Argissolos, com 15,1\%, Plintossolos, com 9,0\%, Neossolos Litólicos, com 7,3\%, e Gleissolos, com 2,5\% (SANTOS et al., 2013).

Apesar de apresentarem boas características físicas, os solos dos Cerrados são geralmente ácidos e de baixa fertilidade, baixos teores de matéria orgânica, baixos teores de cálcio magnésio trocável, baixo índice de saturação de bases, e elevados teores de alumínio trocável (OLIVEIRA; YOKOYAMA, 2003; DE OLIVEIRA et al., 2005).

O cerrado abriga uma alta diversidade fito-fisionômica: i) formação florestal incluindo a Mata Ciliar, Mata de Galeria (Inundável e Não Inundável), Mata Seca (Sempre-Verde, Semidecídua e Decídua) e Cerradão (Mesotrófica e Distrófica); ii) formação savânica incluindo o parque de cerrado, palmeiral, vereda e cerrado sentido restrito (cerrado denso, típico, Ralo e Rupestre); e iii) formação campestre, incluindo campo sujo, campo limpo e campo rupestre (RIBEIRO; WALTER, 2008; BASTOS; FERREIRA, 2012).

Apesar de sua importância ecológica, este bioma vem sendo gradativamente substituído por áreas de pastagens e culturas agrícolas. Nas últimas décadas, as taxas de desmatamento têm variado entre 2,2 a 3 milhões de hectares/ano. Atualmente, a conversão do cerrado natural para outros tipos de cobertura, como pastagens e lavouras, tem variado entre $40 \%$ a 55\% (MACHADO et al., 2004; KLINK; MACHADO, 2005; SANO; ALMEIDA; RIBEIRO, 2008; SILVA; MELLO; STEINKE, 2012). 


\section{MATERIAIS E MÉTODOS}

\subsection{CARACTERIZAÇÃO DAS ÁREAS DE ESTUDO E SEUS SOLOS}

A pesquisa foi realizada numa área rural da bacia hidrográfica do ribeirão Pipiripau, em Planaltina-DF. A bacia está localizada ao nordeste do Distrito Federal, com centroide nas coordenadas $15^{\circ} 27^{\prime} 14^{\prime \prime} \mathrm{S}$ e $47^{\circ} 27^{\prime} 47^{\prime} \mathrm{W}$, apresentando uma altitude média de 1.095 metros. A bacia apresenta declividade média de 5,8\% e solos bem drenados, com predominância do Latossolo Vermelho, Latossolo Vermelho-Amarelo e Cambissolos (CAESB, 2001).

A precipitação média anual na área de estudo é de $1.340 \mathrm{~mm}$, com estações chuvosa e seca marcantes (CHAVES; PIAU, 2008). Devido ao crescimento populacional de Brasília, boa parte da cobertura vegetal natural da bacia deu passo à agricultura intensiva $\mathrm{e}$ à pecuária extensiva, cobrindo aproximadamente $43 \%$ e $28 \%$ da bacia, respectivamente, restando 29\% de Cerrado e Mata Nativa (CAESB, 2001; CHAVES; PIAU, 2008).

Geralmente o solo é manejado com práticas convencionais e conservacionistas, dependendo do tamanho e tipo de propriedade. A maioria das pastagens se encontra degradada, evidenciando-se falhas na cobertura do solo, presença de plantas invasoras e indícios de erosão laminar (CHAVES et al., 2004a; CHAVES et al., 2004b). Visando analisar o efeito dos diferentes tipos de uso e manejo típicos da bacia, seis áreas experimentais, situadas num raio de $1 \mathrm{~km}$, e localizadas sobre um Latossolo Vermelho de textura franco-argilo-arenosa, foram selecionadas.

As seis áreas experimentais apresentam semelhantes condições de altitude (1.050$1.100 \mathrm{~m}$ ) e clima (Cwa de Koppen). Os usos do solo das áreas experimentais corresponderam a um Cerrado stricto sensu, um Cerradão pouco alterado; um Reflorestamento homogêneo de 10 anos; um Reflorestamento misto de um ano de plantio; uma lavoura de milho sob plantio direto; e uma Pastagem de gradada (Tabela 6, Figura 1). 
Tabela 6. Coordenadas geográficas dos centroides das áreas experimentais

\begin{tabular}{lcc}
\hline \multicolumn{1}{c}{ Área experimental } & \multicolumn{2}{c}{ Coordenadas do centroide } \\
\cline { 2 - 3 } & \multicolumn{1}{c}{ Sul } & Oeste \\
\hline Cerrado stricto sensu & $15^{\circ} 39^{\prime} 53^{\prime \prime}$ & $47^{\circ} 30^{\prime} 26^{\prime \prime}$ \\
Cerradão & $15^{\circ} 39^{\prime} 20^{\prime \prime}$ & $47^{\circ} 30^{\prime} 11^{\prime \prime}$ \\
Reflorestamento de 1 ano & $15^{\circ} 39^{\prime} 27^{\prime \prime}$ & $47^{\circ} 30^{\prime} 13^{\prime \prime}$ \\
Reflorestamento de 10 anos & $15^{\circ} 39^{\prime} 16^{\prime \prime}$ & $47^{\circ} 30^{\prime} 25^{\prime \prime}$ \\
Lavoura de milho & $15^{\circ} 39^{\prime} 55^{\prime \prime}$ & $47^{\circ} 39^{\prime} 26^{\prime \prime}$ \\
Pastagem degradada & $15^{\circ} 39^{\prime} 34^{\prime \prime}$ & $47^{\circ} 30^{\prime} 09^{\prime \prime}$ \\
\hline
\end{tabular}

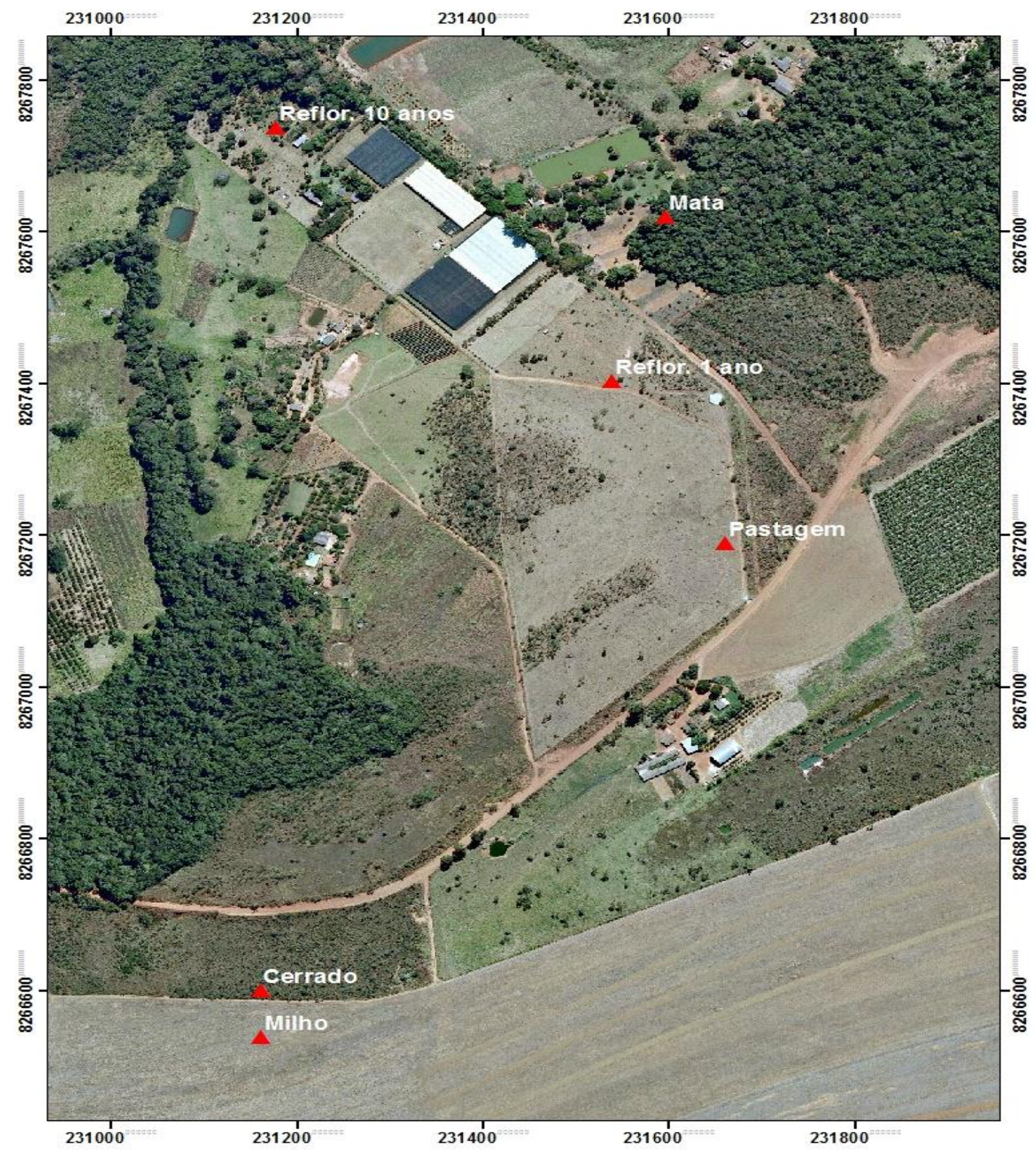

Figura 1. Layout das áreas de estudo e pontos de amostragem. 


\section{A. Cerrado stricto sensu}

O Cerrado stricto sensu corresponde a uma área de reserva legal, localizada na Área Isolada 3 do Núcleo Rural Taquara. Há dois estratos vegetais dominantes na área: um estrato arbóreo-arbustivo e herbáceo-graminoso abundante e disperso. O solo é um Latossolo Vermelho. A área, com cerca de 2 há, sofre queimadas frequentes, mas durante o período de estudo, abril até junho de 2014, elas não foram observadas (Figura 2).
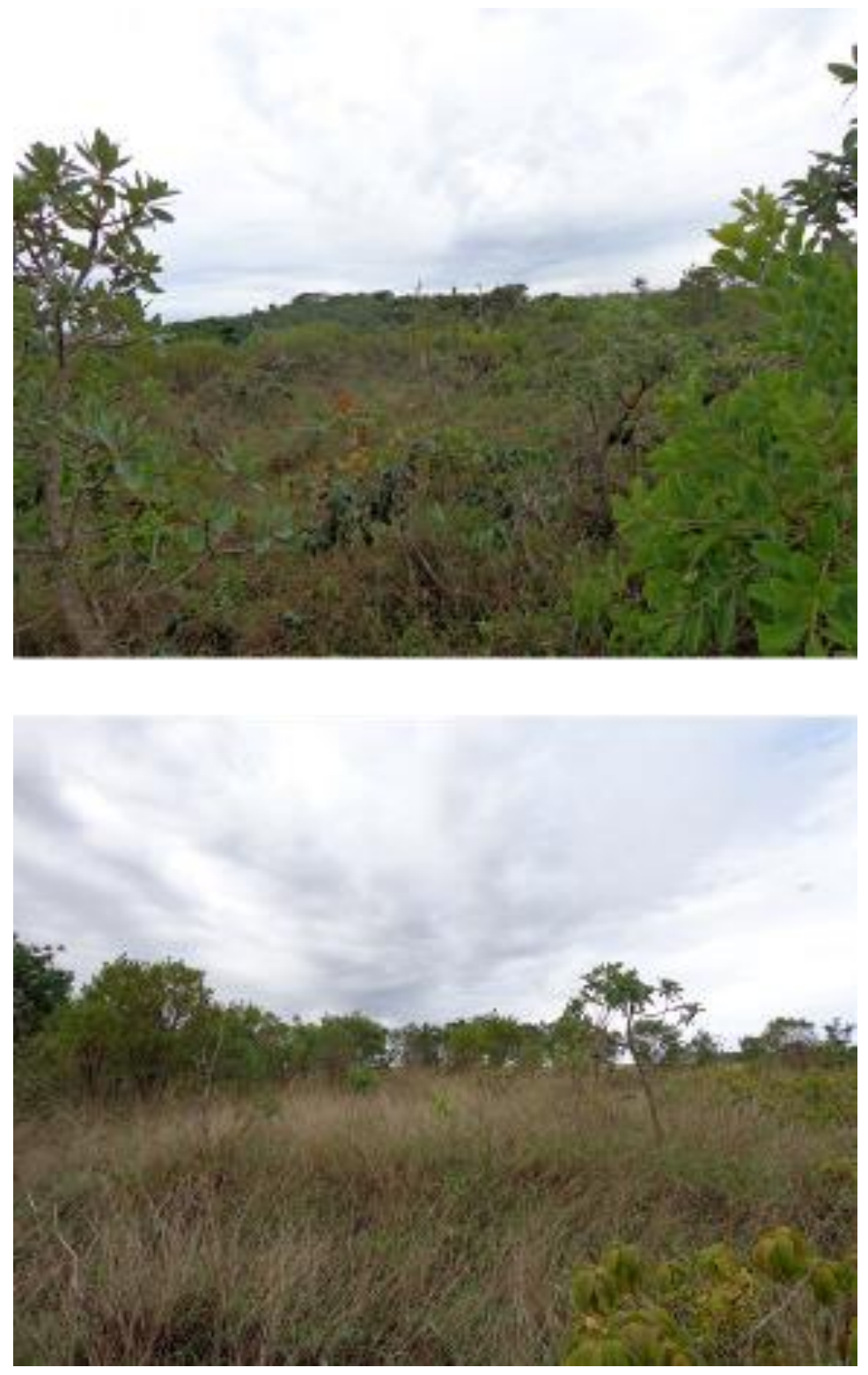

Figura 2. Aspecto geral da área de Cerrado stricto sensu. 


\section{B. Cerradão}

A área corresponde a um Cerradão alterado, convertido em reserva legal. A área se encontra localizada no interior da chácara 14, do Núcleo Rural Taquara. O Cerradão é caracterizado pela presença de árvores altas, com copa aberta. Apresenta um estrato arbustivo-herbáceo abundante e espalhado por toda a área de pesquisa. O solo é um Latossolo Vermelho. O remanescente tem pelo menos 20 anos de idade, sem histórico de queimadas. Durante o período de estudo, a área experimental não sofreu queimada alguma (Figura 3).
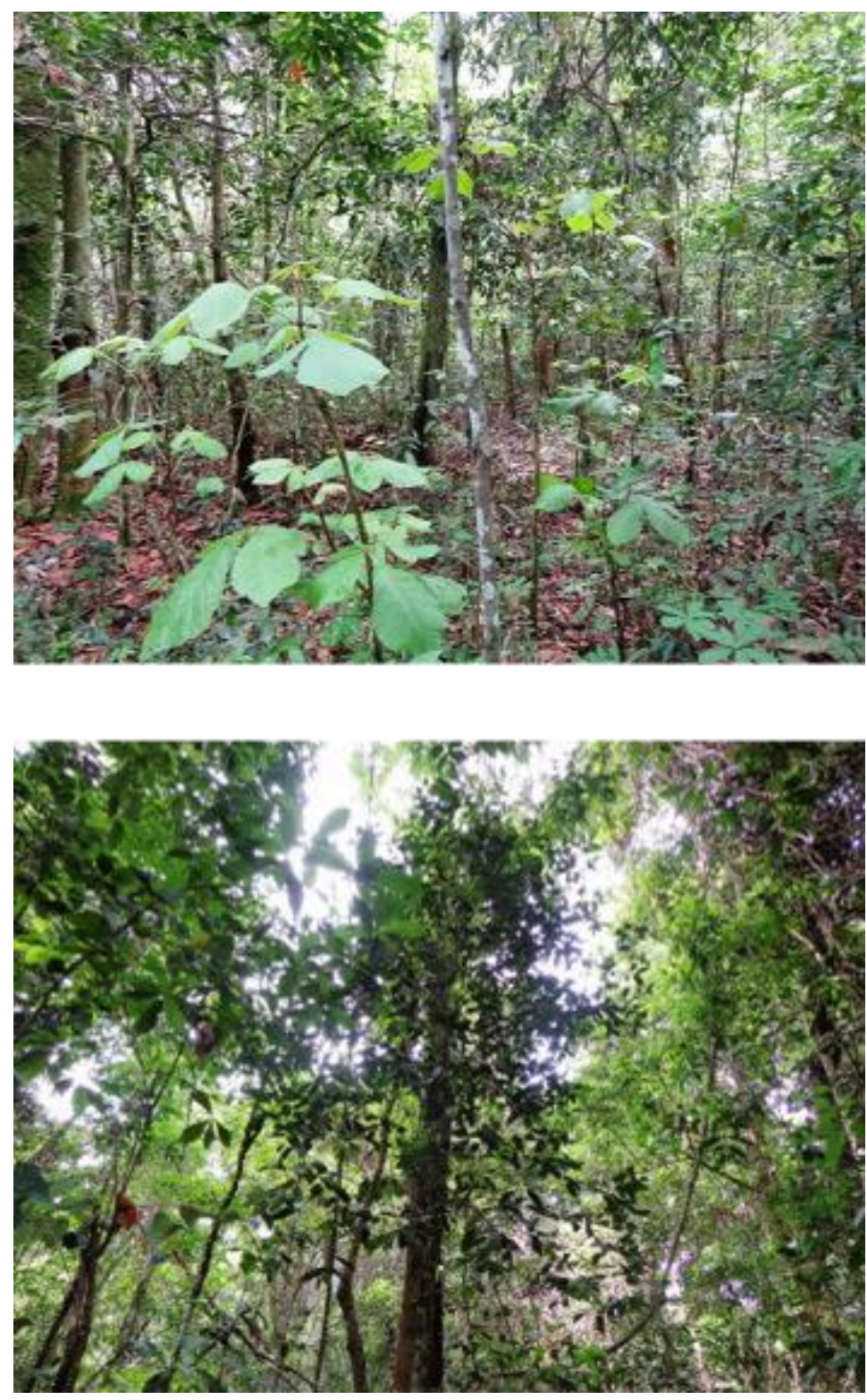

Figura 3. Aspecto geral da área de Cerradão alterado. 


\section{Reflorestamento de $\mathbf{1 0}$ anos}

Reflorestamento de 10 anos se encontra localizado no interior da chácara "La Bromelia". O reflorestamento homogêneo foi feito com a espécie Enterolobium gummiferum, num espaçamento de $5 \times 2 \mathrm{~m}$, cobrindo uma área total de 1 ha. As árvores se caracterizam por ter uma copa aberta, sem subcopa, e estrato arbustivo-herbáceo escasso. Após o plantio, há 10 anos, têm sido realizadas adubações minerais anualmente, mas sem monitoramento de crescimento e estado das arvores. A área não apresenta histórico de queimadas (Figura 4).
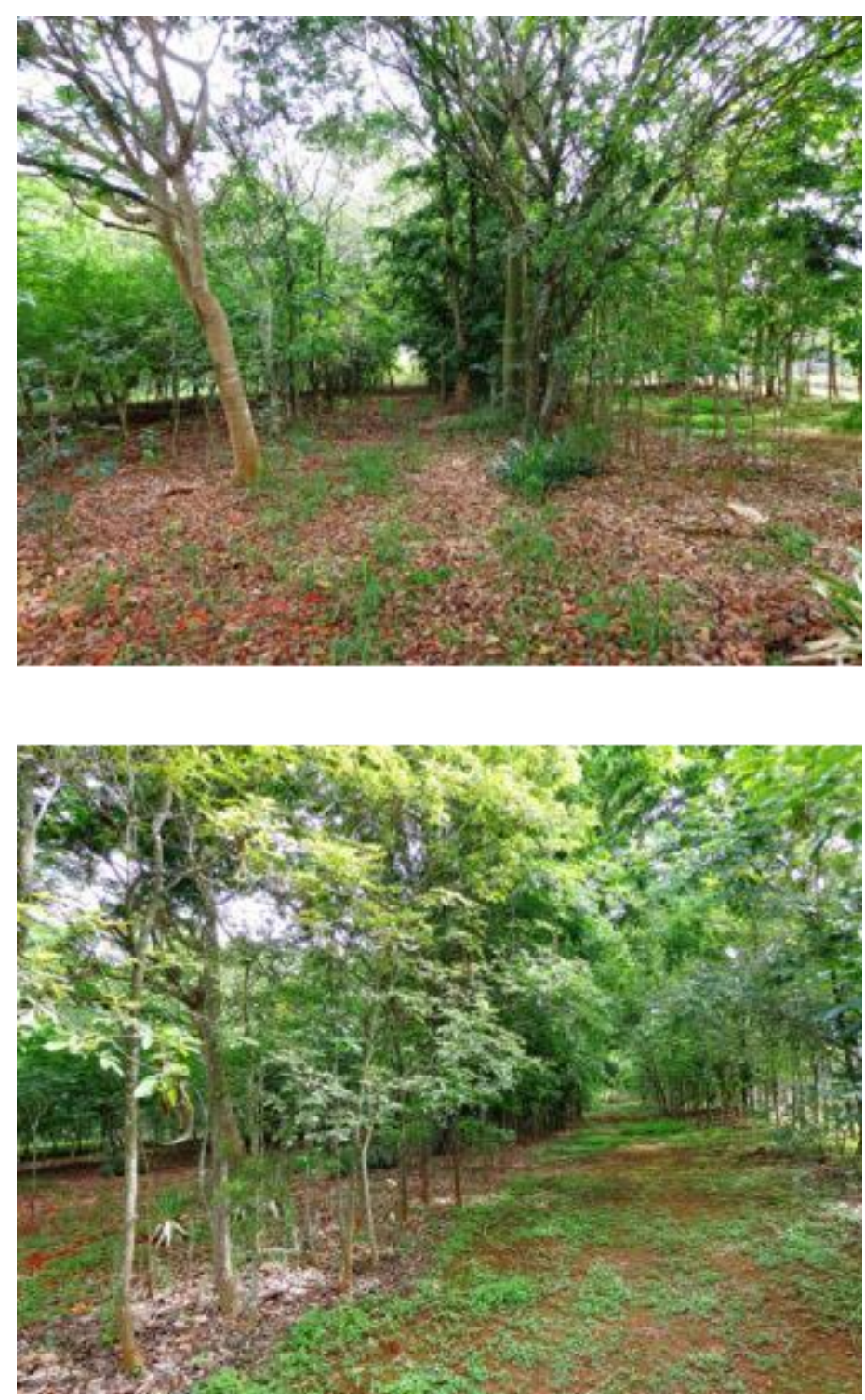

Figura 4. Aspecto geral da área de Reflorestamento de 10 anos. 


\section{Reflorestamento de 1 ano}

O Reflorestamento de 1 ano está situado na Chácara La Bromélia, no Núcleo Rural Taquara (Planaltina-DF). O reflorestamento é uma iniciativa do proprietário em tentar recompor a estrutura natural do local, e teve apoio do Programa "Produtor de Água".

Trata-se de uma área de cerca de 1 ha, contendo 25 diferentes espécies nativas, plantadas num espaçamento de 3x2 m, incluindo Handroanthus impetiginosus, Piptadenia gonoacantha, Triplaris gardneriana, Myracrodruon urundeuva, e Sterculia striata.

As árvores apresentavam uma altura média de $50 \mathrm{~cm}$, sem sub-copa, e envoltas por capim Brachiaria decumbens, com 1,5 m de altura. Durante o período de estudo (abriljunho de 2014) não houve queimada, está ocorrendo apenas após o estudo, em dezembro de 2014 (Figura 5).
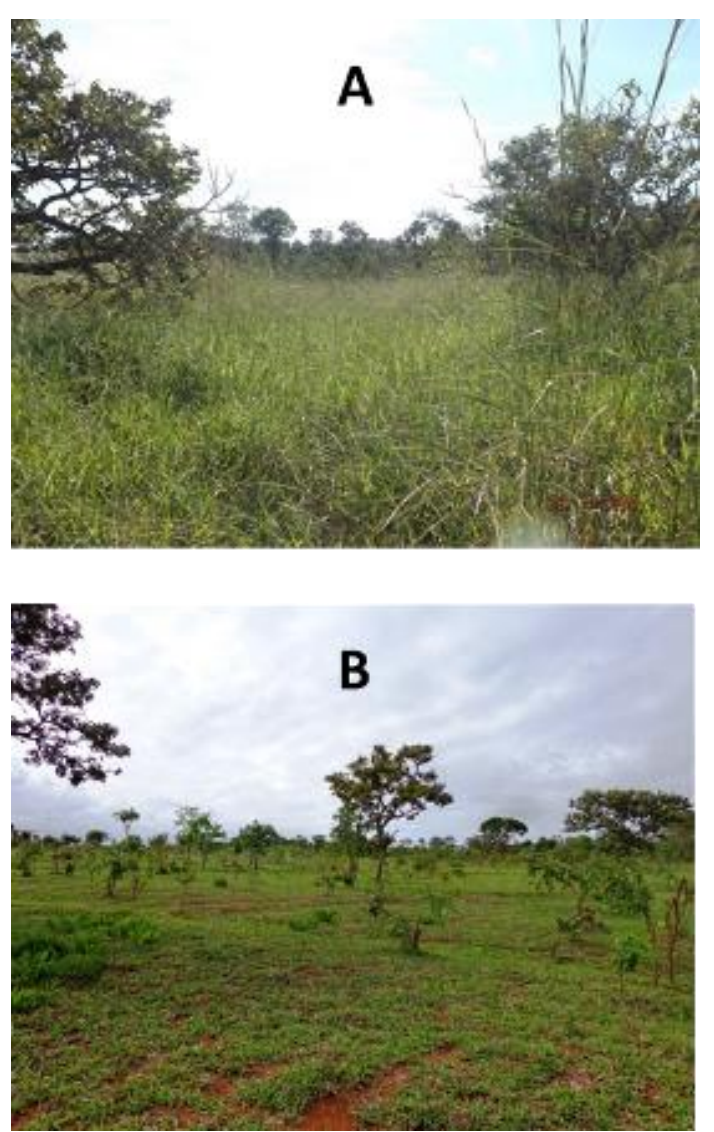

Figura 5. Aspecto geral da área de Reflorestamento de 1 ano. A) Reflorestamento de 1 ano antes da queimada no mês novembro de 2014 . B) Reflorestamento de 1 ano depois da queimada no mês de janeiro de 2015 . 


\section{E. Lavoura de milho}

Trata-se de uma lavoura de milho safrinha (Zea mays), plantada com sementes Pioneer hibrido transgênico, com resistência a lagartas (GenBT). A lavoura foi plantada no mês de março, após a colheita de soja, e colhida no mês de julho. O espaçamento entre linhas foi de $1 \mathrm{~m}$, e de $0,25 \mathrm{~m}$ entre plantas. A lavoura foi adubada com $250 \mathrm{~kg} / \mathrm{ha} \mathrm{com}$ a formulação N-P-K 4:30:16.

Durante o período de estudo, as plantas de milho apresentavam uma altura entre 1,5 e 2 m (fases de pendoamento e enchimento de grãos), com poucas ervas daninhas e restos de cultura de soja. O solo da área é um Latossolo Vermelho. Não houve fogo na área experimental durante o período de estudo (Figura 6).
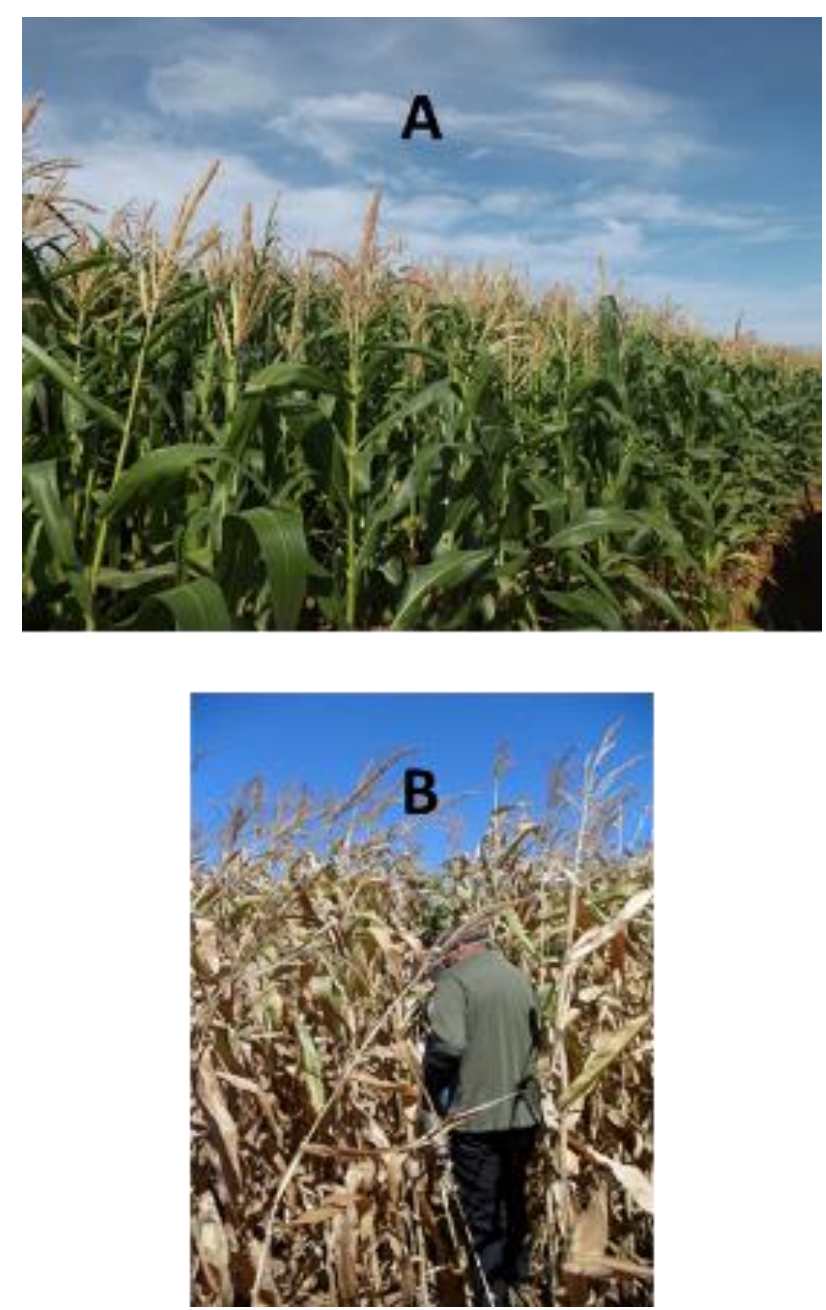

Figura 6. Aspecto geral da área de Lavoura de milho. A) Etapa de pendoamento. B) Etapa de maturação de colheita. 


\section{F. Pastagem degradada}

A Pastagem degradada, com cerca de três hectares, se encontra localizada na chácara 16, contigua a chácara La Bromelia, no Núcleo Rural Taquara (Planaltina-DF). A área é utilizada para a pecuária bovina extensiva. Durante o período de estudo, a vegetação predominante era o capim Brachiaria decumbens, de porte médio $(40 \mathrm{~cm})$, com áreas descobertas do solo, com a presença de poucas árvores, ervas daninhas e cupinzeiros. $\mathrm{O}$ solo da área é o Latossolo Vermelho, com sinais de compactação por pisoteio (Figura 7).
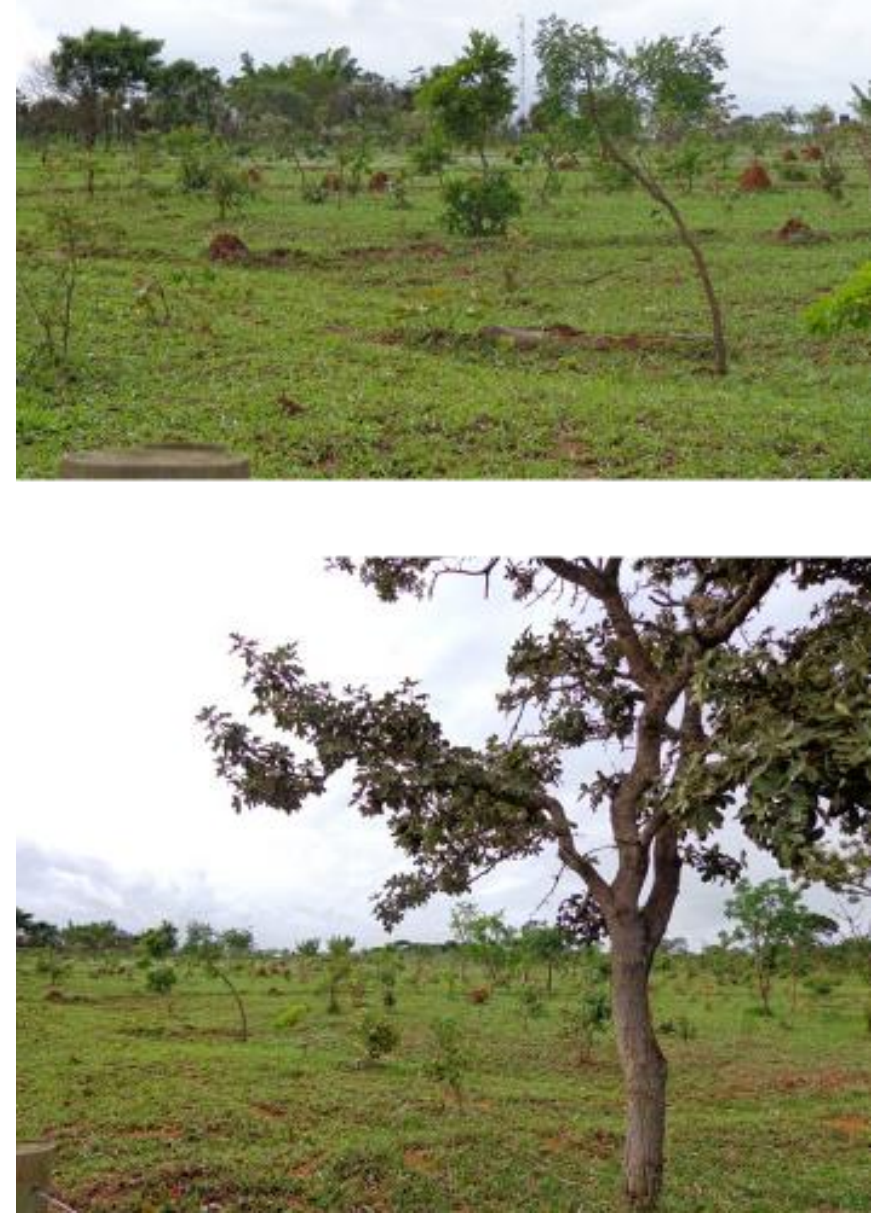

Figura 7. Aspecto geral da área de Pastagem degradada. 


\subsection{CARACTERIZAÇÃO TEXTURAL DOS SOLOS DAS SEIS ÁREAS EXPERIMENTAIS}

Para a caracterização e classificação textural do solo, foi utilizada, em cada área experimental, a metodologia recomendada por Santos et al. (2005). Foram coletadas amostras compostas em 15 diferentes pontos das áreas, em ziguezague, com um trado holandês, na profundidade de 0-30 cm. Em seguida, as amostras foram homogeneizadas num balde limpo, sendo $500 \mathrm{~g}$ do solo retirados deste e colocados em sacos plásticos rotulados, antes do envio para a análise em laboratório.

Para verificar a homogeneidade textural do solo das seis áreas experimentais, suas texturas foram avaliadas através do triângulo textural, obtendo-se assim a respectiva classe (SANTOS et al., 2005) (Figura 8).

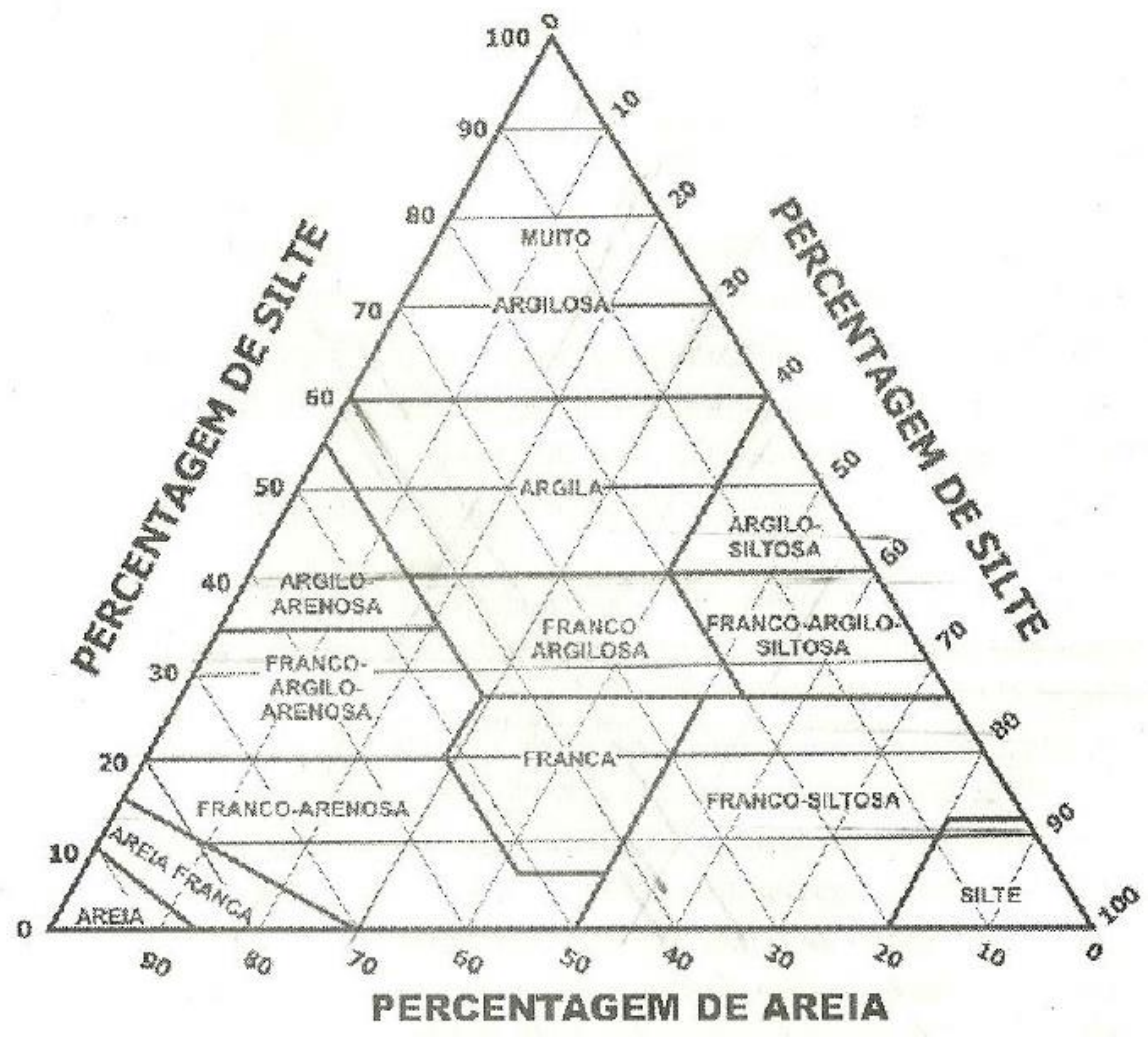

Figura 8. Triangulo de classificação textural. Fonte: Santos et al. (2005). 


\subsection{SELEÇÃo de PARÂMETROS PARA A ELABORAÇÃo do ÍNDICE DE QUALIDADE DO SOLO - IQS $(\mathrm{F}, \mathbf{Q}, \mathbf{B})$}

Na elaboração do índice de qualidade do solo, foram seguidas as diretrizes gerais de Shields; Solar; Martin (2002) e Siche et al. (2007), incluindo a simplicidade, quantificação estatística, a transparência e o potencial de comunicar o estado do fenômeno observado. A seleção dos parâmetros para o índice, por sua vez, buscou incorporar os aspectos físicos, químicos e biológicos do solo que fossem acessíveis a diferentes usuários e aplicáveis a distintas condições de campo, que fossem sensíveis a variações do uso e manejo do solo e do clima, ao longo do tempo (DORAN; PARKIN, 1994; GLOVER; REGANOLD; ANDREWS, 2000).

\subsubsection{Seleção dos Parâmetros Químicos}

Para os parâmetros químicos, foram considerados o teor de matéria orgânica do solo, a capacidade de troca catiônica, a saturação de bases, a acidez ativa e o teor fósforo. Esses parâmetros foram selecionados por suas funções no solo, incluindo a disponibilização de nutrientes para as plantas, e o efeito de tamponamento em relação às ações antrópicas (SOUSA E LOBATO, 2004; SPOSITO, 2008; VOLCHKO et al., 2014) (Tabela 3).

\subsubsection{Seleção dos parâmetros físicos e biológicos}

Os parâmetros físicos, como a taxa de infiltração de água no solo e resistência mecânica à penetração do solo foram selecionados por sua importância na determinação da rigidez das plantas, capacidade de reter ou armazenar nutrientes, penetrabilidade das raízes, a capacidade de aeração, drenagem e armazenamento da água no solo (RUCKS et al., 2004; DE BARROS et al., 2011; ver Tabela 2).

Os parâmetros biológicos, como o percentual de cobertura solo e o número de besouros coprófagos, de hábitos cavadores e roladores, foram escolhidos pela sua importância na proteção do solo contra as intempéries, pelo aporte de nutrientes, função na 
ciclagem de nutrientes, aeração e infiltração de água no solo, entre outros (KLINE, 2000; ANDRESEN, 2005) (Tabela 4).

\subsubsection{Taxa de infiltração de água no solo}

O método de infiltrômetro de anéis concêntricos (SIMÕES; FIGUEIRÊDO; SILVA, 2005) foi utilizado para medir a infiltrabilidade do solo. Assim, em cada uma das seis áreas experimentais foram feitas três repetições do teste de infiltração, em três pontos representativos da área, obtendo-se a velocidade básica de infiltração (PARCHEN, 2007; DE BARROS et al., 2011 (Figura 9A).

As dimensões do cilindro interno do equipamento são 0,30 metros de diâmetro e 0,40 metros de altura, e o cilindro externo de 0,50 metros de diâmetro e 0,50 m de altura (Figura 9B). Depois de instalados no solo, se adicionou água nos anéis externo e interno, e com uma régua graduada mede-se a velocidade de infiltração de água no cilindro interno (PARCHEN, 2007; DE BARROS et al., 2011) (Figura 9C).
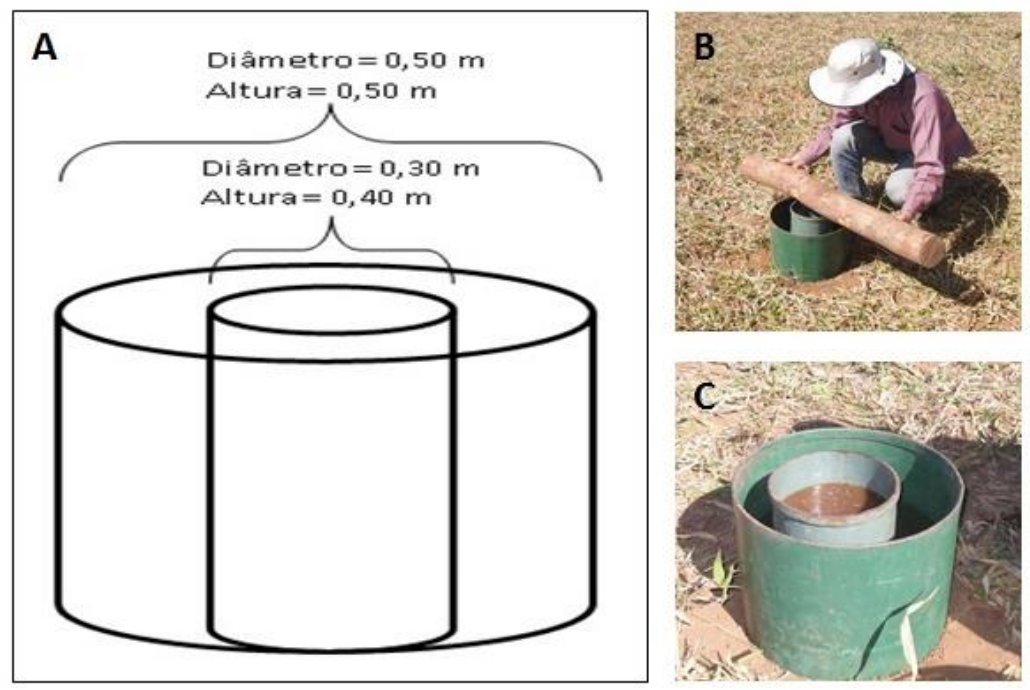

Figura 9. Infiltrômetro de anéis concêntricos. A) Desenho esquemático do infiltrômetro de anéis concêntricos. Fonte: Simões; Figueirêdo; Silva (2005). B) Instalação em campo do infiltrômetro de anéis concêntricos. C) Determinação da taxa de infiltração de água no solo, respetivamente. 
A partir dos dados obtidos em campo, foi confeccionado um gráfico $f(t)$ vs. $t$, cuja assíntota foi tomada como velocidade de infiltração básica-VIB, em $\mathrm{cm} / \mathrm{min}$. (PANACHUKI et al., 2006) (Figura 10).

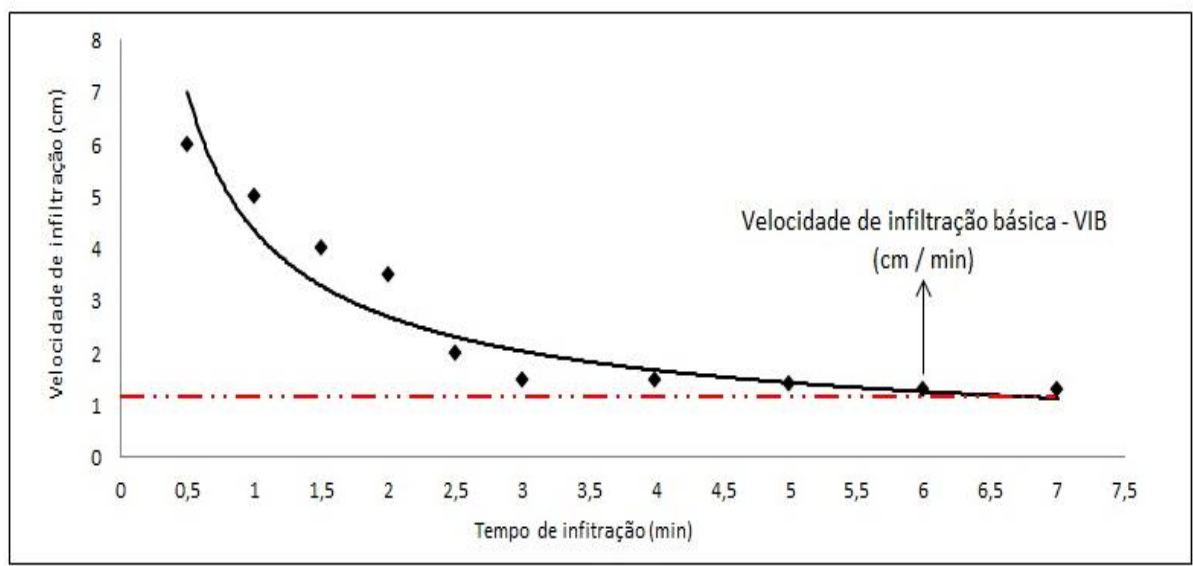

Figura 10. Exemplo de identificação da velocidade de infiltração básica (cm/min).

\subsubsection{Resistencia mecânica do solo à penetração}

A resistência do solo à penetração foi obtida com o penetrômetro de impacto de Stolf. O aparelho é formado por uma haste metálica graduada de 9,5 $\mathrm{mm}$ de diâmetro, com um cone na extremidade inferior de $12,8 \mathrm{~mm}$ de diâmetro, e um peso de $4 \mathrm{~kg}$ e um curso de queda livre de 400 mm (STOLF; FERNANDES; NETO, 1983; STOLF, 1991) (Figura $11)$.

Em cada área experimental foram realizadas três repetições, em três pontos representativos, na profundidade de 0-30 $\mathrm{cm}$. Foi registrado o número de impactos necessários para a penetração de cada 10 cm (STOLF; FERNANDES; NETO, 1983). Em seguida, os números de golpes foram convertidos em Mpa, de acordo com Stolf (1991) e Roboredo et al. (2010):

$$
R_{\left(\mathrm{Kgf} / \mathrm{cm}^{2}\right)}=5,6+6,89 \mathrm{~N}
$$

Onde: $\mathrm{N}=$ número de golpes para penetrar $10 \mathrm{~cm}$ em cada uma das profundidades medidas $(0-10$, 10-20, 20-30 cm). A resistência a penetração, em MPa, é dada por: 


$$
\mathbf{R}_{\mathrm{MPa}}=\mathbf{0 , 0 9 8 0 6 6 5} * \mathbf{R}_{\left(\mathrm{Kgf} / \mathrm{cm}^{2}\right)}{ }^{2}
$$

Onde: $\mathrm{R}_{\mathrm{Kgf} / \mathrm{cm} 2}=$ resultado da equação [1]
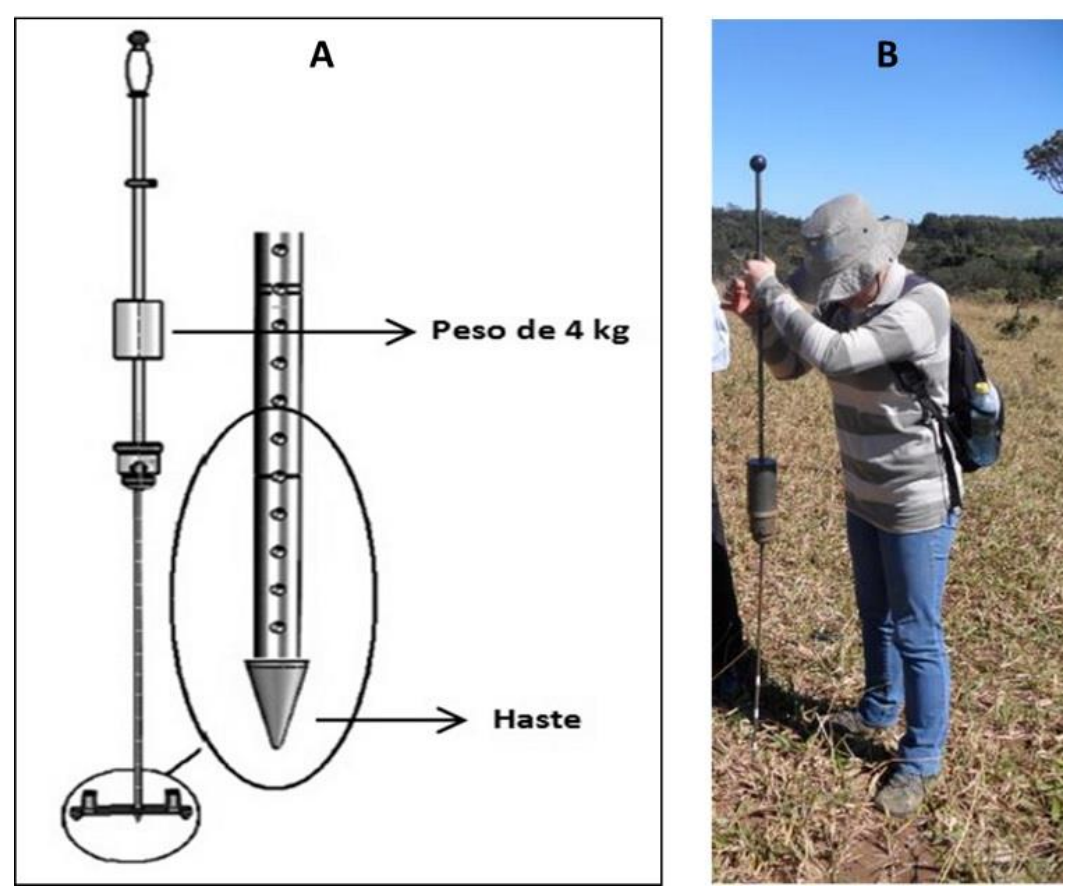

Figura 11. Penetrômetro de impacto. A) Esquema do penetrômetro de impacto Stolf. B) Determinação da resistência mecânica do solo à penetração.

\subsubsection{Cobertura do solo}

A cobertura do solo foi determinada através da vara métrica de kline (KLINE, 2000). Foram feitas três repetições em pontos representativos das seis áreas experimentais. Cada repetição foi a média de dez medidas aleatórias da cobertura dos solos das áreas.

A percentagem da cobertura do solo (resíduos florestais, restos culturais ou raízes) foi então obtida pela contagem do número de linhas interceptadas diretamente sobre um pedaço de resíduo, raiz ou planta, multiplicando-se o resultado por quatro (KLINE, 2000; SHELTON; JASA, 2009) (Figura 12). 

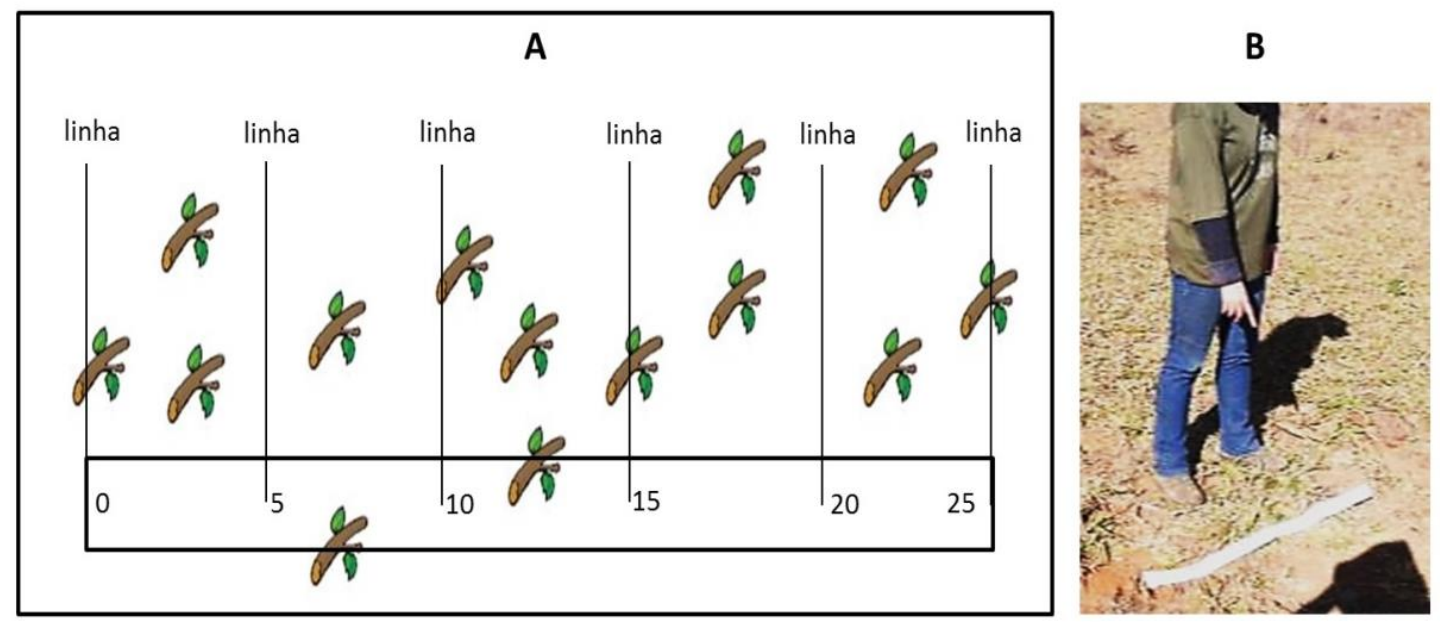

Figura 12. Método da régua de Kline. A) Desenho esquemático régua de Kline para quantificação de cobertura do solo. B) Determinação em campo da quantidade de cobertura do solo.

\subsubsection{Coleta de besouros coprófagos (Scarabaeidae: Scarabaeinae)}

Supôs-se que a qualidade do solo era diretamente proporcional à quantidade de besouros coprófagos $(\mathrm{C}+\mathrm{R})$ coletados em diferentes armadilhas, colocadas nas áreas experimentais. Isto decorre do fato de que quanto maior o número de besouros, maior seria o número de túneis e maior a ciclagem de nutrientes.

Como as parcelas experimentais não apresentaram a mesma área foi utilizado um desenho hierarquizado, para permitir a comparação dos resultados, desenho este que se moldou a cada um dos formatos das áreas (CONCHA-LOZADA; GALLERO ROPERO; FIGUEROA CASAS, 2009).

Assim, em cada área experimental, foi traçado um transepto com distância mínima de 30 metros da borda, onde foram dispostas armadilhas separadas de $30 \mathrm{~m}$ entre si. (CONCHA-LOZADA; GALLERO ROPERO; FIGUEROA CASAS, 2009). Dessa forma, na Lavoura de milho foram alocadas 20 armadilhas; no Cerrado stricto sensu, 15 armadilhas; no Cerradão, 15 armadilhas; no Reflorestamento de 10 anos, 7 armadilhas; no Reflorestamento de 1 ano, 15 armadilhas; e na Pastagem degradada, 15 armadilhas (Figura 13). 


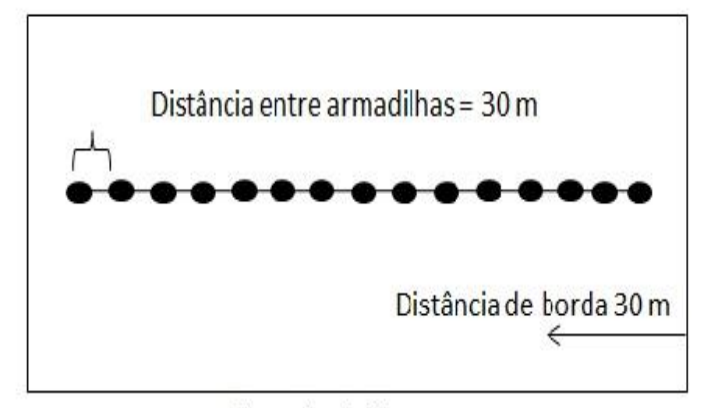

Cerrado stricto sensu

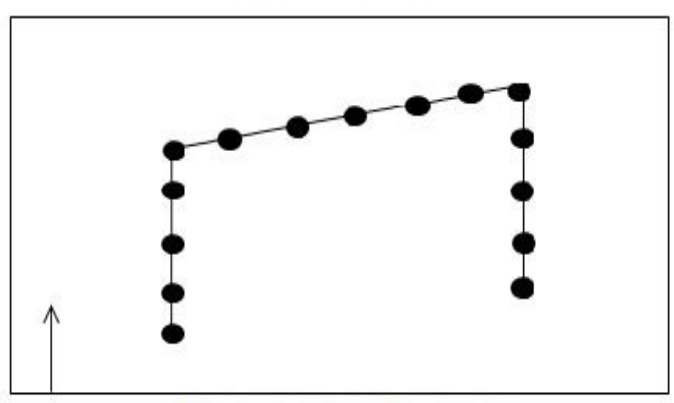

Reflorestamento de 10 anos

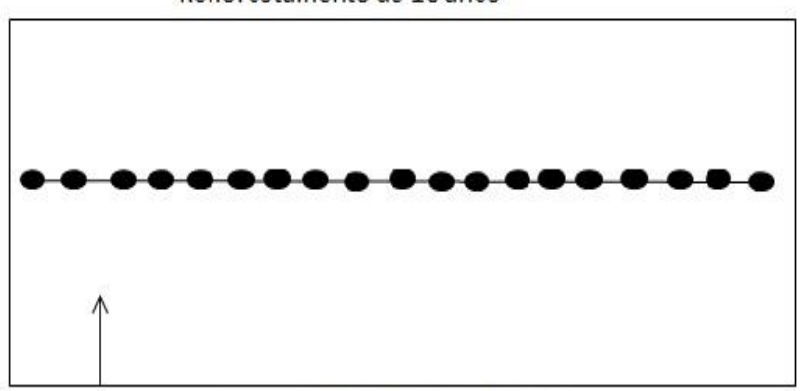

Lavoura de milho (Zca Mays)

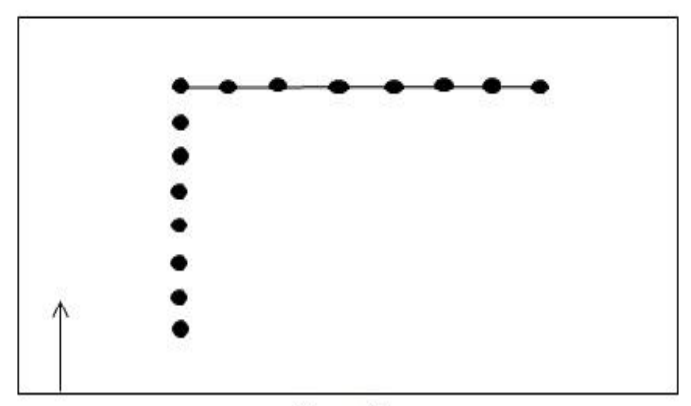

Cerradão

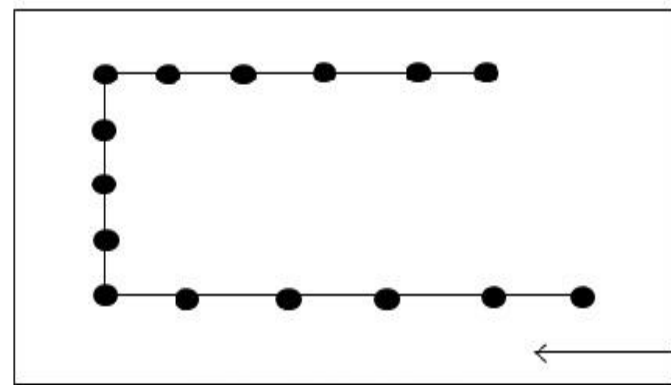

Reflorestamento de 1 ano

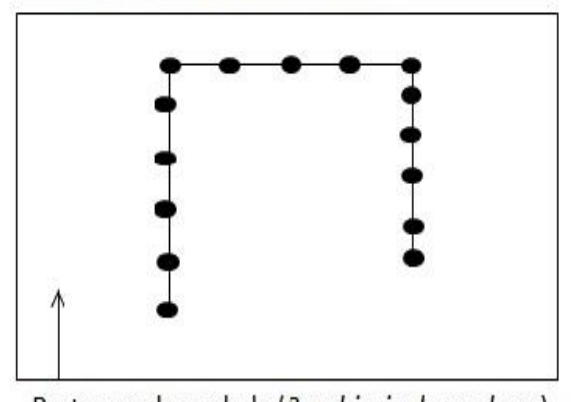

Pastagem degradada (Brachiaria decumbens)

Figura 13. Esquema geral da distribuição das armadilhas nas seis áreas experimentais.

Em cada área experimental foram realizadas três repetições, em seis campanhas, entre abril e junho de 2014. Foram usadas armadilhas Pitfall modificadas, utilizando fezes frescas de porco como isca. As armadilhas foram construídas com copos plásticos de 500 $\mathrm{ml}$, enterradas no nível do solo, com a isca no seu interior. Foram feitos furos no topo e nas laterais para facilitar a entrada dos insetos (CONCHA-LOZADA; GALLERO ROPERO; FIGUEROA CASAS, 2009).

A amostragem foi complementada com coleta manual nas áreas ao redor das armadilhas. As iscas foram renovadas a cada $24 \mathrm{~h}$, num período de 3 dias (VILLAREAL et al., 2006; CONCHA-LOZADA; GALLERO ROPERO; FIGUEROA CASAS, 2009) (Figura 14). 

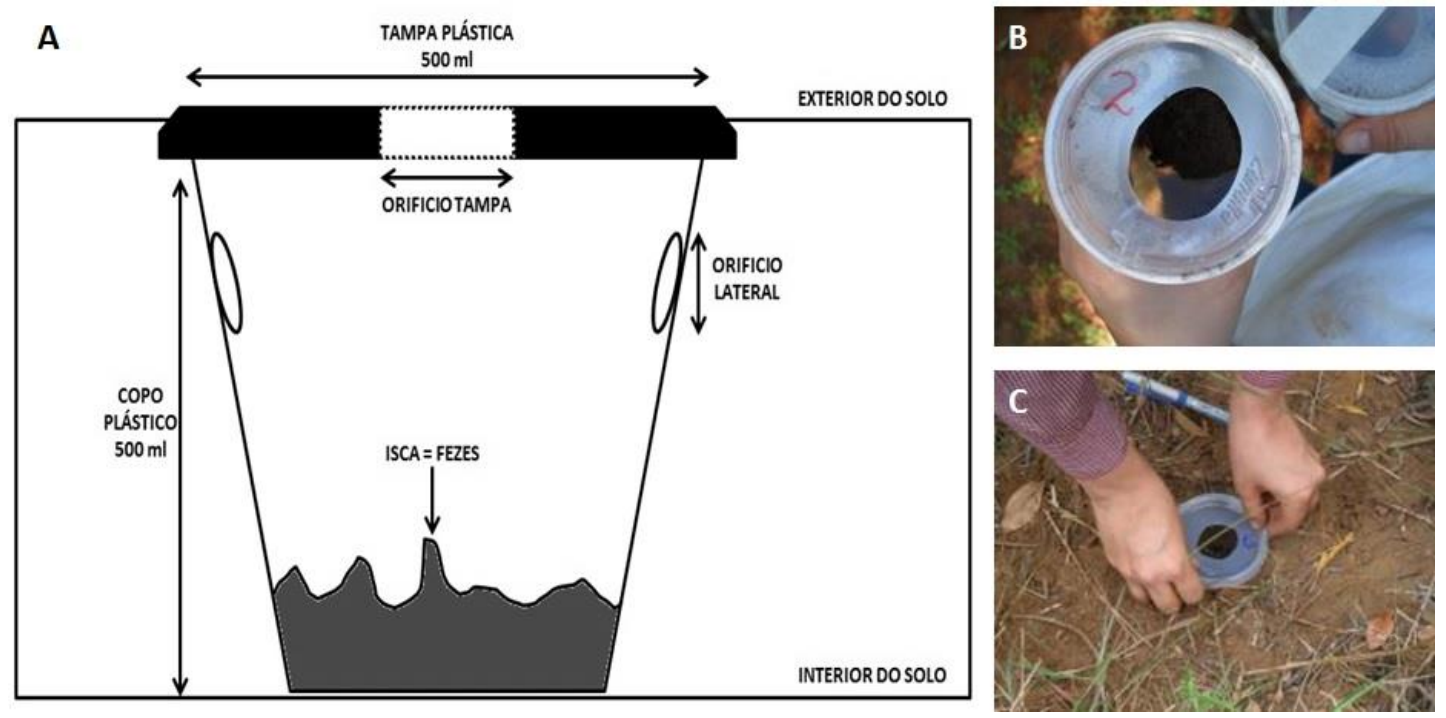

Figura 14. Armadilha pifall. A) Esquema da armadilha Pitfall com isca no seu interior. B) Armadilha pronta para ser instalada. C) Instalação da armadilha no campo ao nível do solo.

Os besouros coprófagos coletados foram colocados em recipiente rotulado e levados ao laboratório de zoologia da Universidade de Brasília para sua identificação no nível de gênero e subgêneros, usando a chave taxonômica de Vaz-de-Mello et al. (2011). Para a identificação no nível de espécie, os besouros coletados foram encaminhados para o prof. Fernando Vaz de Mello, na Universidade Federal de Mato Grosso.

Nesta etapa, foram identificados aqueles indivíduos com hábitos cavadores e roladores $(\mathrm{C}+\mathrm{R})$, bem como a sua abundância e riqueza, segundo o conceito de Villareal (2006), onde o primeiro responde ao número total de besouros coprófagos $\mathrm{C}+\mathrm{R}$ encontrados em cada área experimental e a riqueza observada corresponde ao número de espécies ou morfotipos observadas em cada área experimental.

\subsection{DELINEAMENTO EXPERIMENTAL}

O delineamento experimental utilizado no estudo foi o inteiramente casualizado (DIC), uma vez que a área de estudo era pequena (raio $<1 \mathrm{~km}$ ), além de ser climática e pedológicamente homogênea (ANSERSON; MCCLEAN, 1974; MOORE; McCABE, 2002). O único fator (tratamento) analisado foi o uso e manejo do solo das áreas, 
constituído por seis diferentes classes, sendo realizadas medições de parâmetros físicos, químicos e biológicos, com três repetições cada (Figura 15).

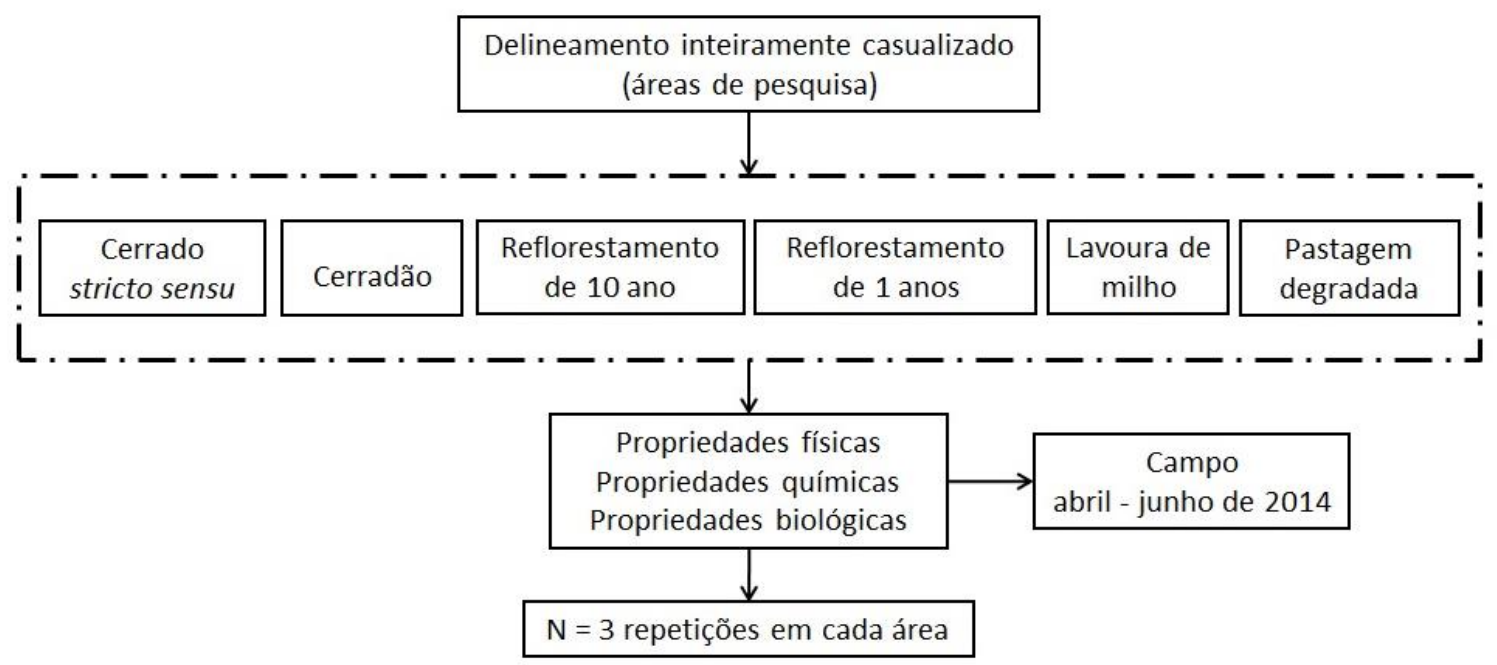

Figura 15. Delineamento experimental usado no Estudo.

\subsection{MODELO ESTATÍSTICO DO EXPERIMENTO}

Em cada área experimental, foram medidos diferentes parâmetros físicos, químicos e biológicos. Como o tipo de uso e manejo do solo foi o tratamento analisado no experimento, o modelo estatístico para cada parâmetro medido foi o seguinte:

$$
\mathbf{y}_{\mathbf{i}}=\mu+\mathbf{T}_{\mathbf{i}}+\xi_{\mathrm{i} 1} \quad(\mathbf{i}=1,2, \ldots, 6)
$$

Onde: $y_{i}=$ valor do parâmetro na área de uso e manejo $i ; \mu=$ média geral dos seis tratamentos; $T_{i}$ $=$ efeito do i-ésimo tratamento; $\xi_{\mathrm{il}}=$ erro aleatório.

\subsection{RELAÇÃO ENTRE OS PARÂMETROS DO SOLO E O IQS $(F, Q, B)$}

Os seguintes parâmetros físicos, químicos e biológicos foram analisados no presente estudo, em cada uma das seis áreas experimentais (Tabela 7): 
Tabela 6. Parâmetros utilizados no presente estudo e no desenvolvimento do IQS $\mathrm{S}_{(\mathrm{f}, \mathrm{q}, \mathrm{b})}$

\begin{tabular}{c|l|c}
\hline Tipo & \multicolumn{1}{|c}{ Parâmetro } & Unidade \\
\hline \multirow{2}{*}{ Físico } & Taxa de infiltração de água no solo (TI) & $\mathrm{mm} \mathrm{h}^{-1}$ \\
& Resistencia mecânica do solo à Penetração (RP) & $\mathrm{MPa}$ \\
\hline \multirow{3}{*}{ Químico } & Teor de fósforo (P) & $\mathrm{mg} / \mathrm{dm}^{3}$ \\
& Capacidade de Troca Catiônica (CTC) & $\mathrm{cmol}_{\mathrm{c}} / \mathrm{dm}^{3}$ \\
& Teor de Matéria Orgânica do Solo (MOS) & $\mathrm{g} / \mathrm{kg}^{-}$ \\
& Acidez ativa ou pH em água (pH) & - \\
\hline \multirow{2}{*}{ Biológico } & Saturação por bases (V) & Percentual de cobertura de solo (CB) \\
& Besouros coprófagos (C+R) & $\%$ \\
\hline
\end{tabular}

Conforme indica a Tabela 7 , um total de nove parâmetros foi selecionado para a estimativa da qualidade do solo nas seis áreas experimentais. Visando padronizar a qualidade do solo com os resultados das medições dos parâmetros da Tabela 7, o enfoque "mais é melhor", um dos três sugeridos por Karlen; Stott (1994), foi selecionado (Figura 16).
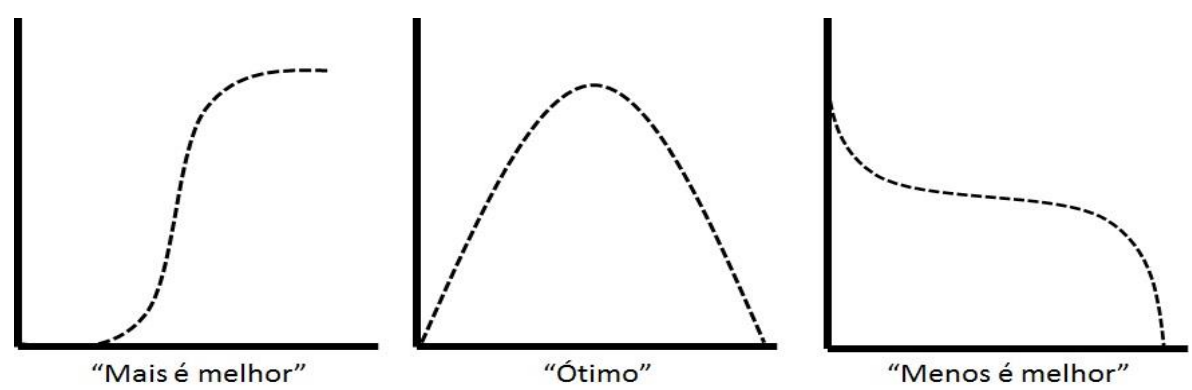

Figura 16. Enfoques possíveis para os parâmetros de qualidade do solo, com o enfoque “mais é melhor" no lado esquerdo. Fonte: adaptado de Karlen e Stott (1994).

Excetuando-se a resistência à penetração e o pH, todos os parâmetros da Tabela 7 são positivamente relacionados com a qualidade do solo. Entretanto, considerando que o $\mathrm{pH}$ dos solos dos Cerrados raramente ultrapassa o valor de sete (SOUSA; LOBATO, 2004), este parâmetro químico foi tomado como seguindo o enfoque de "mais é melhor" de Karlen e Stott (1994).

No caso da resistência mecânica do solo à penetração, como esta é considerada inversamente proporcional à qualidade do solo (DE FREITAS et al., 2012), foi feita uma 
transformação matemática para que essa também caísse no enfoque "mais é melhor" de Karlen; Stott (1994). A transformação foi a seguinte:

$$
\mathbf{R P}_{\mathbf{c}}=\mathbf{M}-\mathbf{R} \mathbf{P}_{\mathbf{o}}
$$

Onde: $\mathrm{RP}_{\mathrm{c}}(\mathrm{MPa})=$ valor corrigido da resistência mecânica do solo à penetração; $\mathrm{M}=$ valor máximo de $\mathrm{RP}$ obtido no campo; $\mathrm{RP}_{\mathrm{o}}(\mathrm{MPa})=$ cada um dos valores da resistência mecânica do solo à penetração obtida no campo.

Para o parâmetro biológico, foi selecionado o grupo de coleópteros coprófagos com hábito cavador e/ou rolador $(\mathrm{C}+\mathrm{R})$, uma vez que é este que efetivamente traz melhorias para a qualidade do solo, aumentando sua aeração e infiltrabilidade, e incorporando a matéria orgânica no interior do solo.

Assim, se supôs que, quanto mais indivíduos do grupo $\mathrm{C}+\mathrm{R}$ fossem capturados nas áreas experimentais, mais túneis e incorporação de matéria orgânica ocorreriam, e maior seria a qualidade do solo nesse quesito (enfoque "mais é melhor"). A equação utilizada para a quantidade dos besouros coprófagos cavadores e roladores capturados por armadilha foi:

$$
\mathrm{C}+\mathrm{R}=\mathrm{NC}+\mathrm{NR}
$$

Onde: $\mathrm{C}+\mathrm{R}=$ besouros coprófagos cavadores e roladores; $\mathrm{NC}=$ número de indivíduos de besouros coprófagos cavadores; $\mathrm{NR}=$ número de indivíduos de besouros coprófagos roladores.

\subsection{TESTES ESTATíSTICOS APLICADOS AOS PARÂMETROS FíSICOS, QUÍMICOS E BIOLÓGICOS}

Na Figura 17 é mostrada a sequência de testes estatísticos aplicados aos parâmetros do solo, usados na pesquisa. Antes das análises de médias e outras funções estatísticas, os dados originais de campo passaram por testes de normalidade e homocedasticidade, usando a metodologia de Lilliefors e Kolmogorov-Smirnov (LUCAMBIO, 2008).

Como os dados não apresentaram distribuição normal, eles foram transformados através da função logarítmica natural (PEREIRA; KOBIYAMA, 2013). Após isso, novo teste de normalidade de Kolmogorov-Smirnov foi aplicado aos dados, confirmando a sua 
normalidade. Posteriormente, foi feita uma análise de variância (ANOVA) e o respectivo teste de F, para analisar a homocedasticidade dos dados experimentais (LIMA, 2010).

Em seguida, foi realizada uma análise de multicolinearidade nos dados, para verificar a presença ou ausência de dependências entre as variáveis (MILOCA; CONEJO, 2011; TOEBE, 2012). Em seguida, foi aplicado o teste de comparação múltipla de médias de Tukey-HSD, para se determinar eventuais diferenças significativas entre as médias dos tratamentos.

Finalmente, foi realizada uma análise de agrupamentos (cluster) com os dados físicos, químicos e biológicos, utilizando-se o método de distância Euclidiana (com o algoritmo de Ward) para gerar grupos com uma variância mínima (MINGOTI, 2005; LIMA, 2010).

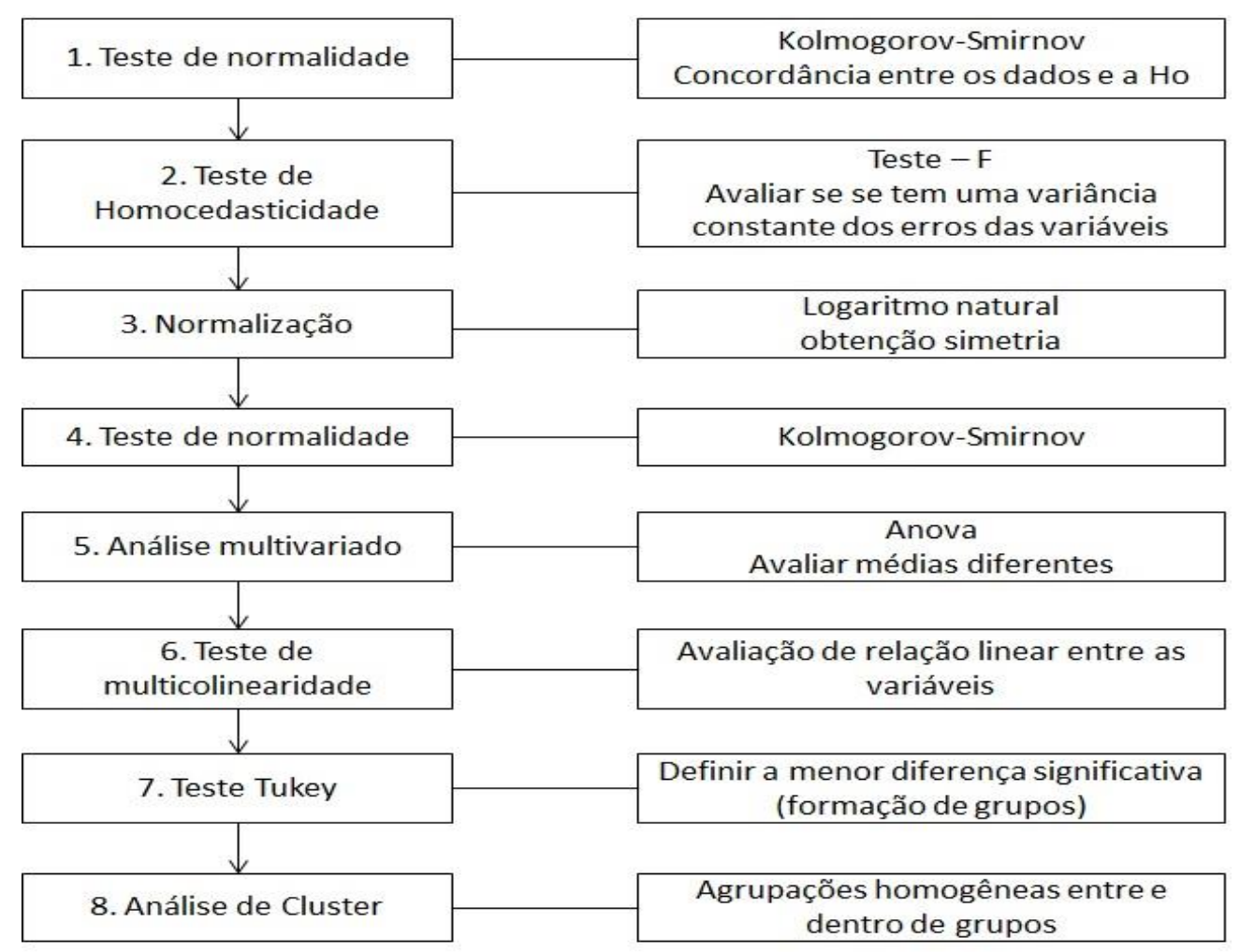

Figura 17. Testes estatísticos utilizados para o desenvolvimento do índice de qualidade do solo - IQS $(\mathrm{f}, \mathrm{q}, \mathrm{b})$.

\subsection{FORMULAÇÃO DO ÍNDICE DE QUALIDADE DO SOLO - IQS}

Para a construção do índice de qualidade do solo - $\mathrm{IQS}_{(\mathrm{f}, \mathrm{q}, \mathrm{b})}$, utilizou-se um número limitado de parâmetros, uma estrutura aditiva e pesos iguais, para que nenhum deles fosse 
super ou subestimado (CHAVES; ALIPAZ, 2007). As etapas abaixo foram usadas no desenvolvimento do índice:

A. As médias de Tukey dos nove parâmetros físicos, químicos e biológicos, obtidos nas diferentes áreas experimentais, foram ranqueadas do $1^{\circ}$ ao $3^{\circ}$ lugar.

B. Em seguida, foram atribuídos escores para os três primeiros lugares, sendo três (3) para o $1^{\circ}$ lugar, dois (2) para o $2^{\circ}$ lugar, e um (1) para o $3^{\circ}$ lugar, ou seja:

$$
(Q)=\left(1 \times 3^{\circ}\right)+\left(2 \times 2^{\circ}\right)+\left(3 \times 1^{o}\right)
$$

Onde: $\mathrm{Q}=$ Parâmetros das propriedades químicas; 1,2 e $3=$ pesos ou escores; $1^{\circ}, 2^{\circ}$ e $3^{\circ}=$ médias ranqueadas dos parâmetros do teste de Tukey.

$$
(F)=\left(1 \times 3^{o}\right)+\left(2 \times 2^{o}\right)+\left(3 \times 1^{o}\right)
$$

Onde: $\mathrm{Q}=$ Parâmetros das propriedades químicas; 1,2 e $3=$ pesos ou escores; $1^{\circ}, 2^{\circ}$ e $3^{\circ}=$ médias ranqueadas dos parâmetros do teste de Tukey.

$$
(B)=\left(1 \times 3^{\circ}\right)+\left(2 \times 2^{o}\right)+\left(3 \times 1^{o}\right)
$$

Onde: $\mathrm{Q}=$ Parâmetros das propriedades químicas; 1,2 e $3=$ pesos ou escores; $1^{\circ}, 2^{\circ}$ e $3^{\circ}=$ médias ranqueadas dos parâmetros do teste de Tukey.

C. Após isso, houve uma normalização dos grupos de parâmetros (F,Q,B), em função de seu numero, de forma que todos tivessem o mesmo peso final, sendo o IQS a soma dos escores normalizados, ou seja:

$$
\operatorname{IQS}_{(\mathbf{f}, \mathbf{q}, \mathbf{b})}=[(\mathrm{EQ} / \mathbf{5})+(\mathrm{EF} / \mathbf{2})+(\mathrm{EB} / \mathbf{2})]
$$

Onde: $\mathrm{EQ}=$ escore total dos parâmetros químicos; $\mathrm{EF}$ = escore total dos parâmetros físicos; $\mathrm{EB}=$ escore total dos parâmetros biológicos.

D. Finalmente, as áreas de pesquisa foram ranqueadas de acordo o valor do índice de qualidade do solo - IQS $(\mathrm{f}, \mathrm{q}, \mathrm{b})$, em classes alta, media e baixa, usando como base o desvio padrão dos escores das áreas (Souza; Soares, 2013), ou seja: 
- Classe alta:

$$
\operatorname{IQS}_{(\mathbf{f}, \mathbf{q}, \mathbf{b})} \geq\left(\overline{\mathbf{I Q S}}_{(\mathbf{f , q , b )}}+1 \mathrm{~S}\right)
$$

Onde: $\mathrm{IQS}_{(\mathrm{f}, \mathrm{q}, \mathrm{b})}=$ valor do índice de qualidade do solo; $\overline{\mathrm{IQS}}_{(\mathrm{f}, \mathrm{q}, \mathrm{b})}=$ média do índice de qualidade do solo; $1 \mathrm{~S}$ = desvio padrão do índice de qualidade do solo.

- Classe media:

$$
\left(\overline{\mathrm{IQS}}_{(\mathbf{f}, \mathbf{q}, \mathrm{b})}-1 \mathrm{~S}\right) \leq \mathrm{IQS}_{(\mathbf{f}, \mathbf{q}, \mathbf{b})}<\left(\overline{\mathrm{IQS}}_{(\mathbf{f}, \mathbf{q}, \mathbf{b})}+\mathbf{1 S}\right)
$$

Onde: $\mathrm{IQS}_{(\mathrm{f}, \mathrm{q}, \mathrm{b})}=$ valor do índice de qualidade do solo; $\overline{\mathrm{IQS}}_{(\mathrm{f} \mathrm{q}, \mathrm{b})}=$ média do índice de qualidade do solo; $1 \mathrm{~S}=$ desvio padrão do índice de qualidade do solo.

- Classe baixa:

$$
\operatorname{IQS}_{(\mathbf{f , q}, \mathbf{b})}<\left(\overline{\mathbf{I Q S}}_{(\mathbf{f}, \mathbf{q}, \mathbf{b})}-1 \mathrm{~S}\right)
$$

Onde: $\mathrm{IQS}_{(\mathrm{f}, \mathrm{q}, \mathrm{b})}=$ valor do índice de qualidade do solo; $\overline{\mathrm{IQS}}_{(\mathrm{f}, \mathrm{q}, \mathrm{b})}=$ média do índice de qualidade do solo; $1 \mathrm{~S}$ = desvio padrão do índice de qualidade do solo.

O IQS proposto no presente Estudo visa comparar da qualidade do solo, influenciada por diferentes usos e manejos. Para que essa comparação não apresente vieses, os solos analisados devem ter a mesma Ordem ( $1^{\circ}$. Nível Categórico) e Sub-ordem ( $2^{\circ}$. Nível Categórico), conforme descrito pelo SBCS (SANTOS et al., 2013).

Além disso, os horizontes A e B devem, idealmente, cair na mesma classe do triângulo textural (Figura 8), uma vez que a textura pode influenciar uma série de propriedades do solo. É interessante também que o IQS compare pelo menos três condições de uso e manejo, para que a pontuação das equações [6], [7] e [8] possa ser adequadamente aplicada. 


\section{RESULTADOS E DISCUSSÃO}

\subsection{Textura dos solos das áreas experimentais}

A partir dos dados granulométricos (Tabela 8), os solos das seis áreas experimentais apresentaram, em média, 312,50 $\mathrm{g} \mathrm{kg}^{-1}$ de argila, 95,83 $\mathrm{g} \mathrm{kg}^{-1}$ de silte, e 591, $67 \mathrm{~g} \mathrm{~kg}^{-1}$ de areia, sendo todos eles texturalmente classificados como franco-argiloarenosos (SOUSA; LOBATO, 2004; SANTOS et al., 2013).

Tabela 7. Granulométrica das áreas experimentais

\begin{tabular}{lc|c}
\hline \multirow{2}{*}{\multicolumn{1}{c}{ Área Experimental }} & \multicolumn{2}{c}{ Granulometria $\mathbf{~ g ~ k g ~}^{-\mathbf{1}} \mathbf{)}$} \\
\cline { 2 - 3 } & Argila & Areia \\
\hline Cerrado stricto sensu & 300,00 & 650,00 \\
Cerradão & 325,00 & 650,00 \\
Reflorestamento de 10 anos & 300,00 & 550,00 \\
Reflorestamento de 1 ano & 325,00 & 575,00 \\
Lavoura de milho & 275,00 & 575,00 \\
Pastagem degradada & 350,00 & 550,00 \\
\hline Média & 312,50 & 591,67 \\
Desvio padrão & 26,22 & 46,55 \\
Coeficiente de variação (\%) & 8,39 & 7,87 \\
\hline
\end{tabular}

A classificação dos solos das seis áreas experimentais como de textura francoargilo-arenosa indica que eles são facilmente trabalhados, apresentam boa porosidade, e não susceptíveis à compactação. (PANACHUKI et al., 2003; SALTON et al., 2008). Entretanto, em função dos teores relativamente elevados de areia, eles são susceptíveis à erosão, e requerem um manejo apropriado (SOUSA; LOBATO, 2004; ZONTA, 2011).

\subsection{Valores dos parâmetros físicos, químicos e biológicos}

Com os dados dos parâmetros físicos, químicos e biológicos transformados e normalizados $(\mathrm{P}>0,05)$, encontrou-se homocedasticidade nos mesmos $(\mathrm{P}=0,05)$. Assim, após essas duas suposições terem sido confirmadas, realizou-se uma análise multivariadaANOVA (Tabela 9). O resultado da ANOVA indicou que pelo menos um tratamento é diferente nos seis analisados $(\mathrm{P}<0,05)$. 
O resultado do teste de multicolinearidade entre os parâmetros físicos, químicos e biológicos não indicou correlação significativa entre as variáveis. (MILOCA; CONEJO, 2011; TOEBE, 2012).

Tabela 8. ANOVA para os parâmetros físicos, químicos e biológicos.

\begin{tabular}{crrrrc} 
& Valor Wilks & Teste F & Efeito & Erro & $\mathrm{P}$ \\
\hline Intercepto & 0,00 & 544,36 & 9 & 4,00 & 0,00 \\
Uso/manejo do solo & 0,00 & 6760,69 & 45 & 21,00 & 0,00 \\
\hline
\end{tabular}

\subsubsection{Médias de infiltrabilidade do solo - TI}

O teste de Tukey para a velocidade básica de infiltração de água no solo-VIB gerou três grupos estatisticamente distintos $(\mathrm{P}<0,05)$. Assim, a área com a maior VIB foi o Cerradão, e a área de Pastagem degradada apresentando a menor VIB média (REICHARDT, 1990; AGUIAR, 2006; Tabela 10).

Tabela 9. Médias de velocidade de infiltração básica - VIB média

\begin{tabular}{lrc}
\hline \multicolumn{1}{c}{ Área Experimental } & $\begin{array}{c}\text { VIB média }_{\left(\mathrm{mm} \mathrm{h}^{-1}\right)} \\
\text { Pastagem degradada }\end{array}$ & $\begin{array}{c}\text { Agrupamento } \\
\text { de Tukey }\end{array}$ \\
Lavoura de milho & 48 & $\mathrm{~A}$ \\
Reflorestamento de 1 ano & 162 & $\mathrm{~B}$ \\
Reflorestamento de 10 anos & 174 & $\mathrm{~B}$ \\
Cerrado stricto sensu & 180 & $\mathrm{~B}$ \\
Cerradão & 1146 & $\mathrm{C}$ \\
\hline
\end{tabular}

$\mathrm{N}=3$. Letras distintas representam médias estatisticamente diferentes a $95 \%$ de probabilidade.

Observa-se que áreas com maior cobertura vegetal e menor intervenção antrópica apresentam uma maior infiltrabilidade, sendo o solo das áreas antrópicas exposto à compactação de maquinário e animais (PANACHUKI et al., 2006; FIORIN, 2008). Bono et al. (2012) encontraram resultados semelhantes num Latossolo vermelho, submetido a diferentes usos e manejos do solo. Para Bertol et al. (2000), as pressões aplicadas pelo pisoteio dos animais ocasionam alterações na densidade e na porosidade do solo, principalmente à profundidade de 0-0,05 $\mathrm{m}$. 


\subsubsection{Médias da resistência mecânica do solo à penetração - RP}

Na tabela 11 são apresentados os resultados obtidos das médias da RP nas seis áreas de pesquisa. Foram observados dois grupos de médias estatisticamente distintas (A e B) (P $<0,05)$. De acordo com a Tabela 11 , a resistência à penetração variou de moderada $(1,68$ MPa) a alta (9,18 MPa), de acordo com a classificação de Benedetti et al. (2010).

Tabela 10. Médias de resistência mecânica do solo à penetração - RP.

\begin{tabular}{lcc}
\hline \multicolumn{1}{c}{ Área Experimental } & $\begin{array}{c}\mathrm{RP}_{\text {média }} \\
(\mathrm{MPa})\end{array}$ & $\begin{array}{c}\text { Agrupamento } \\
\text { de Tukey }\end{array}$ \\
\hline Pastagem degradada & 9,18 & $\mathrm{~A}$ \\
Lavoura de milho & 5,35 & $\mathrm{~B}$ \\
Reflorestamento de 10 anos & 4,68 & $\mathrm{~B}$ \\
Cerradão & 4,00 & $\mathrm{~B}$ \\
Reflorestamento de 1 ano & 3,70 & $\mathrm{~B}$ \\
Cerrado stricto sensu & 1,68 & $\mathrm{~B}$ \\
\hline N=3. Letras distintas representam médias estatisticamente diferentes a 95\% de probabilidade.
\end{tabular}

Valores de RP inferiores a 3,0 MPa favorecem a infiltração de água no solo e o desenvolvimento das raízes (SÁ; SANTOS JUNIOR, 2005). O resultado obtido nesta pesquisa é coerente com aqueles encontrados por Ralisch et al. (2008) num Latossolo vermelho-amarelo, sob lavoura (3,0 MPa), pastagem (2,5 MPa) e floresta $(2,0 \mathrm{MPa})$.

Apesar de apresentar uma cobertura florestal abundante, a área de Cerradão apresentou valores relativamente elevados de RP em função da presença de pedregulhos no perfil do solo. A Pastagem degradada apresentou um solo altamente compactado, devido ao pisoteio do gado.

Segundo Reichert; Reinert; Braida (2003), os solos compactados apresentam alta resistência mecânica à penetração e reduzida a porosidade total. Como consequência, o crescimento das raízes é reduzido, com menor aeração e infiltração.

\subsubsection{Médias do teor de fósforo - $P$}

O teor de fósforo no solo medido nas seis áreas experimentais, avaliado pelo teste múltiplo de Tukey, gerou seis grupos diferentes de médias $(\mathrm{P}<0,05)$ (Tabela 12). Segundo a classificação de Sousa; Lobato (2004) para P em solos com teor de argila entre 16 - 35 
$\%$, as áreas de pesquisa se categorizaram com de alto $\left(>20 \mathrm{mg} / \mathrm{dm}^{3}\right)$ e muito baixo $(0-5,0$ $\mathrm{mg} / \mathrm{dm}^{3}$ ) teor de $\mathrm{P}$.

Tabela 11. Médias do teor de fósforo no solo - P

\begin{tabular}{lcc}
\hline \multicolumn{1}{c}{ Área Experimental } & $\begin{array}{c}\mathrm{P} \\
\left(\mathrm{mg} / \mathrm{dm}^{3}\right)\end{array}$ & $\begin{array}{c}\text { Agrupamento de } \\
\text { Tukey }\end{array}$ \\
\hline Cerrado stricto sensu & 0,10 & $\mathrm{~A}$ \\
Reflorestamento de 1 ano & 0,70 & $\mathrm{~B}$ \\
Cerradão & 1,10 & $\mathrm{C}$ \\
Pastagem degradada & 1,50 & $\mathrm{D}$ \\
Reflorestamento de 10 anos & 2,90 & $\mathrm{E}$ \\
Lavoura de milho & 24,20 & $\mathrm{~F}$ \\
\hline $\mathrm{N}=$ 3. Letras distintas representam médias estatisticamente diferentes a 95\% de probabilidade. \\
\hline
\end{tabular}

Se observa que a Lavoura de milho apresentou um alto teor de $\mathrm{P}\left(24,2 \mathrm{mg} / \mathrm{dm}^{3}\right)$, enquanto as outras áreas experimentais apresentaram valores baixos de $\mathrm{P}\left(<5,0 \mathrm{mg} / \mathrm{dm}^{3}\right)$ (Sousa; Lobato, 2004). O alto teor de P na Lavoura de milho decorre do fato de esta área ser adubada anualmente com formulação fosfatada, enquanto as outras não, apresentando valores típicos dos solos dos Cerrados (SOUSA; LOBATO, 2004).

Considerando que os solos das seis áreas experimentais apresentaram valores muito semelhantes de argila, o efeito da textura no teor de fósforo do solo pode ser eliminado (Machado et al., 2011).

\subsubsection{Médias do teor de matéria orgânica do solo-MOS}

A Tabela 13 apresenta as médias dos teores de matéria orgânica do solo para as seis áreas experimentais, classificadas pelo teste de Tukey em dois grupos diferentes (A e B). De acordo com Sousa; Lobato (2004), as áreas experimentais podem ser divididas em duas categorias, alta (MOS $\left.>30 \mathrm{~g} \mathrm{~kg}^{-1}\right)$ e média $\left(21<\operatorname{MOS}<30 \mathrm{~g} \mathrm{~kg}^{-1}\right)$. 
Tabela 12. Médias de Matéria Orgânica do Solo - MOS

\begin{tabular}{lcc}
\hline \multicolumn{1}{c}{ Área Experimental } & $\begin{array}{c}\text { MOS } \\
\left(\mathrm{g} \mathrm{kg}^{-1}\right)\end{array}$ & $\begin{array}{c}\text { Agrupamento de } \\
\text { Tukey }\end{array}$ \\
\hline Reflorestamento de 1 ano & 23,7 & $\mathrm{~A}$ \\
Pastagem degradada & 24,1 & $\mathrm{~A}$ \\
Lavoura de milho & 26,5 & $\mathrm{~A}$ \\
Reflorestamento de 10 anos & 28,7 & $\mathrm{~A}$ \\
Cerrado stricto sensu & 47,3 & $\mathrm{~B}$ \\
Cerradão & 48,8 & $\mathrm{~B}$ \\
\hline
\end{tabular}

$\mathrm{N}=3$. Letras distintas representam médias estatisticamente diferentes a 95\% de probabilidade.

Os maiores teores de MOS das áreas de Cerradão e Cerrado stricto sensu decorreram da maior biomassa vegetal, aumentando o fornecimento de nutrientes para as plantas, permitindo a formação e estabilização dos agregados do solo (STONE; SILVEIRA, 2001).

As outras áreas experimentais apresentaram valores reduzidos de MOS, em função de sua maior exposição às intempéries. Resultados semelhantes foram encontrados por Souza; Alves (2003).

\subsubsection{Médias da capacidade de troca catiônica- CTC}

A capacidade de troca catiônica no solo das seis áreas de pesquisa, avaliado pelo teste de Tukey, gerou cinco grupos diferentes de médias $(\mathrm{P}<0,05)$. Apenas a área de Reflorestamento de 10 anos apresentou valores de CTC considerados altos, e o restante de médio a baixo (SOUSA; LOBATO 2004; Tabela 14).

Tabela 13. Médias de Capacidade de Troca Catiônica - CTC

\begin{tabular}{lcc}
\hline \multicolumn{1}{c}{ Área Experimental } & $\begin{array}{c}\mathrm{CTC} \\
\left(\mathrm{cmol}_{\mathrm{c}} / \mathrm{dm}^{3}\right)\end{array}$ & $\begin{array}{c}\text { Agrupamento de } \\
\text { Tukey }\end{array}$ \\
\hline Cerrado stricto sensu & 4,57 & $\mathrm{~A}$ \\
Reflorestamento de 1 ano & 6,45 & $\mathrm{~B}$ \\
Pastagem degradada & 6,52 & $\mathrm{~B}$ \\
Lavoura de milho & 6,66 & $\mathrm{C}$ \\
Cerradão & 8,90 & $\mathrm{D}$ \\
Reflorestamento de 10 anos & 11,43 & $\mathrm{E}$ \\
\hline N =3. Letras distintas representam médias estatisticamente diferentes a 95\% de probabilidade. \\
\hline
\end{tabular}


A alta CTC registrada pata o Reflorestamento de 10 anos pode estar relacionada ao fato que a área é adubada uma vez por ano, e apresenta uma boa velocidade de ciclagem de nutrientes, facilitando a acumulação e retenção de compostos como o cálcio, potássio, magnésio e sódio disponível à planta. No caso do Cerrado stricto sensu, a baixa CTC resulta do alto processo de intemperismo e lixiviação, com baixa taxa de ciclagem de nutrientes, e alta acidez do solo.

Chaves et al. (2012), estudando o efeito do uso e manejo em um Latossolo vermelho dos Cerrados, encontraram de CTC ao redor de $10 \mathrm{cmol}_{\mathrm{c}} / \mathrm{dm}^{3}$ para lavouras, enquanto os valores de pastagens foram ao redor de $8,0 \mathrm{cmol}_{c} / \mathrm{dm}^{3}$, próximos aos valores encontrados no presente estudo.

\subsubsection{Médias de pH}

As médias do parâmetro de $\mathrm{pH}$ das seis áreas experimentais resultaram em dois grupos estatisticamente diferentes $(\mathrm{P}<0,05)$, sendo um deles $(\mathrm{AB})$ comum aos outros. De acordo com Sousa e Lobato (2004), valores de pH entre 5,6 e 6,3 são considerados adequados para os solos dos Cerrados.

Nesse sentido, apenas a Pastagem degradada e o Reflorestamento de 10 anos apresentaram médias nessa faixa, com o Cerrado stricto senso apresentando o menor $\mathrm{pH}$ $(5,2)$, típico de um solo que não recebeu calagem ou outro tipo de adubação artificial.

$\mathrm{O}$ baixo $\mathrm{pH}$ da Lavoura de milho $(5,4)$, por sua vez, pode estar relacionado à aplicação de fertilizantes amoniacais, os quais são rapidamente transformados em nitratos, liberando ácidos e aumentando a acidez na parte superficial do solo (FAO, 2004).

Tabela 14. Médias de $\mathrm{pH}_{\mathrm{H} 2 \mathrm{O}}$ das áreas experimentais.

\begin{tabular}{lcc}
\hline \multicolumn{1}{c}{ Área Experimental } & $\mathrm{pH}_{\mathrm{H} 2 \mathrm{O}}$ & $\begin{array}{c}\text { Agrupamento de } \\
\text { Tukey }\end{array}$ \\
\hline Cerrado stricto sensu & 5,2 & $\mathrm{~A}$ \\
Lavoura milho & 5,4 & $\mathrm{AB}$ \\
Cerradão & 5,4 & $\mathrm{AB}$ \\
Reflorestamento de 1 ano & 5,5 & $\mathrm{AB}$ \\
Reflorestamento de 10 anos & 5,6 & $\mathrm{AB}$ \\
Pastagem degradada & 5,9 & $\mathrm{~B}$ \\
\hline N =3. Letras distintas representam médias estatisticamente diferentes a 95\% de probabilidade.
\end{tabular}




\subsubsection{Médias da saturação por bases - V}

O teste de Tukey para o parâmetro de saturação de bases - V gerou seis grupos diferentes de médias $(\mathrm{P}<0,05)$. De acordo com Sousa e Lobato (2004), apenas as áreas de Reflorestamento de 10 anos e Pastagem degradada apresentaram valores de $\mathrm{V}$ adequados $(>36 \%)$.

Tabela 15. Médias de Saturação de Bases - V

\begin{tabular}{lcc}
\hline \multicolumn{1}{c}{ Área Experimental } & $\mathrm{V}$ & $\begin{array}{c}\text { Agrupamento de } \\
\text { Tukey }\end{array}$ \\
\hline Cerrado stricto sensu & $(\%)$ & $\mathrm{A}$ \\
Reflorestamento de 1 ano & 29 & $\mathrm{~B}$ \\
Cerradão & 30 & $\mathrm{C}$ \\
Lavoura milho & 31 & $\mathrm{D}$ \\
Pastagem degradada & 39 & $\mathrm{E}$ \\
Reflorestamento de 10 anos & 52 & $\mathrm{~F}$ \\
\hline N =3. Letras distintas representam médias estatisticamente diferentes a 95\% de probabilidade.
\end{tabular}

O Cerrado stricto sensu apresentou o menor valor de V, possivelmente em função do elevado intemperismo e lixiviação, e da ausência de calagem ou adubação. No caso do Cerradão, a maior biomassa vegetal e a velocidade de ciclagem podem ter contribuído para valores de V superiores ao do Cerrado.

O Reflorestamento de 10 anos foi a única com $\mathrm{V}>50 \%$, possivelmente relacionada a boa biomassa vegetal e a alta velocidade de ciclagem, além de uma pequena relação $\mathrm{C} / \mathrm{N}$ da sua serapilheira (LOPES; GUILHERME, 2004).

\subsubsection{Médias do parâmetro de cobertura do solo - CS}

O teste de Tukey para o parâmetro cobertura do solo- CB gerou dois grupos diferentes de médias $(\mathrm{P}<0,05)$. As áreas experimentais com maior $\mathrm{CB}$ foram a do Cerradão e a do Reflorestamento de 1 ano, com 92,67 \% e 92,33\%, respectivamente (Tabela 17). 
Tabela 16. Médias do percentual de cobertura do solo - CS

\begin{tabular}{lcc}
\hline \multicolumn{1}{c}{ Área Experimental } & CB & Agrupamento de \\
& $(\%)$ & Tukey \\
\hline Pastagem degradada & 14,00 & $\mathrm{~A}$ \\
Lavoura de milho & 16,00 & $\mathrm{~A}$ \\
Cerrado stricto sensu & 23,33 & $\mathrm{~A}$ \\
Reflorestamento de 10 anos & 38,33 & $\mathrm{~A}$ \\
Reflorestamento de 1 ano & 92,33 & $\mathrm{~B}$ \\
Cerradão & 92,67 & $\mathrm{~B}$ \\
\hline N =3. Letras distintas representam médias estatisticamente diferentes a $95 \%$ de probabilidade.
\end{tabular}

No caso do Cerradão, trata-se da área com maior biomassa vegetal, e com grande produção de serapilheira. Valores semelhantes de CS foram encontrados por (ANDRADE; TAVARES; COUTINHO, 2003). Já no caso do Reflorestamento de 1 ano, o alto valor de CB estava associado à alta densidade de capim e raízes, uma vez que a manutenção das covas era precária.

A área de Lavoura de milho, por sua vez, apresentou um baixo valor de $\mathrm{CB}$, uma vez que os restos da cultura anterior (soja) apresentam um baixo valor de $\mathrm{C} / \mathrm{N}$, favorecendo a sua mineralização (SILVA et al., 2008).

\subsubsection{Médias de besouros cavadores e roladores (número de espécies) - $C+R$}

O teste de Tukey para o parâmetro de besouros coprófagos $-\mathrm{C}+\mathrm{R}$ (Tabela 18) gerou seis grupos diferentes de médias $(\mathrm{P}<0,05)$. A maior abundância de indivíduos $\mathrm{C}+\mathrm{R}$ foi capturada na Lavoura de milho (284) e o menor número foi obtido na área de Reflorestamento de 10 anos (31).

Tabela 17. Médias de besouros coprófagos cavadores e roladores - $\mathrm{C}+\mathrm{R}$

\begin{tabular}{lcc}
\hline \multicolumn{1}{c}{ Área Experimental } & Ind. C+R & $\begin{array}{c}\text { Agrupamento de } \\
\text { Tukey }\end{array}$ \\
\hline Reflorestamento de 10 Anos & 31 & $\mathrm{~A}$ \\
Reflorestamento de 1 ano & 93 & $\mathrm{~B}$ \\
Cerrado stricto sensu & 127 & $\mathrm{C}$ \\
Cerradão & 170 & $\mathrm{D}$ \\
Pastagem degradada & 180 & $\mathrm{E}$ \\
Lavoura de milho & 284 & $\mathrm{~F}$ \\
\hline $\mathrm{N}$ =3. Letras distintas representam médias estatisticamente diferentes a 95\% de probabilidade. \\
\hline
\end{tabular}


A Tabela 19 apresenta a abundância de espécies, indicando que um total de 885 indivíduos, distribuídos em 10 gêneros e 23 espécies de besouros coprófagos com atividade cavadora e roladora, foi capturado nas seis áreas.

Uma possível explicação para o elevado número de besouros coprófagos cavadores e roladores $(\mathrm{C}+\mathrm{R})$ na Lavoura de milho é a elevada oferta alimentícia, uma vez que esse tipo de área é atrativo para a fauna terrestre (CONCHA-LOZADA; GALLEGO ROPERO; PARDO-LOCARNO, 2010), principalmente na fase de enchimento de grãos.

Por outra parte na tabela 19 se observa a presença, nas seis áreas experimentais, da espécie Dichotomius nisus permitindo inferir que a espécie pode ser considerada como cosmopolita, e de alta importância ecológica (CONCHA-LOZADA; GALLEGO ROPERO; FIGUEROA CASA, 2009).

Noriega et al. (2012) também encontrou uma alta diversidade de besouros coprófagos numa lavoura de café, explicada, segundo eles, pela maior oferta alimentícia. As diferenças entre a biomassa encontradas respondem aos processos de perturbação e fragmentação, gerando que o ensamble estivesse dominado pela espécie Oxysterum conspicillatum, o que sugere que a presença da espécie na localidade seria importante para a manutenção funcional do ecossistema.

Já Vidaurre et al. (2008) concluiram que a maior riqueza (46 espécies) e abundância (3391 indivíduos) foram registradas em áreas naturais, e em áreas com maior antropização a riqueza e abundância diminuíram vertiginosamente.

Por outro lado, Nichols et al., (2013) reportaram que as populações de espécies com estratégias de nidificação de rolamento ou de tunelamento (cavadores) foram altamente dependes do tipo de habitat. As espécies roladoras sofreram maiores declínios em abundância em áreas com dedicação agrícola-florestal, mas teve abundâncias moderadamente mais altas em áreas agrícolas não florestadas. Tabém encontraram que as espécies roladoras e cavadoras respondem de forma semelhante à conversão de florestas modificadas e a remoção completa da cobertura florestal. 
Tabela 19. Número e espécies de besouros coprófagos cavadores + roladores - $(\mathrm{C}+\mathrm{R})$

Área Experimental

\begin{tabular}{|c|c|c|c|c|c|c|c|c|}
\hline Gênero & Espécie & $\mathrm{LM}$ & $\overline{\mathrm{CSS}}$ & PD & $\mathrm{R} 1$ & $\mathrm{CE}$ & $\mathrm{R} 10$ & $\mathrm{~T}$ \\
\hline Agamopus & Agamopus viridis $(\mathrm{R})$ & & & 1 & & & & 1 \\
\hline \multirow{2}{*}{ Canthon } & Canthon conformis (R) & 85 & 11 & & 3 & & & 99 \\
\hline & Canthon lituratos $(\mathrm{R})$ & 2 & & 1 & & & & 3 \\
\hline \multirow{7}{*}{ Canthidium } & Canthidium sp1 (C) & 14 & 3 & & & & & 17 \\
\hline & Canthidium sp2 (C) & 4 & & & & 26 & 3 & 33 \\
\hline & Canthidium sp3 (C) & 1 & & & 2 & & & 3 \\
\hline & Canthidium sp4 (C) & 1 & & & 1 & & & 2 \\
\hline & Canthidium sp5 (C) & & & & & 2 & & 2 \\
\hline & Canthidium marseuli (C) & 3 & 4 & & & & & 7 \\
\hline & Canthidium megathopoides $(\mathrm{C})$ & & 4 & & & & & 4 \\
\hline Coprophaneus & Coprophaneus horus (C) & 1 & & & & & & 1 \\
\hline \multirow{6}{*}{ Dichotomius } & Dichotomius aff. assifer sp1 (C) & & & & & 19 & 5 & 24 \\
\hline & Dichotomius bicuspis (C) & 31 & 8 & & 2 & 12 & 1 & 54 \\
\hline & Dichotomius bos (C) & & 1 & 4 & & & & 5 \\
\hline & Dichotimius crinicollis $(\mathrm{C})$ & 6 & & 16 & 2 & 2 & & 26 \\
\hline & Dichotomius nisus (C) & 46 & 24 & 40 & 4 & 58 & 17 & 189 \\
\hline & Dichotomius aff. quadratriceps (C) & & 1 & & & & & 1 \\
\hline Deltochilum & Deltochilum komareki $(\mathrm{R})$ & & & & & 2 & & 2 \\
\hline Digitonthophagus & Digitonthophagus gazela (C) & & & 1 & & & & 1 \\
\hline Ontherus & Onterus apendiculatus $(\mathrm{C})$ & 22 & 41 & 6 & & 8 & & 77 \\
\hline \multirow{2}{*}{ Onthophagus } & Onthophagus buculus (C) & 32 & 10 & 19 & 15 & & & 76 \\
\hline & Onthophagus hirculus (C) & 36 & 9 & 91 & 53 & & 3 & 192 \\
\hline Uroxys & Uroxys sp1 (C) & & 11 & 1 & 11 & 41 & 2 & 66 \\
\hline \multicolumn{2}{|c|}{ Abundância relativa (numero total de indivíduos) } & 284 & 127 & 180 & 93 & 170 & 31 & 885 \\
\hline \multicolumn{2}{|c|}{ Riqueza (numero de espécies) } & 14 & 12 & 10 & 10 & 9 & 6 & 23 \\
\hline
\end{tabular}




\subsection{Análise de Clusters das propriedades físicas, químicas e biológicas do solo}

\subsubsection{Analise de clusters para as propriedades físicas do solo}

De acordo com a Figura 18, três clusters (G I, G II e G III) foram formados, com uma distância euclidiana de 20\%. O primeiro grupo foi formado pelas áreas de Cerrado stricto sensu e Cerração. O segundo grupo, formado por efeito de encadeamento, foi constituído pelas áreas de Lavoura de milho, Reflorestamento de 10 anos e Reflorestamento de 1 ano. O terceiro grupo foi formado unicamente pela Pastagem degradada.

A formação do primeiro grupo, juntando as áreas florestais naturais, reflete o fato que o solo é um meio natural que tem diferentes níveis na sua composição física, mineral e morfológica, permitindo que fatores edáficos, climáticos e biológicos, o transformem e que ele mesmo possa se decompor, tendo, tudo isto o alvo de dar suporte e permitir sua aeração e da água (RALISCH et al., 2008).

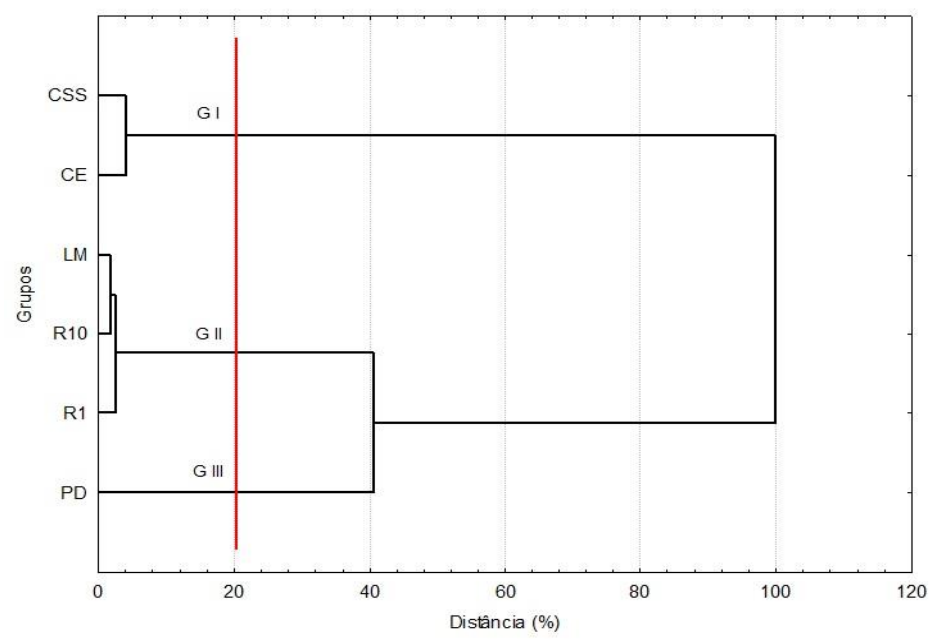

Figura 18. Clusters das propriedades físicas do solo. CSS = Cerrado stricto sensu, $\mathrm{CE}=$ Cerradão, $\mathrm{LM}=$ Lavoura de milho, $\mathrm{R} 10=$ Reflorestamento de 10 anos, $\mathrm{R} 1=$ Reflorestamento de 1 ano, PD = Pastagem degradada.

No segundo grupo, onde se juntaram as áreas de lavoura e reflorestamentos, indica que os usos e manejo do solo têm alterado suas condições físicas. Neste caso, a resistência à penetração do solo e a taxa de infiltração de água no solo foram atributos denominados intermediários, os quais são alterados com o uso e manejo do solo após alguns anos. Ou 
seja, a resistência do solo à penetração aumenta em relação direta com a compactação do solo (ISLAM; WEIL, 2000; BRADY; WEIL, 2010).

A formação de um terceiro grupo, constituído unicamente pela área de Pastagem degradada, indica que esta área não compartilhou característica alguma com as outras cinco áreas. Isto pode ser resultado do fato que o pisoteio do gado pode ter sido excessivo, com subsequente redução da infiltrabilidade do solo (BONO et al., 2012).

\subsubsection{Analise de clusters para as propriedades químicas do solo}

$\mathrm{O}$ analise de conglomerados para as seis áreas de pesquisa, comparando as propriedades químicas avaliadas (matéria orgânica do solo, fósforo, $\mathrm{pH}$, capacidade de troca catiônica e saturação por bases), formaram três clusters (G I, G II e G III) com distância euclidiana de 80\% (Figura 19).

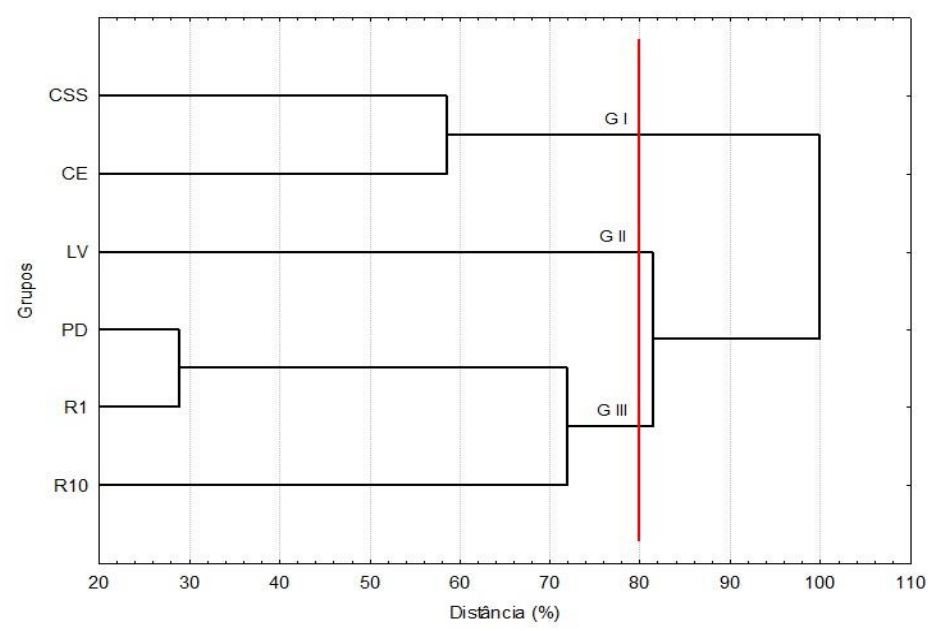

Figura 19. Clusters das propriedades químicas do solo. CSS = Cerrado stricto sensu, $\mathrm{CE}=$ Cerradão, $\mathrm{LM}=$ Lavoura de milho, $\mathrm{R} 10=$ Reflorestamento de 10 anos, R1 = Reflorestamento de 1 ano, PD = Pastagem degradada.

O primeiro grupo foi formado pelas áreas de Cerrado stricto sensu e Cerração. O segundo grupo foi constituído apenas pela Lavoura de milho, e o terceiro grupo, num efeito de encadeamento, agregou as áreas de Pastagem degradada, Reflorestamento de 1 ano e Reflorestamento de 10 anos. O isolamento do grupo II reflete o melhoramento do solo da Lavoura de milho para produção agrícola. A adubação química com N-P-K permitiu o 
enriquecimento nutricional do seu solo, tornando-o quimicamente distinto das demais áreas experimentais.

O Grupo III, formado pelas áreas de Reflorestamento (1 e 10 anos) e Pastagem degradada, são condições intermediárias de intensidade de uso/adubação do solo, situandose entre a Lavoura de milho com uso mais intensivo, com adubação mais frequente e o Cerrado stricto sensu e Cerradão com uma condição mais natural, sem adubação (GOEDERT, 2005; MACHADO et al., 2011).

Freitas et al. (2014), estudando um Latossolo vermelho submetido a diferentes manejos, reportaram que a análise de agrupamentos permitiu identificar a formação de dois grupos, um formado pela mata nativa e o outro pelas áreas de floresta plantada e canade-açúcar.

\subsubsection{Analise de cluster para as propriedades biológicas do solo}

$\mathrm{O}$ analise de conglomerados para as seis áreas de pesquisa, comparando as propriedades biológicas avaliadas, resultaram em três clusters (G I, G II e G III), com uma distancia euclidiana de 50\%. O primeiro grupo foi formado pelas áreas de Cerrado stricto sensu e Reflorestamento de 10 anos. O segundo grupo foi constituído pelas áreas de Cerradão e Reflorestamento de 1 ano, e o terceiro grupo foi formado pelas áreas de Lavoura de milho e Pastagem degradada (Figura 20).

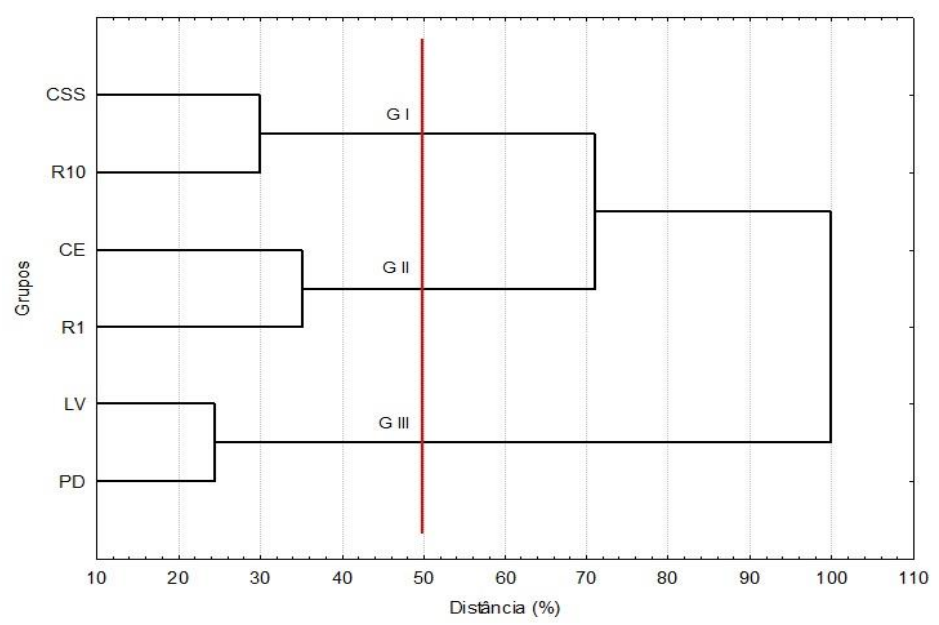

Figura 20. Clusters das propriedades biológicas do solo. $\mathrm{CSS}=$ Cerrado stricto sensu, $\mathrm{CE}=$ Cerradão, $\mathrm{LM}=$ Lavoura de milho, $\mathrm{R} 10=$ Reflorestamento de 10 anos, R1 = Reflorestamento de 1 ano, PD = Pastagem degradada. 
Os grupos formados pelos parâmetros biológicos se relacionaram com a percentagem de cobertura do solo de cada uma das áreas de pesquisa. Assim o grupo I estava associado a áreas com cobertura do solo entre $20-40 \%$. O grupo II foi formado por as áreas com cobertura do solo superior a $90 \%$. O grupo III, por sua vez, foi formado pelas áreas com menor percentual de cobertura do solo $(<20 \%)$.

Moreira et al. (2012) reportaram que a cobertura do solo se relaciona intimamente com a abundância da fauna coprófaga, ajudando no funcionamento da interação entre indicadores físicos, químicos e biológicos. Por outro lado, os besouros coprófagos têm a vantagem de serem de fácil amostragem, e sua ecologia/biologia e ciclos biológicos são bem conhecidos. Hernández et al. (2003) encontraram dois clusters em seu estudo, sendo um deles de áreas de cobertura nativa e outra de pastagens artificiais.

\subsubsection{Analise de clusters com propriedades físicas, químicas e biológicas do solo}

A análise de conglomerados, incluindo os parâmetros físicos, químicos e biológicos resultou em três grupos (GI, GII e GIII), com uma distância euclidiana de 70\% (Figura 21). Os grupos desta Figura foram semelhantes aos clusters obtidos na análise de parâmetros químicos, indicando que estes, com maior número de variáveis (5), dominaram o processo de agrupamento, quando todos os parâmetros foram (MACHADO et al., 2011; DE FREITAS et al., 2014)

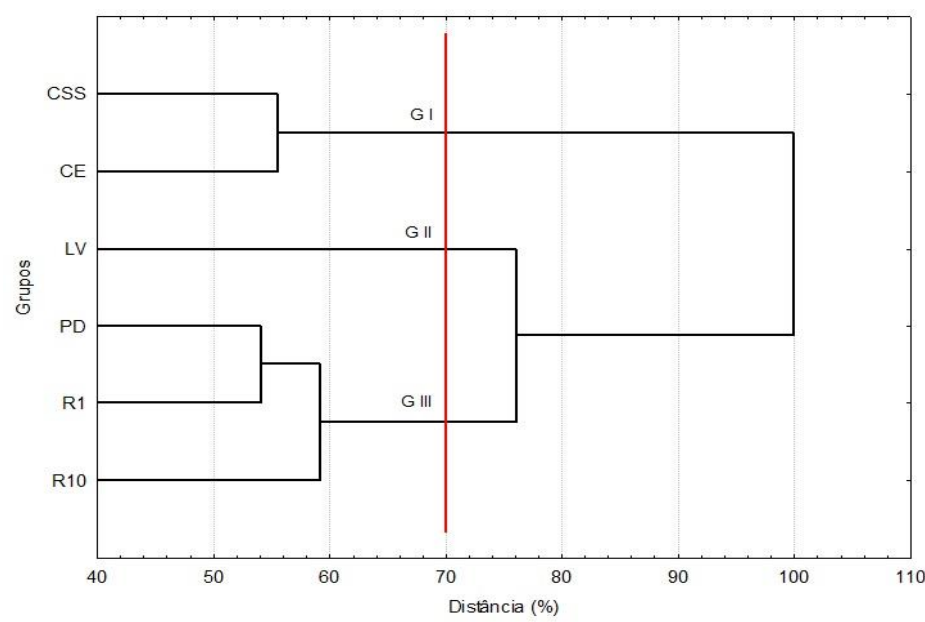

Figura 21. Clusters das propriedades físicas, químicas e biológicas do solo (CSS = Cerrado stricto sensu, $\mathrm{CE}=$ Cerradão, $\mathrm{LM}=$ Lavoura de milho, $\mathrm{R} 10=$ Reflorestamento de 10 anos, $\mathrm{R} 1=$ Reflorestamento de 1 ano, $\mathrm{PD}=$ Pastagem degradada) . 


\section{5. ÍNDICE DE QUALIDE DO SOLO - IQS $(\mathbf{f , q , b )}$}

A pontuação (frequência) relativa aos três primeiros lugares das médias dos parâmetros físicos, químicos e biológicos nas seis áreas experimentais está apresentada na Tabela 20. Nesta Tabela, as áreas de Cerradão e de Reflorestamento de 10 anos apresentaram a maior pontuação (6 e 7 médias obtidas entre o $1^{\circ}$. e o $3^{\circ}$. lugar, respectivamente).

Tabela 18. Frequência das médias dos parâmetros físicos, químicos e biológicos em relação dos três primeiros lugares.

\begin{tabular}{|c|c|c|c|c|c|c|c|c|c|}
\hline \multirow{2}{*}{ Área Experimental } & \multicolumn{3}{|c|}{ Químicos } & \multicolumn{3}{|c|}{ Físicos } & \multicolumn{3}{|c|}{ Biológicos } \\
\hline & $1^{\circ}$ & $2^{\circ}$ & $3^{\circ}$ & & $2^{\circ}$ & $3^{\circ}$ & $1^{\circ}$ & $2^{\circ}$ & $3^{\circ}$ \\
\hline Cerradão & 1 & 1 & & 1 & & 1 & 1 & & 1 \\
\hline Reflorestamento de 10 anos & 2 & 2 & 1 & & & 1 & & & 1 \\
\hline Cerrado stricto sensu & & 1 & & 1 & 1 & & & & \\
\hline Lavoura de milho & 1 & & 2 & & & & 1 & & \\
\hline Pastagem degradada & 1 & 1 & 1 & & & & & 1 & \\
\hline Reflorestamento de 1 ano & & & 1 & & 1 & & & 1 & \\
\hline
\end{tabular}

A Tabela 21, por sua vez, apresenta o IQA das áreas experimentais, já tendo sido computados os escores $(1,2$ e 3$)$, relativos ao $1^{\circ}, 2^{\circ}$. e $3^{\circ}$. lugar, e a normalização pelos pesos (2, 5 e 2) de cada grupo de parâmetros (F, Q, e B, respectivamente).

Tabela 21. Valores normalizados e finais do $\operatorname{IQS}_{(\mathrm{f}, \mathrm{q}, \mathrm{b})}$

\begin{tabular}{lcc}
\hline \multicolumn{1}{c}{ Área Experimental } & $\mathrm{IQS}_{(\mathrm{f}, \mathrm{q}, \mathrm{b})}$ & Classe \\
\hline Cerradão & 5,00 & Alta \\
Reflorestamento de 10 anos & 3,20 & Média \\
Cerrado stricto sensu & 2,90 & Média \\
Lavoura de milho & 2,50 & Média \\
Pastagem degradada & 2,20 & Média \\
Reflorestamento de 1 ano & 2,20 & Média \\
\hline
\end{tabular}

Os resultados da tabela 21 indicam que a maior qualidade do solo foi obtida na área de Cerradão (5,0), seguida do Reflorestamento de 10 anos $(3,2)$, e do Cerrado stricto sensu $(2,9)$, todas formações florestais consolidadas. As outras áreas experimentais (Lavoura, 
Pastagem e Refl. 1 ano), com os menores valores de IQS, são áreas sob forte influencia antrópica.

Entretanto, considerando as médias e o desvio padrão dos IQS da Tabela 21, apenas a área de Cerradão apresentou alta qualidade do solo, enquanto nas cinco outras áreas experimentais a qualidade foi classificada como média. A alta qualidade do solo sob o Cerradão está associada à sua alta biomassa vegetal, gerando microclima e umidade que favorece a decomposição da matéria orgânica, proporcionando uma fonte alimentícia para os organismos que moram ou se desenvolvem no solo (CONCEIÇÃO et al., 2005).

Por outro lado, as áreas de Pastagem degradada e Reflorestamento de 1 ano foram as áreas experimentais que apresentaram os menores valores de qualidade do solo, em função de sua alta exposição às intempéries, pisoteio e fogo. A Pastagem apresentou solo muito compactado e baixo percentual de cobertura do solo. O Reflorestamento de 1 ano, por sua vez, apresentou médias inferiores nos parâmetros físicos, químicos e biológicos às outras áreas, contribuindo para a baixa qualidade.

Os resultados do índice de qualidade do solo-IQS $(\mathrm{f}, \mathrm{q}, \mathrm{b})$ do presente estudo foram semelhantes àqueles obtidos por Araújo et at. (2007), que, utilizando propriedades físicas, químicas e biológicas, obtiveram a seguinte sequência de qualidade do solo: vegetação nativa de Cerrado $>$ Pastagem natural $>$ Reflorestamento de pínus $>$ Pastagem plantada > cultivo convencional.

Chaer; Tótola (2007), por sua vez, estudando plantios de eucalipto com diferentes manejos, indicou que as áreas submetidas a sistemas que mantém a camada orgânica do solo tem uma qualidade do solo parecida às áreas com vegetação nativa. Por outro lado, as áreas submetidas a sistemas de preparo que resultam na perda da camada orgânica apresentam-se graficamente distantes da área de referência, sugerindo perda de qualidade do solo. 


\section{CONCLUSÕES}

As principais conclusões do presente Estudo foram as seguintes:

- $\quad$ Foi obtido um índice de qualidade do solo $\operatorname{IQS}_{(\mathrm{f}, \mathrm{q}, \mathrm{b})}$, a partir de propriedades físicoquímicas e biológicas, para a avaliação do efeito do tipo de uso e manejo do solo, não requerendo necessariamente uma condição natural como controle.

- Dois parâmetros foram usados no IQS para as propriedades físicas e biológicas do solo, e cinco para as propriedades químicas;

- $\quad$ Seis áreas experimentais, situadas sobre o mesmo tipo de solo (Latossolo vermelho) foram estudadas: Cerrado stricto sensu, Cerradão, Reflorestamento de 10 anos, Reflorestamento de 1 ano, Lavoura de milho e Pastagem degradada.

- As propriedades físicas, químicas e biológicas apresentaram diferenças significativas nas seis áreas experimentais, indicando que o tipo de uso e manejo do solo influencia aquelas;

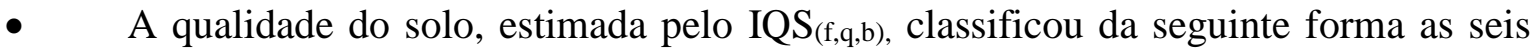
áreas de pesquisa avaliadas: Cerradão > Reflorestamento de 10 anos > Cerrado stricto sensu > Lavoura de milho > Pastagem degradada > Reflorestamento de 1 ano.

- Os maiores valores de $\mathrm{IQS}_{(\mathrm{f}, \mathrm{q}, \mathrm{b})}$ estiveram associados a formações florestais maduras, enquanto os menores ocorreram em áreas com usos mais intensivos. 


\section{ANEXO 1. BESOUROS COPRÓFAGOS (COLEÓPTERA: SCARABAEINAE) COLETADOS NAS SEIS ÁREAS DE PESQUISA.}

\section{Gênero: Agamopus}

Espécie: Agamopus viridis Fonte: Concha-Lozada (2015)

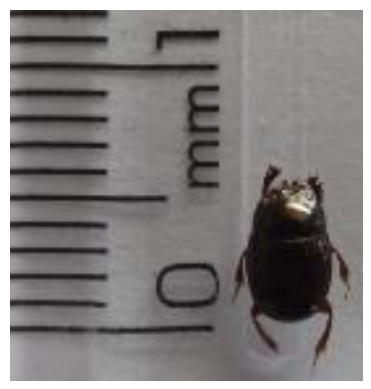

2. Gênero: Canthon

Espécie: Canthon conformis Fonte: Concha-Lozada (2015)

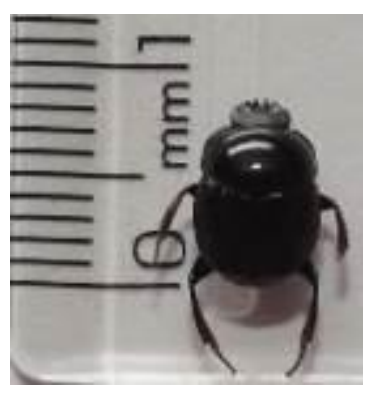

Espécie: Canthon lituratos Fonte: Concha-Lozada (2015)

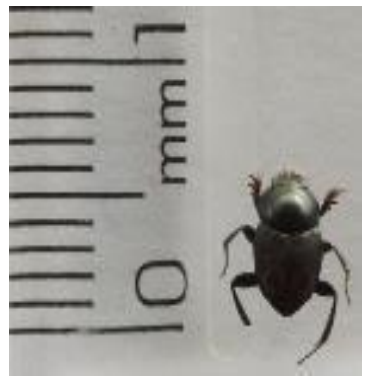

\section{Gênero: Canthidium}

Espécie: Canthidium sp1 Fonte: Concha-Lozada (2015)

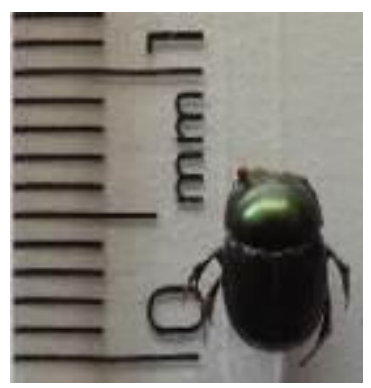


Espécie: Canthidium sp2

Fonte: Concha-Lozada (2015)

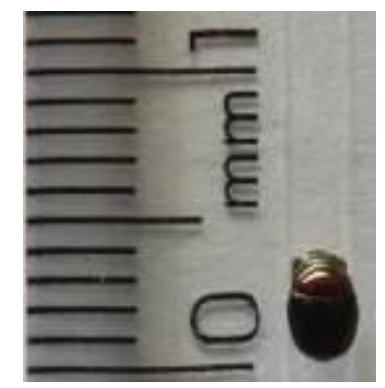

Espécie: Canthidium sp3

Fonte: Concha-Lozada (2015)

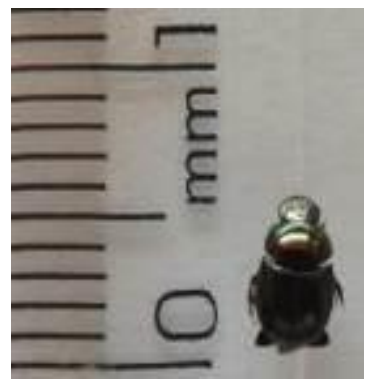

Espécie: Canthidium sp4 Fonte: Concha-Lozada (2015)

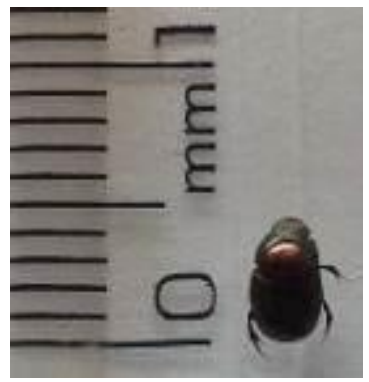

Espécie: Canthidium sp5 Fonte: Concha-Lozada (2015)

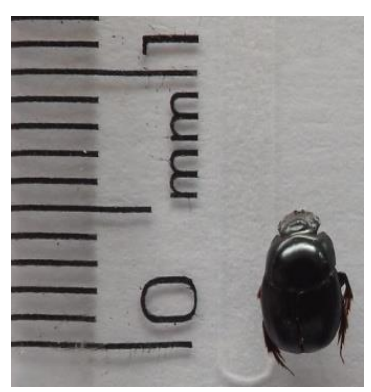

Espécie: Canthidium marseuli Fonte: Concha-Lozada (2015)

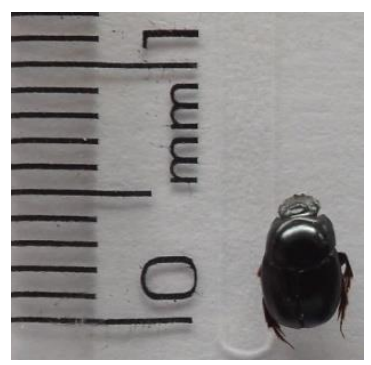

Espécie: Canthidium megathopoides Fonte: Concha-Lozada (2015)

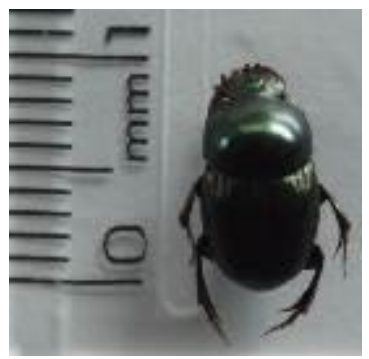




\section{Gênero: Coprophaneus}

Espécie: Coprophaneus horus Fonte: Concha-Lozada (2015)

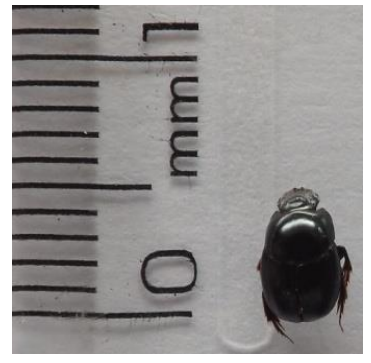

\section{Gênero: Dichotomius}

Espécie: Dichotomius aff. assifer $\mathrm{sp} 1$

Fonte: Concha-Lozada (2015)

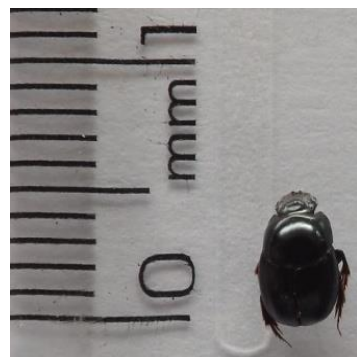

Espécie: Dichotomius bicuspis Fonte: Concha-Lozada (2015)

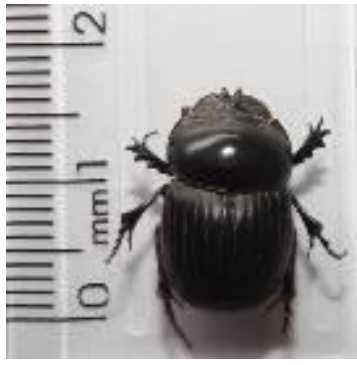

Espécie: Dichotomius bos

Fonte: Concha-Lozada (2015)

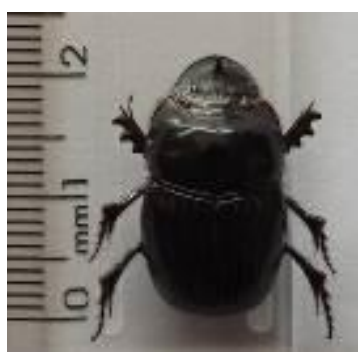

Espécie: Dichotimius crinicollis

Fonte: Concha-Lozada (2015)

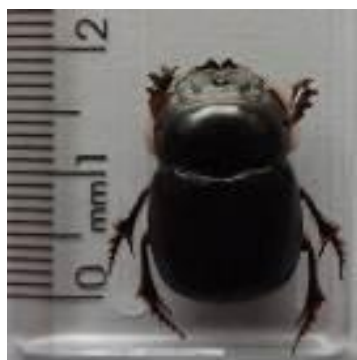


Espécie: Dichotomius nisus

Fonte: Concha-Lozada (2015)

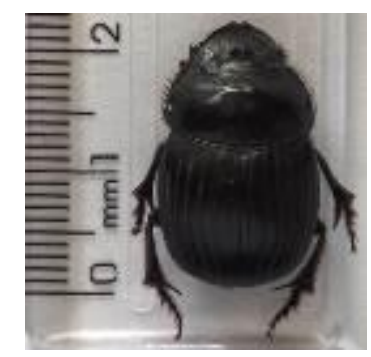

Espécie: Dichotomius aff. quadratriceps

Fonte: Concha-Lozada (2015)

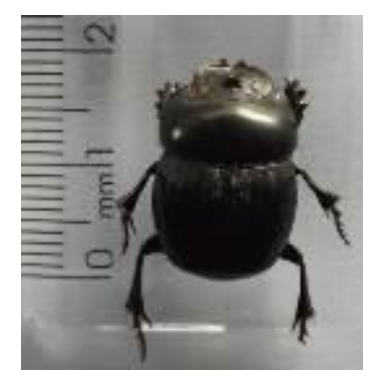

\section{Gênero: Deltochilum}

Espécie: Deltochilum komareki

Fonte: Concha-Lozada (2015)

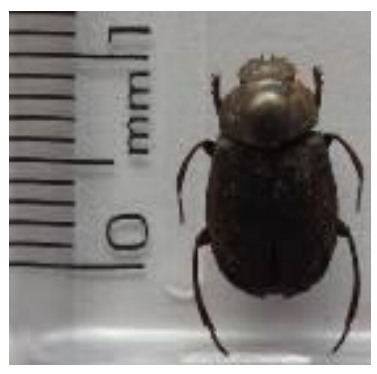

7. Gênero: Digitonthophagus

Espécie: Digitonthophagus gazela Fonte: Concha-Lozada (2015)

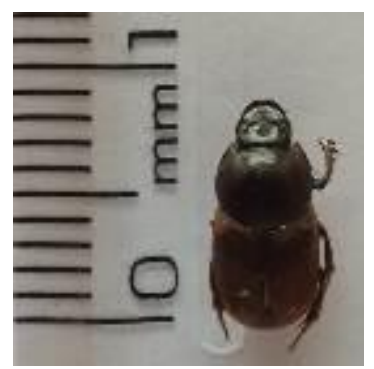


8. Gênero: Ontherus

Espécie: Onterus apendiculatus Fonte: Concha-Lozada (2015)

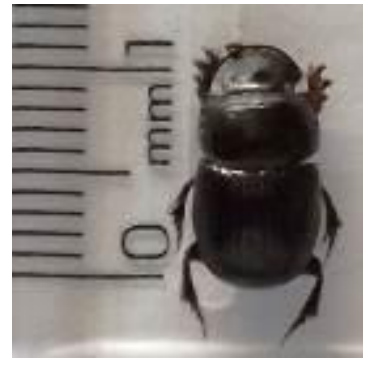

\section{Gênero: Onthophagus}

Espécie: Onthophagus buculus

Fonte: Concha-Lozada (2015)

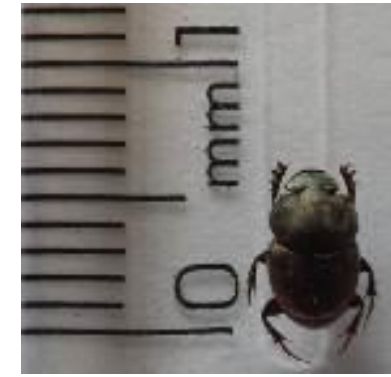

Espécie: Onthophagus hirculus Fonte: Concha-Lozada (2015)

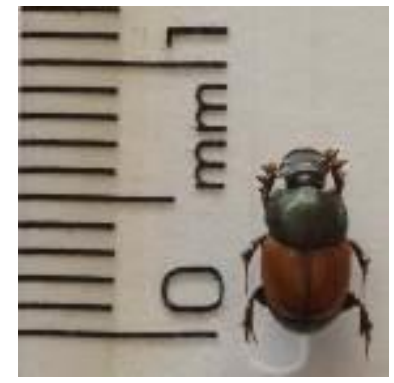

10. Gênero: Uroxys

Espécie: Uroxys sp1 Fonte: Concha-Lozada (2015)

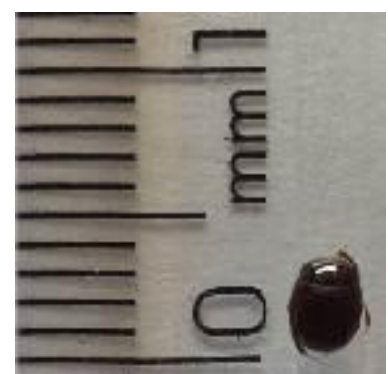


ANEXO 2. ÍNDICE DE QUALIDADE DO SOLO - IQS $(\mathbf{f , q , b )}$ DESENVOLVIDO COM PARAMETROS FÍSICOS, QUIMICOS E BIOLOGICOS DO SOLO

\begin{tabular}{|c|c|c|c|c|c|c|c|c|c|c|c|c|c|c|}
\hline \multirow{3}{*}{$\begin{array}{c}\text { Área Experimental } \\
\text { (Uso e manejo do solo) }\end{array}$} & \multicolumn{9}{|c|}{$\begin{array}{l}\text { Contagem de variáveis e ranking respeito às } \\
\text { três médias mais altas do teste de Tukey }\end{array}$} & \multicolumn{3}{|c|}{$\begin{array}{l}\text { Pesos de importância ou } \\
\text { escores para cada grupo de } \\
\text { propriedades }\end{array}$} & \multirow{3}{*}{$\begin{array}{c}\text { Calculo do índice de } \\
\text { qualidade do solo IQS } \\
\text { (Ponderação) }_{(\mathrm{f}, \mathrm{b})}\end{array}$} & \multirow{3}{*}{$\begin{array}{c}\begin{array}{c}\text { Classificação } \\
\operatorname{IQS}_{(\mathrm{f}, \mathrm{q}, \mathrm{b})}\end{array} \\
\text { Classe IQS }_{(\mathrm{f}, \mathrm{q}, \mathrm{b}}\end{array}$} \\
\hline & \multicolumn{3}{|c|}{ Químicas } & \multicolumn{3}{|c|}{ Físicas } & \multicolumn{3}{|c|}{ Biológicas } & \multirow{2}{*}{ Química } & \multirow{2}{*}{ Física } & \multirow{2}{*}{ Biológica } & & \\
\hline & $1^{\circ}$ & $2^{\circ}$ & $3^{\circ}$ & $1^{\circ}$ & $2^{\circ}$ & $3^{\circ}$ & $1^{\circ}$ & $2^{\circ}$ & $3^{\circ}$ & & & & & \\
\hline Cerradão & 1 & 1 & 0 & 1 & 0 & 1 & 1 & 0 & 1 & 5 & 4 & 4 & 5,00 & Alto \\
\hline Reflorestamento de 10 anos & 2 & 2 & 1 & 0 & 0 & 1 & 0 & 0 & 1 & 11 & 1 & 1 & 3,20 & Médio \\
\hline Cerrado stricto sensu & 0 & 1 & 0 & 1 & 1 & 0 & 0 & 0 & 0 & 2 & 5 & 0 & 2,90 & Médio \\
\hline Lavoura de milho & 1 & 0 & 2 & 0 & 0 & 0 & 1 & 0 & 0 & 5 & 0 & 3 & 2,50 & Médio \\
\hline Pastagem degradada & 1 & 1 & 1 & 0 & 0 & 0 & 0 & 1 & 0 & 6 & 0 & 2 & 2,20 & Médio \\
\hline Reflorestamento de 1 ano & 0 & 0 & 1 & 0 & 1 & 0 & 0 & 1 & 0 & 1 & 2 & 2 & 2,20 & Médio \\
\hline
\end{tabular}




\section{REFERÊNCIAS}

AGUIAR, L. Estimativa do escoamento superficial a partir de testes da infiltração potencial na Bacia do Ribeirão Itaim, Taubaté-SP. <Dissertação de mestrado>. Mestrado em Ciências Ambientais, Departamento de Ciências Agrárias, Universidade de Taubaté, Taubaté, 104f. 2006.

ANDRADE, A. G.; TAVARES, S. R. D. L.; COUTINHO, H. L. C. Contribuição da serrapilheira para recuperação de áreas degradadas para manutenção da sustentabilidade de sistemas agroecológicos. Informe Agropecuário, v.24, n.220, p.55-63. 2003.

ANDRESEN, E. Interacción entre Primates, semillas y Escarabajos Coprófagos en Bosques Húmedos Tropicales: Un Caso de Diplocoria. Universidad y Ciencia, n.2, p.73-84. 2005.

AMACHER, M. C.; O’NEILL, K. P.; PERRY, C. H. Soil Vital Signs: A New Soil Quality Index (SQI) for Assessing Forest Soil Health. Research. paper. RMRS-RP65WWW. Fort Collins, CO: U.S. Department of Agriculture, Forest Service, Rocky Mountain Research Station. 12p. 2007.

ARAÚJO, R.; GOEDERT, W. J.; LACERDA, M. P. C. Qualidade de um solo sob diferentes usos e sob cerrado nativo. Revista Brasileira de Ciência do Solo, v.31, n.5, p.1099-1108. 2007.

BAGLIANO, R. V. Principais organismos utilizados como bioindicadores relatados com uso de avaliadores de danos ambientais. Revista Meio Ambiente e Sustentabilidade, v. 2 n.1, 2012.

BARRIOS, E.; COUTINHO, H. L. C.; MEDEIROS, C. A. B. InPaC-S: Participatory knowledge integration on indicators of soil quality, methodological guide. World agroforestry, Embrapa and Centro internacional de agricultura tropical. 180p. 2012.

BARRIOS, E.; COUTINHO, H. L. C.; MEDEIROS, C. A. B. InPaC-S: Integração participativa de conhecimentos sobre indicadores de qualidade do solo, guia metodológico. World agroforestry, Embrapa e Centro internacional de agricultura tropical. 183p. 2011.

BARRIOS, E. Soil biota, ecosystems and land productivity. Ecological economics, v.64, n.2, p.269-285. 2007.

BARRIOS, E.; DELVE, R. J.; BEKUNDA, M.; MOWO, J.; AGUNDA, J.; RAMISCH, J.; TREJO, M. T.; THOMAS, R. J. Indicators of soil quality: A South-South development of a methodological guide for linking local and technical knowledge. Geoderma, v.135, p.248-259. 2006.

BASTOS, L. A.; FERREIRA, I. M. Composições fitofisionômicas do bioma cerrado: estudo sobre o subsistema de Vereda. Espaço em Revista, v.12, n.1. 2012. 
BENEDETTI, M. M.; DUARTE, I. N.; DE MELO, H. B. jr.; BORGES, E . N. Resistência do soloà penetração em um latossolo vermelho distrófico típico sob diferentes usos. Enciclopédia Biosfera, Centro Científico Conhecer, Goiânia, v.6, n.11. 2010.

BERTELLA, F.; ACORSI, M.; BIESEKI, L.; SCHERER, R. P.; PENHA, F. G.; PERGHER, S. B. C.; LENGLER, H. C. M. Determinação da capacidade de troca catiônica em argilas. XVI Encontro de Química da Região Sul (16-SBQSul). FURB, 13 a 15 de novembro. 2008.

BERTOL, I.; ALMEIDA, J. D.; ALMEIDA, E. D.; KURTZ, C. Propriedades físicas do solo relacionadas a diferentes níveis de oferta de forragem de capim-elefante-anão cv. Mott. Pesquisa Agropecuária Brasileira, v.35, n.5, p.1047-1054. 2000.

BERTRAND, M.; LUMARET, J. P. Réactions des populations de microarthropodes à l'enfoissement des fèces de mouton par les insectes Scarabaeidae em milieux à fortes cantraintes. Pedobiologia, v.27, p.51-66, 1984.

BLUM, W. E. Functions of soil for society and the environment. Reviews in Environmental Science and Bio/Technology, v.4, n.3, p.75-79. 2005.

BOCKARI-GEVAO, S. M.; ISMAIL, W. I. W.; YAHYA, A.; SUNG, C. T. B. A modified soil tilth index and its relationship with rice yield. Science Asia, v.32, p.25-30. 2006.

BONO, J. A. M.; MACEDO, M. C. M.; TORMENA, C. A.; NANNI, M. R.; GOMES, E. P.; MÜLLER, M. M. L.Infiltração de água no solo em um latossolo vermelho da região sudoeste dos Cerrados com diferentes sistemas de uso e manejo. Revista Brasileira de Ciência do Solo, v.36, n.6, p.1845-1853. 2012.

BOUMANS, R.; COSTANZA, R.; FARLEY, J.; VILLA, F.; WILSON, M. Modeling the dynamics of the integrated earth system and the value of global ecosystem services using the GUMBO model. Ecological Economics, v.41, p.529-560. 2002.

BRADY, N. C.; WEIL, R. R. Soil Architecture and Physical Properties. Chapter 4. In: BRADY, N. C.; WEIL, R. R. Elements of the nature and properties of soils. New Jersey, Prentice Hall, Third edition, 624p. 2010.

BRADY, N. C.; WEIL, R. C. Soil architecture and physical properties. Chapter 4. In: BRADY, N. C. WEIL. R. C. (Ed.). The Nature and Properties of Soils. 14th Edition. Pearson Education, Prentice Hall. 992p. 2008.

BRADY, N. C.; WEIL, R. R. The Nature and Properties of Soils. 13th edition, Prentice Hall, Upper Saddle River, New Jersey. 960p. 2002.

BRAJA, M. D. Fundamentos De Engenharia Geotécnica. São Paulo: Thomson Learning, 561p. 2007. 
BROWN, S.; SPRENGER, M.; MAXEMCHUK, A.; COMPTON, H. Ecosystem function in alluvial tailings after biosolids and lime addition. Journal Environmental Quality., v.34, p.139-48. 2005.

CABRERA, G. La macrofauna edáfica como indicador biológico del estado de conservación/perturbación del suelo. Resultados obtenidos en Cuba. Pastos y Forrajes, v.35, n.4, p.346-363. 2012.

CAESB - COMPANHIA DE SANEAMENTO DO DISTRITO FEDERAL. Plano de proteção ambiental da bacia hidrográfica do ribeirão Pipiripau, diagnóstico ambiental. EMATER/DF - SEMARH, v.1, 206p. 2001.

CAPUTO, H. P. Mecânica dos Solos e Suas Aplicações. Rio de Janeiro: Livros Técnicos e Científicos, 6ª edição, 234p. 1996.

CARDOSO, E. L.; SILVA, M. L. N.; CURI, N.; FERREIRA, M. M.; FREITAS, D. A. F. Qualidade química e física do solo sob vegetação arbórea nativa e pastagens no Pantanal Sul-Mato-Grossense. Revista Brasileira de Ciência do Solo, v.5, n.02, p.613-622. 2011.

CARVALHO, R.; GOEDERT, W. J.; ARMANDO, M. S. Atributos físicos da qualidade de um solo sob sistema agroflorestal. Pesquisa Agropecuária Brasileira, v.39, n.11, p.1153-1155. 2004.

CELI, J.; DÁVALOS, A. Manual de monitoreo. Los escarabajos peloteros como indicadores de la calidad ambiental. EcoCiencia, Quito, n.7, 1p. 2001.

CHAER, G. M.; TÓTOLA, M. R. Impacto do manejo de resíduos orgânicos durante a reforma de plantios de eucalipto sobre indicadores de qualidade do solo. Revista Brasileira de Ciência do Solo, v.31, n.6, p.1381-1396. 2007.

CHAVES, A. A. A.; LACERDA, M. P. C.; GOEDERT, W. J.; RAMOS, M. L. C.; KATO, E. Indicadores de qualidade de Latossolo Vermelho sob diferentes usos. Pesquisa Agropecuária Tropical, Goiânia, v. 42, n. 4, p. 446-454, 2012.

CHAVES, H. M. L.; PIAU, L. P. Efeito da variabilidade da precipitação pluvial e do uso e manejo do solo sobre o escoamento superficial e o aporte de sedimento de uma bacia hidrográfica do Distrito Federal. Revista Brasileira de ciência do solo, v.32, p.333-343. 2008.

CHAVES, H. M. L.; ALIPAZ, S. An integrated indicator based on basin hydrology, environment, life, and policy: The watershed sustainability index. WaterResources Management, v.1, n.5, p.883- 895. 2007.

CHAVES, H. M. L.; BRAGA, B.; DOMINGUES, A. F.; SANTOS, D. G. Quantificação dos benefícios ambientais e compensações financeiras do "programa do produtor de água" (ANA): I. Teoria. Revista brasileira de recursos hídricos, v.9, n.3, p.05-14. 2004a. 
CHAVES, H. M. L.; BRAGA, B.; DOMINGUES, A. F.; SANTOS, D. G. Quantificação dos benefícios ambientais e compensações financeiras do "programa do produtor de água" (ANA): II. Aplicação. Revista brasileira de recursos hídricos, v.9, n.3, p.15-21. 2004b.

CONCEIÇÃO, P. C.; AMADO, T. J. C.; MIELNICZUK, J.; SPAGNOLlO, E. Soil organic matter and other attributes as indicators to evaluate soil quality in conservation systems. Revista Brasileira de Ciência do Solo, v.29, n.5, p.777-788. 2005 .

CONCHA-LOZADA, C. M.; GALLEGO ROPERO, M. C.; PARDO-LOCARNO, L. C. Fragmentación de ecosistemas montanos e impactos estructurales y poblacionales sobre la comunidad de escarabajos coprófagos (Col.: Scarabaeinae) en el alto río Cauca, Popayán, Colombia. Boletín científico centro de museos, museo de historia natural, v.14, n.1, p.43-55. 2010.

CONCHA-LOZADA, C. M.; GALLEGO ROPERO, M. C.; FIGUEROA CASAS, A. Escarabajos estercoleros (Coleóptera: Scarabaeinae) en tres usos del suelo, vereda Clarete. Popayán-Cauca. Capítulo 17, p.301-312. En: FIGUEROA CASAS, A.; VALENCIA ROJAS, M. P. Fragmentación y coberturas vegetales de ecosistemas andinos, departamento del Cauca. Sello editorial Universidad del Cauca. 400p. 2009.

COSTA, F. D. S.; AlBUQUERQUE, J. A.; BAYER, C.; FONTOURA, S. M. V.; WOBETO, C. Propriedades físicas de um Latossolo Bruno afetadas pelos sistemas plantio direto e preparo convencional. Revista Brasileira de Ciência do Solo, v.27, n.3, p.527-535. 2003.

COREY. R. Química de suelos. Escuela Nacional de Agricultura. Colegio de PostGraduados. Chapingo, México. 165p. 1968.

CRUZ, A. B.; BARRA, J. E.; DEL CASTILLO, R. F.; GUTIÉRREZ, C. La calidad del suelo y sus indicadores. Revista Ecosistemas, v.13, n.2; p.90-97. 2004.

DAILY G. C. Management objectives for the protection of ecosystem services. Environmental Science Policy, v.3, p.333-9. 2000.

DAILY, G. C. Nature's services: Societal dependence on natural ecosystems. Island Press, 412p. 1997.

DA SILVA, C. F.; PEREIRA, M. G.; CORREIA, M. E. F.; DA SILVA, E. M. R. Fauna edáfica em áreas de agricultura tradicional no entorno do Parque Estadual da Serra do Mar em Ubatuba (SP). Revista de Ciências Agrárias/Amazonian Journal of Agricultural and Environmental Sciences, v.52, n.1, p.107-115. 2011.

DAVIS, A. J.; HOLLOWAY, J. D.; HUIJBREGTS, H.; KRIKKEN, J.; KIRKSPRIGGS, A. H.; SUTTON, S. L. Dung beetles as indicators of change in the forests of northern Borneo. Journal of Applied Ecology, n.38, p.593-616, 2001. 
DE ARAÚJO, E. A.; KER, J. C.; NEVES, J. C. L.; LANI, J. L. Qualidade do solo: conceitos, indicadores e avaliação. Applied Research \& Agrotechnology, v.5, n.1, p.187-206. 2012.

DE BARROS, C. A. P.; MINELlA, J. P. G.; TASSI, R.; DALBIANCO, L.; OTTONELLI, A. S. Estimativa de infiltração de água no solo na escala de bacia hidrográfica no planalto Riograndense, Resumo expandido. XXXIII Congresso brasileiro de ciência do solo. Solos nos biomas brasileiros: sustentabilidade e mudanças climáticas, 4p. 2011.

DECAËNS, T.; DUTOIT, T.; ALARD, D.; LAVELLE, P. Factors influencing soil macrofaunal communities in post-pastora. Applied Soil Ecology, v.9, n.1, p.361367. 1998.

DE FREITAS, D. A. F.; SILVA, M. L. N.; CARDOSO, E. L.; CURI, N. Índices de qualidade do solo sob diferentes sistemas de uso e manejo florestal e cerrado nativo adjacente1. Revista Ciência Agronômica, v.43, n.3, p.417-428. 2012.

DE FREITAS, L.; CASAGRANDE, J. C.; DE OLIVEIRA, I. A.; DE SOUZA JÚNIOR, P. R.; CAMPOS, M. C. C. Análises multivariadas de atributos químicos do solo para caracterização de ambientes. Revista Agro@mbiente On-line, v.8, n.2, p.155-164. 2014.

DE GROOT, R. S.; WILSON, M. A.; BOUMANS, R. M. A typology for the classification, description and valuation of ecosystem functions, goods and services. Ecological economics, v.41, n.3, p.393-408. 2002.

DE LA ROSA, D; SOBRAL, R. Soil quality and methods for its assessment. 167-200p. In: BRAIMOH, A. K.; VLEK, P. L. G. Land use and soil resources. Springer Netherlands. 269p. 2008.

DE OLIVEIRA, I. P.; DE PINHO COSTA, K. A.; K. J. G.; MOREIRA, F. P. Considerações sobre a acidez dos solos de cerrado. Revista eletrônica faculdade Montes Belos, Goiás, v.1, n.1, p.01-12. 2005.

DIDHAM, R. K.; GHAZOUL, J.; STORK, N. E.; DAVIS, A. J. Insects in fragmented forests: a functional approach. Trends in Ecology and Evolution, v.11, p.255260, 1996.

DORAN, J. W.; ZEISS, M. R. Soil health and sustainability: managing the biotic component of soil quality. Applied Soil Ecology, v.15, n.1, p.3-11. 2000.

DORAN, J. W.; PARKIN, T. B. Defining and assessing soil quality. Chapters 1-8, p.121. In: DORAN, J. W.; COLEMAN, D. C.; BEZDICEK, D. F.; STEWART, B. A. Defining soil quality for a sustainable environment. SSSA special publication, Inc., Madison, Wisconsin, USA, n.35. 244p. 1994.

ESCOBAR, F. Diversidad y distribución de los escarabajos del estiércol (Coleóptera: Scarabaeidae: Scarabaeinae) de Colombia. Programa de inventarios de 
biodiversidad. Instituto Humboldt. Sociedad entomología aragonesa - SEA, v.1, p.197-210, 2000.

EUROPEAN COMMISSION. Soil protection: the story behind the strategy. Brussels, Belgium: European Commission, 26p. 2006.

FAO - FOOD AND AGRICULTURE ORGANIZATION OF THE UNITED NATIONS. Conservación de los recursos naturales para una agricultura sostenible. Módulos de capacitación. Land and Water Digital Media Series, n.27, p.10207147. 2004.

FIORIN, T. T. Estimativa da infiltração de água no solo a partir de pedofunções. <Tese de Doutorado>, Programa de Pós-Graduação em Ciência do Solo, Universidade Federal de Santa Maria. 116f. 2008.

FISHER, B.; TURNER, R. K.; MORLING, P. Defining and classifying ecosystem services for decision making. Ecological economics, v.68, n.3, p.643-653. 2009.

FUNACH; ASCAPAM; PRONATTA. Proyecto de desarrollo tecnológico: Capacitación en obtención de nuevos productos derivados de la caña y el manejo adecuado de la agroindustria panelera, Municipio de Mocoa. El suelo, propiedades físicas-químicas, conservación. 38p. 2002.

GALLO, D.; NAKANO, O.; SILVEIRA NETO, S.; CARVALHO, R. P. L.; BATISTA, G. C.; BERTI FILHO, E., PARRA, J. R. P., ZUCCHI, R. A. F.; ALVES, S. B. Entomología agrícola. Piracicaba, FEALQ, 919p. 2002.

GARAVITO, F. N. Propiedades químicas de los suelos. Instituto Geográfico “Agustín Codazzi”, Subdirección Agrologica. Ministerio de Hacienda e Crédito Publico, Republica de Colombia. Volumen X, No. 11. Bogotá D.E. 422p. 1974.

GARCÍA, A. Edafología y Química Agrícola. 2005. Disponível em: <www.unex.es/edafo/GCSL3DegFisQuim.htm>. Acesso em: 22.04.2015.

GARCÍA, A.; BELLO, A. Diversidad de los organismos del suelo y transformaciones de la materia orgánica. In: I Conferencia Internacional eco-biología del suelo y el compost. España, 2p. 2004.

GLOVER, J. D.; REGANOLD, J. P.; ANDREWS, P. K. Systematic method for rating soil quality of conventional, organic, and integrated apple orchards in Washington State. Agriculture, ecosystems and environment, v.80, n.1, p.29-45. 2000.

GOEDERT, W. J.; OLIVEIRA, S.A. Fertilidade do solo e sustentabilidade da atividade agrícola. Capítulo XVIII, p.991-1017. In: NOVAIS, R. F.; ALVAREZ V.; V. H.; BARROS, N. F.; FONTES, R. L. F.; CANTARUTTI, R. B.; NEVES, J. C. L. (Eds). Fertilidade do solo. Viçosa: Sociedade Brasileira de Ciência do Solo. 1040p. 2007. 
GOEDERT, W. J. Qualidade do solo em sistemas de produção agrícola. In: Congresso brasileiro de ciência do solo, 30., Recife, 2005. Anais, 1 CD-ROM, Recife: SBCS. 2005.

GUILLARD, P. Coprophagous beetles in pasture ecosystems. Journal of the Australian Institute of Agricultural Science, v.33, p.30-40, 1967.

HANLON, R.D.G.; ANDERSON, J.M. The effects of Collembola grazing on microbial activity in decomposing leaf litter. Oecologia (Berlin), n.38, p.93-100. 1979.

HARRIS, R. F.; KARLEN, D. L.; MULLA, D. J. A conceptual framework for assessment and management of soil quality and health. p.61-82. In: DORAN, J. W.; JONES, A. J. Methods for Assessing Soil Quality. SSSA special publication, Inc., Madison, Wisconsin, USA, n.49. 410p. 1996.

HERNÁNDEZ, B.; MAES, J. M.; HARVEY, C. A.; VÍlCHEZ, S.; MEDINA, A.; SÁNCHEZ, D. Abundancia y diversidad de escarabajos coprófagos y mariposas diurnas en un paisaje ganadero en el departamento de Rivas, Nicaragua. Agroforestería en las Américas, v.10, n.39-40, p.93-102. 2003.

HERRICK, J. E. Soil quality: an indicator of sustainable land management?. Applied Soil Ecology, v.15, n.1, p.75-83. 2000.

HILLEL, D. Introduction to soil physics. Department of Plant and Soil Sciences, University of Massachussets, Amherst, Massachussets. Academic Press., 364p. 1982.

IBGE - INSTITUTO BRASILEIRO DE GEOGRAFIA E ESTATÍSTICA. Manual Técnico de Pedologia. Manuais Técnicos em Geociências. Diretoria de Geociências, Coordenação de Recursos Naturais e Estudos Ambientais. Número 4, 2a edição. Rio de Janeiro. 2007.

ISLAM, K. R.; WEIL, R. R. Soil quality indicators properties in Mid-Atlantic soils as influenced by conservation management. Journal of Soil and Water Conservation, v.55, n.01, p.69-78. 2000.

JENNY, H. The soil resource: origin and behavior. New York: Springer-Verlag, Ecological Studies, v.37, 337p. 1980.

KALISZ, P. J; STONE, E. L. Soil mixing by Scarab Beetle and Pocket Grophers in North-Central Florida. Soil Sci. Soc. Am. J.,v.48, n.1, p.169-172. 1984.

KARLEN, D. L.; DORAN, J. W.; WEINHOLD, B. J.; ANDREWS, S. S. Soil quality: Humankind's foundation for survival. Journal of soil and water conservation, v.58, n.4, p.171-179. 2003.

KARLEN, D. L.; MAUSBACH, M. J.; DORAN, J. W.; CLINE, R. G.; HARRIS, R. F.; SCHUMAN, G. E. Soil quality: a concept, definition, and framework for evaluation (a guest editorial). Soil Science Society of America Journal, v.61, n.1, p.4-10. 1997. 
KARLEN, D. L.; STOTT, D. E. A framework for evaluating physical and chemical indicators of soil quality. Chapters 1-8, p.53-72. In: DORAN, J. W.; COLEMAN, D. C.; BEZDICEK, D. F.; STEWART, B. A. Defining soil quality for a sustainable environment. SSSA special publication, Inc., Madison, Wisconsin, USA, n.35. 244p. 1994.

KIBBLEWHITE, M. G.; RITZ, K.; SWIFT, M. J. Soil health in agricultural systems. Philosophical Transactions of the Royal Society B: Biological Sciences, v.363, n.1492, p.685-701. 2008.

KIMBERLING, D. N.; KARR, J. R.; FORE, L. S. Measuring human disturbance using terrestrial invertebrates in the shrub-steppe of Eastern Washington (USA). Ecological Indicators, v.1, n.2, p. 63-81, 2001.

KLINK, C. A.; MACHADO, R. B. A conservação do Cerrado brasileiro. Megadiversidade, v.1, n.1, p.147-155. 2005.

KLINE, R. Estimating crop residue cover for soil erosion control. Soil FACTSHEET/British Columbia ministry of agriculture and food, n.641.220-1, p.1-4. 2000.

LAL, R. Encyclopedia of soil Science. CRC press, second edition, 2060p. 2005.

LAL, R. Physical management of soils of the tropics: priorities for the 21 st century. Soil Science, v.165, n.3, p.191-207. 2000.

LANZA, E. G. de la; HERNÁNDEZ, P. S.; CARVAJAL, P. J. L. Organismos Indicadores de la calidad del agua y de la contaminación (Bioindicadores). Plaza y Valdés. México. 633p. 2000.

LARSON, W. E.; PIERCE, F. J. Conservation and enhancement of soil quality. In:

Evaluation for sustainable land management in the developing world: proceedings of the International Workshop on Evaluation for Sustainable Land Management in the Developing World. Chiang Rai, Thailand, 15-21 September 1991. [Bangkok, Thailand: International Board for Soil Research and Management, 1991]. 1991.

LEHMANN, A.; STAHR, K. The potential of soil functions and planner-oriented soil evaluation to achieve sustainable land use. Journal of Soils and Sediments, v.10, n,6, p.1092-1102. 2010.

LETEY, J. Relationship between soil physical properties and crop reduction. Adv. Soil Science, v.1, p.27-294, 1985.

LIMA, J. E. de. Curso de análise estatística multivariada. Universidade Federal de Viçosa, Centro de ciências agrarias, Departamento de economia rural. 113p. 2010.

LOPES, A. S.; GUILHERME, L. R. G. Interpretação da Análise do Solo: Conceitos e aplicações. Boletim Técnico n.2, Ed. Atual, São Paulo. ANDA -Associação Nacional para Difusão de Adubos, 51p. 2004. 
LOPES, A. S.; GUILHERME, L. R. G. Interpretação de análise do solo: conceitos e aplicações. Associação Nacional para Difusão de Adubos, São Paulo, Boletim técnico, n.2. 1992.

LOUISEAU, P.; JUANEAU, A.; RICOU, G. Etudes sur le recyclage dans l'écosystème prairial. I. Influence de la conduite du pâturage sur l'activité biologique des pelouses montagnardes. Acta Oecol., Oecol. Appl., v.5, n.1, p.23-41, 1984.

LUCAMBIO, F. Diferentes testes para verificar normalidade de uma amostra aleatória. Departamento de Estatística, Universidade Federal do Paraná. 5p. 2008.

MACHADO, R. B., RAMOS NETO, M. B.; PEREIRA, P.; CALDAS, E.; GONÇALVES, D.; SANTOS, N.; TABOR, K. STEININGER, M. Estimativas de perda da área do Cerrado brasileiro. Conservation International do Brasil, Brasília. 2004.

MACHADO, V. J.; DE SOUZA, C. H. E.; DE ANDRADE, B. B.; LANA, R. M. Q.; KORNDORFER, G. H. Curvas de disponibilidade de fósforo em solos com diferentes texturas após aplicação de doses crescentes de fosfato monoamônico. BioscienceJournal, v.27, n.1, p.70-76. 2011.

MAHILUM, B. C. Basic Soil Science and Concepts in Tropical Soils. Trop Ag Hawaii, Inc., Honoka, 284p. 2004.

MANLAY, R. J.; FELLER, C.; SWIFT, M. J. Historical evolution of soil organic matter concepts and their relationships with the fertility and sustainability of cropping systems, Agriculture, Ecosystems and Environment. Elsevier, v.119, Issues 3-4, p.217-233, 2007.

MAKINO, T.; KAMIYA, T.; TAKANO, H.; ITOU, T.; SEKIYA, N.; SASAKI, K.; MAEJIMA, Y.; SUGAHARA, K. Remediation of cadmium-contaminated paddy soils by washing with calcium chloride: Verification of on-site washing. Environmental Pollution, v.147, n.1, p.112-9. 2007.

MARTIN, A. Short and long term effects of the effects of the endogeic earthworm Millsonia anomalam (Megaloscolecidae: Oligochaetea) of tropical savannas, on soil organic matter. Biology and Fertility of Soils, n.11, p.234-238. 1991.

McGEOCH, M. A.; VAN RENSBURG, B. J.; BOTES, A. The verification and application of bioindicators: a case study of dung beetles in a savanna ecosystem, Journal of Applied Ecology, v.39, p.661-672, 2002.

MELO FILHO, J. D.; SOUZA, A. L. V.; SOUZA, L. D. S. Determinação do índice de qualidade subsuperficial em um Latossolo Amarelo Coeso dos Tabuleiros Costeiros, sob floresta natural. Revista Brasileira de Ciência do Solo, v.31, n.6, p.1599-1608. 2007.

MELlONI, R.; MELlONI, E. G. P.; ALVARENGA, M. I. N.; VIEIRA, F. B. M. Avaliação da qualidade de solos sob diferentes coberturas florestais e de pastagem 
no sul de Minas Gerais. Revista Brasileira de Ciência do Solo, v.32, n.06, p.24612470. 2008.

MILHOMEM, M. S.; MELLO, F. Z. V. de; DINIZ, I. R. Técnicas de coleta de besouros copronecrófagos no Cerrado. Pesquisa agropecuária brasileira, v.38, n.11, p.1249-1256, 2003.

MILlER, G. T. Ciencia ambiental: Desarrollo sostenible, un enfoque integral. Thomson. Octava edición. México, 323p. 2007.

MILOCA, S. A.; CONEJO, P. D. Multicolinearidade em Modelos de Regressão. XXII semana acadêmica da matemática. 2011.

MINGOTI, S. A. Análise de dados através de métodos de estatística multivariada, uma abordagem aplicada. Bello Horizonte: Editora UFMG, 297p. 2005.

MOORE, D. S.; McCABE, G. P. Introdução à prática da estatística. 3a edição, LTC Editora, Rio de Janeiro, 536p. 2002.

MORAVEC, C.; WHITING, D; WILSON, C; REEDER, J. The Living Soil. Colorado State University, Extension, Colorado Master Gardener Program \# 212, 20p. 2014.

MOREIRA, F. Manual de biología de suelos tropicales. Instituto Nacional de Ecología. 348p. 2012.

MOÇO, M. D. S.; GAMA-RODRIGUES, E. F. D.; GAMA-RODRIGUES, A. C. D.; CORREIA, M. E. F. Caracterização da fauna edáfica em diferentes coberturas vegetais na região norte fluminense. Revista Brasileira de Ciência do Solo, v.29, n.4, p.555-564. 2005.

OLIVEIRA, I. P.; YOKOYAMA, L. P. Implantação e condução do Sistema Barreirão. p. 265 - 302. In: KLUTHCOUSKI, J.; STONE, L. F.; AIDAR, H. Integração lavoura - pecuária. Santo Antônio de Goiás: Embrapa Arroz e Feijão. 2003.

NICHOLS, E.; URIARTE, M.; BUNKER, D. E.; FAVILA, M. E.; SLADE, E. M.; VULINEC, K., LARSEN, T.; VAZ-DE-MELLO, F. Z.; LOUZADA, J.; NAEEM, S.; SPECTOR, S. H. rait-dependent response of dung beetle populations to tropical forest conversion at local and regional scales. Ecology, v.94, n.1, p.180-189. 2013.

NORIEGA, J. A.; PALCIO, J. M.; MONROY, J. D.; VALENCIA, D. Estructura de un ensamblaje de escarabajos coprofagos (Coleoptera: Scarabaeinae) en tres sitios con diferente uso del suelo en Antioquia, Colombia. Actualidades Biologicas (Medellin), v.34, p.43-54, 2012.

PACA - PROFISSIONAL ALLIANCE FOR CONSERVATION AGRICULTURE. Soil degradation. Education series, n.2. 9p. Disponível em: <http://www.conserveagri.org/content.htm>. Acesso em: 02.05.2015.

PANACHUKI, E.; SOBRINHO, T. A.; VITORINO, A. C. T.; DE CARVALHO, D. F.; URCHEI, M. A. Avaliação da infiltração de água no solo, em sistema de integração 
agricultura-pecuária, com uso de infiltrômetro de aspersão portátil. Acta scientiarumagronomy, v.28, n.1, p.129-138. 2006.

PANACHUKI, E. Infiltração de água no solo e erosão hídrica, sob chuva simulada, em sistema de integração agricultura-pecuária. <Dissertação de Mestrado>. Programa de Pós-Graduação em Agronomia, Universidade Federal de Mato Grosso do Sul. 67f. 2003.

PARCHEN, C. A. P. Desenvolvimento de Metodologia para Mensuração de AlgunsParâmetros de Processos Hidrológicos de Superfícieem Ambiente Florestal. Tese de doutorado. Universidade Federal do Paraná - UFPR. Setor de Ciências Agrárias. Curitiba. 201p. 2007.

PEREIRA, M. A. F.; KOBIYAMA, M. Análise de variâncias pluviométricas na região da bacia hidrográfica do Cubatão do Sul (SC) Analysisoftherainfallvariance in theregionofthe Cubatão do Sul Watershed (SC). AMBIÊNCIA, v.9, n.1, p.95-111. 2013.

PIMENTEL, D.; WILSON, C.; MCCULLUM, C.; HUANG, R.; DWEN, P.; FLACK, J.; TRAN, Q.; SALTMAN, T.; CLIFF, B. Economic and environmental benefits of biodiversity. BioScience, v.47, n.11, p.747-757. 1997.

PRATT, P. F. Química do solo. 88p. 1966.

QUINTERO, I.; ROSLIN, T. Rapid recovery of dung beetle communities following habitat fragmentation in Central Amazonia. Ecology, v.86, n.12, p.3303-3311. 2005 .

RALISCH, R.; MIRANDA, T. M.; OKUMURA, R. S.; BARBOSA, G. D. C.; GUIMARÃES, M. D. F.; SCOPEL, E.;BALBINO, L. C.Resistência à penetração de um Latossolo Vermelho Amarelo do Cerrado sob diferentes sistemas de manejo. Revista Brasileira de Engenharia Agrícola e Ambiental, v.12, n.4, p.381-384. 2008.

REICHARDT, K. A água em sistemas agrícolas. São Paulo: Manole, 188p. 1990.

REICHERT, J. M.; REINERT, D. J.; BRAIDA, J. A. Qualidade dos solos e sustentabilidade de sistemas agrícolas. Ciência e Ambiente, v.27, p.29-48. 2003.

REYNOLDS, W. D.; BOWMAN, B. T.; DRURY, C. F.; TAN, C. S.; LU, X. Indicators of good soil physical quality: density and storage parameters. Geoderma, v.110, n.1-2, p.131-146. 2002.

RICKLEFS, R. E. A Economia da Natureza. 5 ed. Rio de Janeiro: Guanabara Koogan, 2003.

RIBEIRO, J. F.; WALTER, B. M. T. As principais fitofisionomias do bioma cerrado. Em: SANO, S. M.; DE ALMEIDA, S. P.; RIBEIRO, J. F. Cerrado: ecologia e flora. Embrapa Cerrados/Embrapa Informação Tecnológica, Brasília, 1ed, v.1, p.151-212. 2008. 
ROBOREDO, D; MAIA, J.C. DE S; OLIVEIRA, O.J. DE; ROQUE, C.G. Uso de dois penetrômetros na avaliação da resistência mecânica de um latossolo vermelho distrófico. Engenharia Agrícola, Jaboticabal, v.30, n.2, p.307-314. 2010.

ROSCOE, R.; BODDEY, R. M.; SALTON, J. C. Sistema de manejo e matéria orgânica do solo. p.17-42. Em: ROSCOE, R.; MERCANTE, F. M.; SALTON, J. L. Dinâmica da Matéria Orgânica do Solo em Sistemas conservacionistas, Modelagem Matemática e Métodos Auxiliares. Embrapa - Empresa Brasileira de Pesquisa Agropecuária, Embrapa Solos. Ministério da Agricultura, Pecuária e Abastecimento. Dourados - MS. 307p. 2006.

RUCKS, L.; GARCÍA, F.; KAPLÁN, A.; PONCE DE LEÓN, J.; HILL, M. Propiedades Físicas del Suelo. Facultad de Agronomía, Universidad de la República, Departamento de Suelos y Aguas. Montevideo, Uruguay. 68p. 2004.

SÁ, M. D.; SANTOS JÚNIOR, J. D. G. Compactação do solo: consequências para o crescimento vegetal. Embrapa Cerrados, Planaltina - DF, documento 136, 26p. 2005 .

SALTON, J. C.; MIELNICZUK, J.;BAYER, C.; BOENI, M.; CONCEIÇÃO, P. C.; FABRÍCIO, A. C.; MACEDO, M. C. M.; BROCH, D. L. Agregação e estabilidade de agregados do solo em sistemas agropecuários em Mato Grosso do Sul. Revista Brasileira de Ciência do Solo, v.32, n.1, p.11-21. 2008.

SANO, S. M.; DE ALMEIDA, S. P.; RIBEIRO, J. F. Cerrado: ecologia e flora. Embrapa Cerrados/Embrapa Informação Tecnológica, Brasília, 1ed, v.1, p.151-212. 2008.

SANTOS, H. G. dos; JACOMINE, P. K. T.; ANJOS, L. H. C. dos; OLIVEIRA, V. A. de; LUMBRERAS, J. F.; COELHO, M. R.; ALMEIDA, J. A. de; CUNHA, T. J. F.; OLIVERIA, J. B. de. Sistema brasileiro de classificação de solos. Embrapa empresa brasileira de pesquisa agropecuária/Embrapa solos/Ministério da agricultura, pecuária e abastecimento. $3^{\mathrm{a}}$ edição, revisada e ampliada, 353p. 2013.

SANTOS, H. G. dos; JACOMINE, P. K. T; ANJOS, L. H. C. dos; OLIVEIRA, V. Á. de; OLIVEIRA, J. B. de; COELHO, M. R; LUMBRERAS, J. F; CUNHA, T. J. F. F. Sistema Brasileiro de Classificação de Solos. Embrapa - Empresa Brasileira de Pesquisa Agropecúaria, Embrapa Solos. Ministério da Agricultura, Pecuária e Abastecimentos. $2^{\mathrm{a}}$ Edição, Brasília, 306p. 2006.

SANTOS, R. D. dos; LEMOS, R. C. de; SANTOS, H. G. dos; KER, J. C; ANJOS, L. H. C. dos. Manual de descrição e coleta de solo no campo. Sociedade brasileira de ciência do solo - EMBRAPA - Centro nacional de pesquisa de solos-EMBRAPA. Quinta edição, revisada e ampliada, Viçosa. 100p. 2005.

SCHINDELBECK, R. R.; VAN ES, H. M.; ABAWI, G. S.; WOLFE, D. W.; WHITLOW, T. L.; GUGINO, B. K.; IDOWUA, O. J.; MOEBIUS-CLUNE, B. N. Comprehensive assessment of soil quality for landscape and urban management. Landscape and Urban Planning, v.88, n.2, p.73-80. 2008. 
SCOTT, G. F.; FORD, J. G. Soil quality and no-till. Chapter 2, p.3-8. In: GODSEY, C.; SCOTT, G. F.; FORD, J. G.; SMOLEN, M.; TAYLOR, R.; SCHROCK, M.; EPPLIN, F. M.; ZHANG, H.; MEDLIN, C.; HUNGER, R. M.; DAMICONE, J. P.; ROYER, T. A.; EDWARDS, J.; BANKS, J. C.; KOCHENOWER, R. No-till sropping systems in Oklahoma. E-996, 76p. 2000.

SCHOENHOLTZ, S. H.; VAN MIEGROET, H.; BURGER, J. A. A review of chemical and physical properties as indicators of forest soil quality: challenges and opportunities. Forest ecology and management, v.138, p.335-356. 2000.

SEPÚlVEDA, T. V.; TREJO, J. A. V.; DAVID, A. Suelos contaminados por metales y metaloides: muestreo y alternativas para su remediación. Secretaría de Medio Ambiente y Recursos Naturales, Instituto Nacional de Ecología, México, DF. 144p. 2005.

SEYBOLD, C. A.; MAUSBACH, M. J.; KARLEN, D. L.; ROGERS, H. H. Quantification of soil quality. Chapter 27, p.387-404. In: RATTAN, L; KIMBLE, J. M.; FOLleTt, R. F.; STEWART, B. A. Soil Processes and the Carbon Cycle, Advances in soil science. CRC Press, Washington, D.C., USA. 613p. 1997.

SHELTON, D.; JASA, P. Estimating Percent Residue Cover Using the LineTransect Method. University of Nebraska-Lincoln Extension. IARN Institute of Agriculture and Natural Resources. 3p. 2009.

SHIELDS, D.; SOLAR, S.; MARTIN, W. The role of values and objectives in communicating indicators of sustainability. Ecological Indicator, v.2, n.1-2, p.149160. 2002.

SICHE, R.; AGOSTINHO, F.; ORTEGA, E.; ROMEIRO, A. Índices versus indicadores: precisões conceituais na discussão da sustentabilidade de países. Ambiente e Sociedade, Campinas, v.X, n.2, p.137-148. 2007.

SILVA, S. M.; CORREA, F. J. Análisis de la contaminación del suelo: revisión de la normativa y posibilidades de regulación económica. Semestre Económico, v.12, n.23, p.13-34. 2009.

SILVA, F. F.; FREDDI, O. S.; CENTURION, J. F.; ARATANI, R. G.; ANDRIOLI, F. F.; ANDRIOLI, I. Propriedades físicas de um Latossolo Vermelho cultivado no sistema plantio direto. Irriga, v.13, p.191-204, 2008.

SILVA, G. B.; MELLO, A. Y.; STEINKE, V. A. Unidades de conservação no bioma cerrado: desafios e oportunidades para a conservação no Mato Grosso. Geografia, v.37, n.3, p.541-554. 2012.

SOUSA, D. de; LOBATO, E. Cerrado: correção do solo e adubação. Planaltina: Embrapa Cerrados. 416p. 2004.

SOUZA, Z. M. D.; ALVES, M. C. Movimento de água e resistência à penetração em um Latossolo Vermelho distrófico de cerrado, sob diferentes usos e manejos. Revista Brasileira de Engenharia Agrícola e Ambiental, v.7, n.1, p.18-23. 2003. 
SMITH, R. L.; SMITH, T.M. Ecología. 4a Edición. Pearson Educación, S.A., Madrid. 664p. 2001.

SIMÕES, W. L; FIGUEIRÊDO, V. B; SILVA, E. L DA. Uso do cilindro infiltrômetro único em diferentes solos. EngenhariaAgrícolaJaboticabal, v.25, n.2, p.359-366. 2005.

SPOSITO, G. The chemistry of soils.Second edition, Oxford university press, Inc. 329p.2008.

STOLF, R. Teoria e teste experimental de fórmulas de transformação dos dados de penetrômetro de impacto em resistência do solo. Revista brasileira de ciência de solo. v.15, p.229-235. 1991.

STOLF, R; FERNANDES, J; NETO, V. L. F. Recomendação para o uso do penetrômetro de impacto modelo IAA/Planalsucar-Stolf. Piracicaba: IAA/PLANALSUCAR. Série Penetrômetro de Impacto, Kamaq máquinas e implementos agrícolas, n.1, 9p. 1983.

STONE, L. F.; SILVEIRA, P. D.Efeitos do sistema de preparo e da rotação de culturas na porosidade e densidade do solo. Revista Brasileira de Ciência do Solo, v.25, n.2, p.395-401. 2001.

STORK, N. E; EGGLETON P. Invertebrates as determinants and indicators of soil quality. American Journal of Alternative Agriculture, v.7, n.1-2, p.38-47. 1992.

SWIFT, M. J.; HEAL, O. W.; ANDERSON, J. M. Decomposition in terrestrial ecosystems. University of California Press, v.5, 372p. 1979.

TAVARES, J. F.; RIBON, A. A. Resistência do Solo à Penetração em Resposta ao Número de Amostras e Tipo de Amostragem. Revista Brasileira de Ciência do Solo, v.32, n. 2, p.487-494. 2008.

THOMANZINI, M. J.; THOMANZINI, A. P. B. W. Levantamento de insetos e análise entomofaunística em floresta, capoeira e pastagem no Sudeste Acreano. Rio Branco: EMBRAPA Acre. 41p. Circular Técnica, n.35, 2002.

TOEBE, M. Não-normalidade multivariada e multicolinearidade em análise de trilha na cultura de milho. Dissertação (mestrado). Universidade Federal de Santa Maria, Centro de Ciências Rurais, Programa de Pós-Graduação em Agronomia, RS. 107p. 2012.

TÓTH, G.; STOLBOVOY, V.; MONTANARELLA, L. Soil Quality and Sustainability Evaluation - An integrated approach to support soil-related policies of the European Union. EUR 22721EN. Office for Official Publications of the European Communities, Luxembourg. 40p. 2007.

TURBÉ, A.; DE TONI, A.; BENITO, P.; LAVELLE, P.; LAVELLE, P.; RUIZ, N.; VAN DER PUTTEN, W. H.; LABOUZE, E.; MUDGAL, S. Soil biodiversity: functions, threats and tools for policy makers. Bio Intelligence Service, Institut 
de Recherche pour le Développement and Netherlands Institute of Ecology, Report for European Commission (DG Environment), Technical Report 049. 2010.

USDA - UNITED STATES DEPARTMENT OF AGRICULTURE; NRCS NATURAL RESOURCES CONSERVATION SERVICE. Keys to Soil Taxonomy. Soil Survey Staff, Eleventh edition, United States Government Printing Office, Washington, D.C. 346p. 2010.

UBERTI, A. A. A. Estudos para a elaboração do mapa de fragilidade ambiental do município de Joinville - Santa Catarina. Boletim técnico de conceitos e metodologias. 51p. 2011.

VAN HERWIJNEN, R.; AL-TABBAA, A.; HUTCHINGS, T. R.; MOFFAT, A. J.; OUKI, S. K.; JOHNS, M. L. The impact of waste compost-based soil amendments on the leaching behavior of a heavy metal contaminated soil. Environmental Eng. Science, v.24, n.7, p.897-904. 2007.

VAZ-DE-MELLO, F. Z; EDMOND, W. D; OCAMPO, F. C; SCHOOLMEESTERS, P. A multilingual key to the genera and subgenera of the subfamily Scarabaeinae of the New World (Coleoptera: Scarabaeidae). Zootaxa, v.2854, n.1-3, 2011.

VAZ-DE-MELLO, F. Z. Estado de conhecimento dos Scarabaeidae s. str. (Coleoptera: Scarabaeoidea) do Brasil. In: MARTÍN-PIERA, F.; MORRONE, J. J.; MELIC, A. (Eds.). Hacia un proyecto CYTED para el Inventario y estimación de la Diversidad Entomológica en Iberoamérica. Zaragoza: Sociedad Entomológica Aragonesa, p.181-195, 2000.

VEZZANI, F. M.; MIELNICZUK, J. Uma visão sobre qualidade do solo. Revista brasileira de ciência do solo. Viçosa, v.33, n.4, p.743-755. 2009.

VIDAURRE, T.; GONZALES, L.; LEDEZMA, M. J. Escarabajos coprófagos (scarabaeidae: scarabaeinae) del palmar de las islas, Santa Cruz-Bolivia, Kempffiana, v.4, n.1, p. 3-20, 2008.

VILLAREAL, H.; ÁLVAREZ, M.; CÓRDOBA, S; ESCOBAR, F. FAGUA, G.; GAST, F; MENDOZA, H; OSPINA, M; UMAÑA, A.M. Manual de métodos para el desarrollo de inventarios de biodiversidad. Programa de Inventarios de Biodiversidad. Instituto de Investigación de Recursos Biológicos Alexander von Humboldt. Segunda edición. Bogotá, Colombia, 236p. 2006.

VILLAREAL, H.; ÁlVAREZ, M.; CÓRDOBA, S.; ESCOBAR, F.; FAGUA, G.; GAST, F.; MENDOZA, H.; OSPINA, M.; UMAÑA, A. M. Manual de métodos para el desarrollo de inventarios de biodiversidad. Programa de inventarios de biodiversidad. Instituto de Investigación de Recursos Biológicos Alexander von Humboldt. Bogotá, Colombia, 236p. 2004.

VOLCHKO, Y.; NORMAN, J.; ROSÉN, L.; BERGKNUT, M.; JOSEFSSON, S.; SODERQVIST, T.; NORBERG, T.; WIBERG, K.; TYSKLIND, M. Using soil function evaluation in multi criteria decision analysis for sustainability appraisal of 
remediation alternatives. Science of the Total Environment, v. 485-486, p.785791. 2014.

VOLCHKO, Y.; NORRMAN, J.; BERGKNUT, M.; ROSÉN, L.; SÖDERQVIST, T. Incorporating the soil function concept into sustainability appraisal of remediation alternatives. Journal of environmental management, v.129, p.367-376. 2013.

WARKENTIN, B. P.; FLETCHER, H. F. Soil quality for intensive agriculture. In: Proceedings of the International Seminar on Soil Environment and Fertility Management in Intensive Agriculture. Tokio, 821p. 1977.

WIENHOLD, B. J.; ANDREWS, S. S.; KARLEN, D. L. Soil quality: a review of the science and experiences in the USA. Environmental Geochemistry and Health, v.26, n.2, p. 89-95. 2004.

WINK, C.; GUEDES, J. V. C.; FAGUNDES, C. K.; ROVEDDER, A. P. Insetos edáficos como indicadores da qualidade ambiental. Revista de Ciências Agroveterinárias, Lages, v.4, n.1, p.60-71, 2005.

YAN, S.; SINGH, A.N.; FU, S.; LIAO, C.; WANG, S.; LI, Y.; CUI, Y.; HU, L. A soil fauna index for assessing soil quality, Soil Biology \& Biochemistry. v.47, p.158-165. 2012.

ZONTA, J. H. Infiltração de água no solo sob diferentes perfis de precipitação. <tese de Doutorado>, Universidade Federal de Viçosa, programa de pós-graduação em engenharia agrícola, Viçosa, Minas Gerais, 115f. 2011. 